\title{
The Suburbanisation of the Poor?
}

\section{Investigating the distribution and concentration of deprivation in Auckland and Wellington, New Zealand 1991-2013}

By

Joseph Arthur Roche

A thesis submitted to the Victoria University of Wellington in partial fulfilment of the requirements for the degree of Master of Science in Human Geography

School of Geography, Environment, and Earth Sciences

Victoria University of Wellington 


\section{Acknowledgements}

I would first like to thank my supervisor, Professor Philip Morrison. Thank you for your support, ideas and directions, of both my research and myself. Thanks for sticking with me; I could not have made it to the end otherwise.

Second, I would like to thank the office staff, particularly Miranda Voke who was incredibly supportive and helpful in times of need.

Third, I would like to thank all my family for supporting and encouraging me to follow through with this master's degree. In particular, thanks to my mum and dad for checking in on me when I neglected to be a good son and call you both. A big thank you to my sister Mata for always offering to get me coffee or other supplies in the last few months of the slog.

Fourth, a massive thank you to all my friends. Thanks for understanding when I failed at having a social life during the last few months of the thesis. A big shout out to the 3 pm quiz team who not only put up with my intermittent hurriedness as quizmaster, but also with the massive inconsistencies of the bi-daily stuff quiz.

Lastly, a special acknowledgement to Chantal Mawer, who was incredibly supportive, compassionate, and caring over the whole master's period and beyond. 


\begin{abstract}
Inequality has emerged as a key issue in contemporary global urban debates. Many developed cities across the world are characterised by growing social-spatial inequalities, housing liberalisation, and gentrification, which limit the housing options of poor households. When the poor have limited housing options, they must deploy coping mechanisms. There is recent international literature on the suburbanisation of poverty predominantly in European and American cities. The aim of my research is to identify whether - given rising house prices - there has been a shift of the urban poor away from the central cities in New Zealand, towards the middle suburbs and peripheries. Furthermore, my research seeks to observe whether poor populations are becoming more concentrated. Using the New Zealand deprivation score, I analyse the trend towards a marked suburbanisation of deprivation in the two biggest cities in New Zealand, Auckland and Wellington. I find a shift of deprivation away from the city centre and towards the middle and outer suburbs in both cities. I find that the spatial distribution of deprivation changes with the macroeconomic conditions of the time. I also find in cases of no 'suburbanisation of the poor' that instead the poor are crowding and consuming less housing. These findings can inform future urban development practices.
\end{abstract}




\section{Contents}

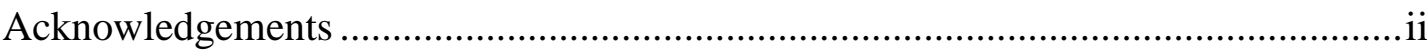

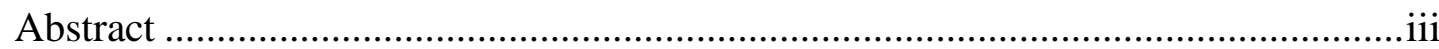

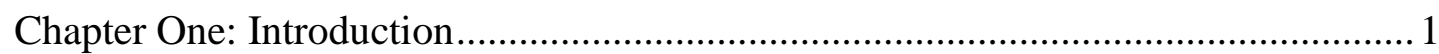

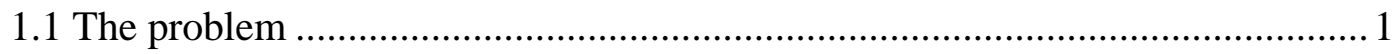

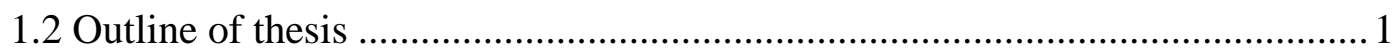

Chapter Two: Literature and conceptual approach .................................................. 4

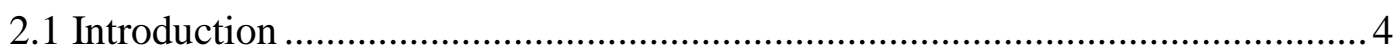

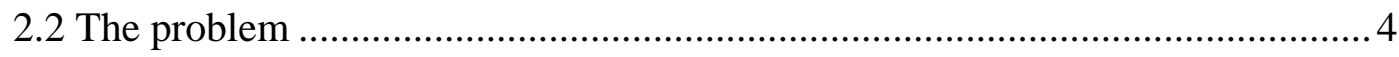

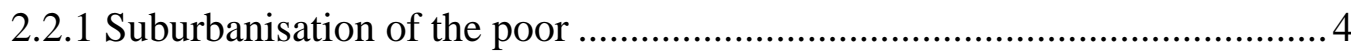

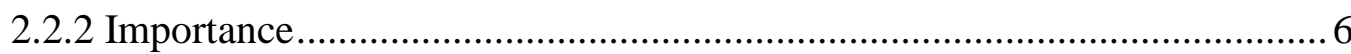

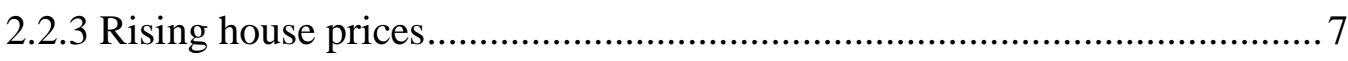

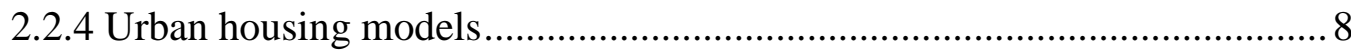

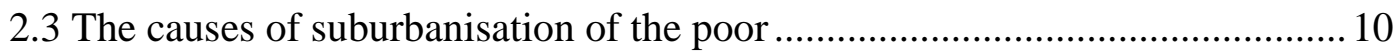

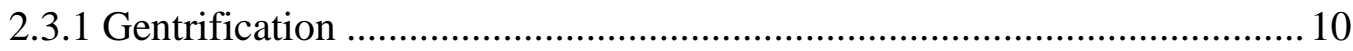

2.3.2 Production and Consumption ............................................................... 10

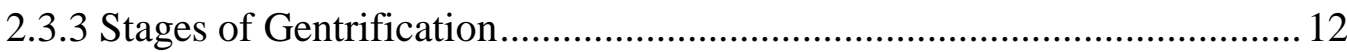



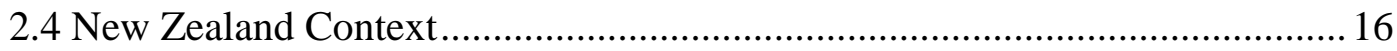

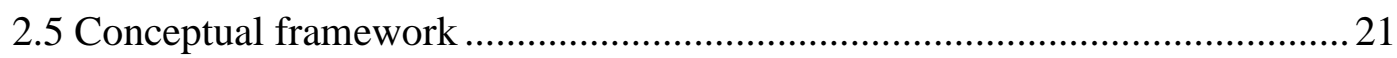

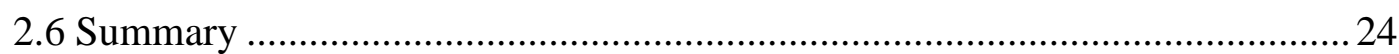

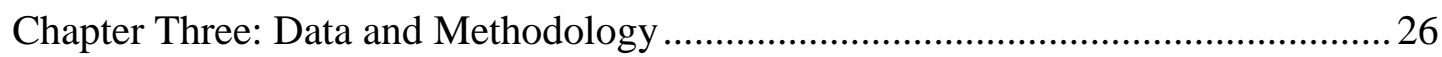

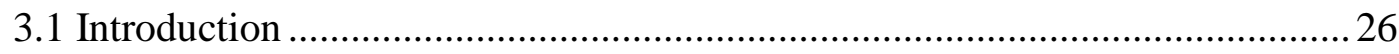

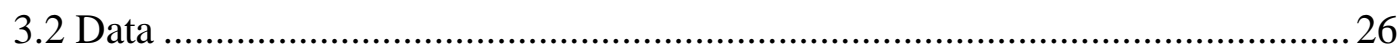

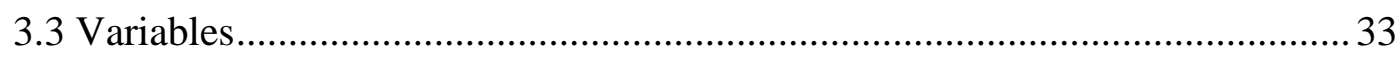

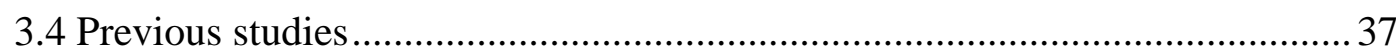


3.5 Methods

3.6 Summary

Chapter Four: The distribution of deprivation in Wellington and Auckland 42

4.1 Introduction

4.2 Methods

4.3 Suburbanisation of disadvantage in Australian cities .44

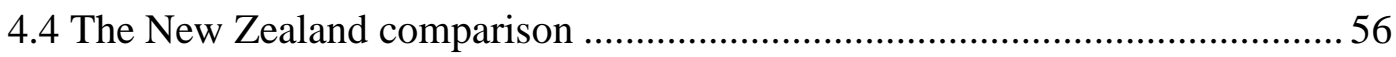

4.5 Summary

Chapter Five: Temporal differences in the distribution of deprivation in Wellington and Auckland, New Zealand 1991-2006 and 2006 -2013.

5.1 Introduction 71

5.2 Conceptualising the problem 72



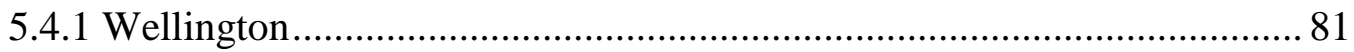

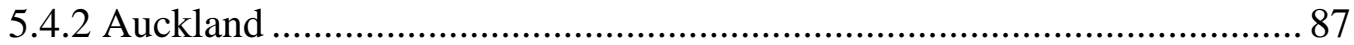

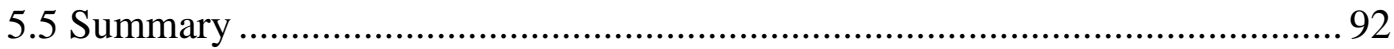

Chapter Six: The changing concentration of the individual components that make up deprivation in Wellington and Auckland .............................................................. 93

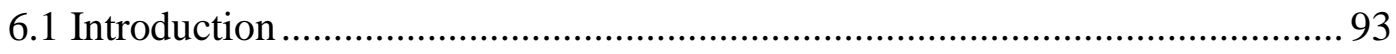

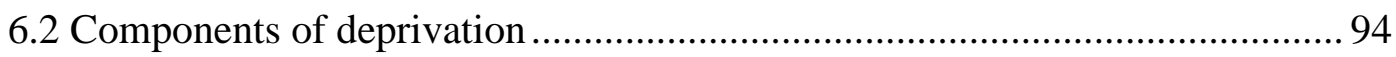

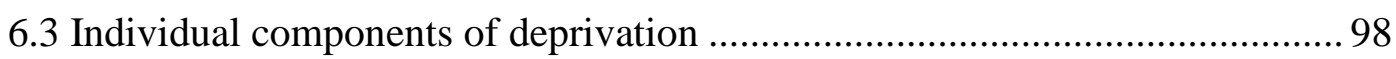

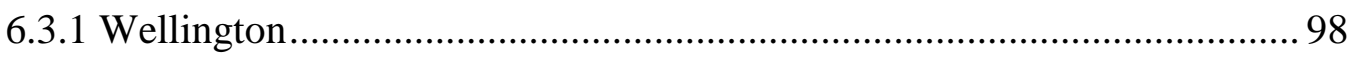

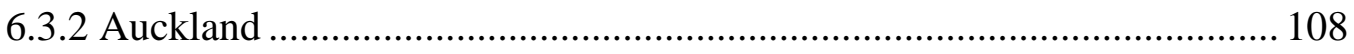



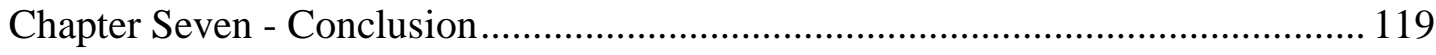

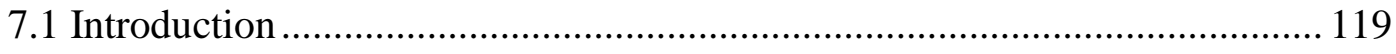

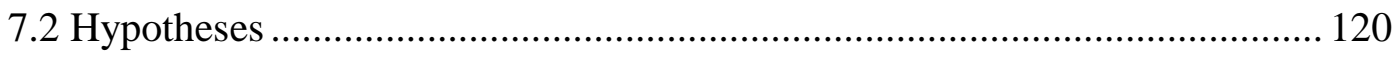




\section{Table of Figures}

Figure 2.1. Conceptual framework model ..........................................................................21

Figure 3.1: Area units for the Wellington Region, 2013 .....................................................27

Figure 3.2: Meshblocks for the urban area of the Wellington region, 2013............................28

Figure 3.3: Standard deviation of deprivation in area units for the Wellington urban area, 2013

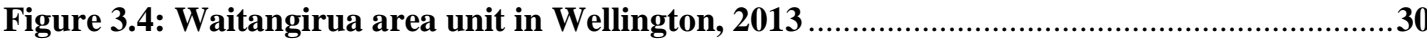

Figure 3.5: Meshblock 2060600 within Waitangirua area unit in the Wellington region, $2013 \ldots 31$

Figure 3.6: Some approaches to measuring socioeconomic position ......................................32

Figure 3.7: Distribution of NZDep2013 scores, with the NZDep2013 decile scale superimposed

Figure 4.1. Proportion of highly disadvantaged CDs in suburbs, Sydney 1986.....................45

Figure 4.2. Proportion of highly disadvantaged CDs in suburbs, Sydney 2006

Figure 4.3. Distribution of disadvantaged locations, Sydney 1986 and $2006 . . \ldots \ldots \ldots \ldots \ldots \ldots \ldots \ldots . . \ldots \ldots$

Figure 4.4. Distribution of disadvantaged locations for Adelaide, 1986 and 2011 ....................49

Figure 4.5. Distribution of disadvantaged locations for Brisbane, 1986 and 2011 ....................49

Figure 4.6. Distribution of disadvantaged locations for Melbourne, 1986 and $2011 \ldots \ldots \ldots \ldots \ldots \ldots . . .50$

Figure 4.7. Distribution of disadvantaged locations for Perth, 1986 and 2011........................51

Figure 4.8. Distribution of disadvantaged locations for Sydney, 1986 and 2011 ......................51

Figure 4.9. Spatial distribution of disadvantage for Adelaide, (a) 1986 and (b) 2011 ...............52

Figure 4.10. Spatial distribution of disadvantage for Brisbane, (a) 1986 and (b) $2011 \ldots \ldots \ldots \ldots . . .52$

Figure 4.11. Spatial distribution of disadvantage for Melbourne, (a) 1986 and (b) 2011 ...........53

Figure 4.12. Spatial distribution of disadvantage for Perth, (a) 1986 and (b) 2011 ..................54

Figure 4.13. Spatial distribution of disadvantage for Sydney, (a) 1986 and (b) $2011 \ldots \ldots \ldots \ldots \ldots . . . . .55$

Figure 4.14. Population for Auckland and Wellington, 1991-2013 ….................................55

Figure 4.15. Average annual population growth for Auckland and Wellington, 1991-2013 ........57

Figure 4.16. Distribution of highly deprived meshblocks in Wellington, 1991 and 2013 ...........60

Figure 4.17. Distribution of highly deprived meshblocks in Wellington, 1991 and 2013 ............61

Figure 4.18. Proportion of highly deprived meshblocks in area units, Wellington 1991 and 2013

Figure 4.19. Spatial distribution of highly deprived meshblocks, Wellington 1991 and 2013 .....63

Figure 4.20. Distribution of highly deprived meshblocks in Auckland, 1991 and 2013 .64 
Figure 4.22. Proportion of highly deprived meshblocks in area units, Auckland 1991 and 201365

Figure 4.23. Spatial distribution of highly deprived meshblocks, Auckland 1991 and 2013 .......66

Figure 5.1. Male unemployment rate for New Zealand, 1987 to 2017 ................................72

Figure 5.2. Male unemployment rate for Auckland and Wellington, 1987 to 2017 ..................73

Figure 5.3. Spatial distribution of highly deprived meshblocks in Wellington, 1991-2006..........81

Figure 5.4. Spatial distribution of highly deprived meshblocks in Wellington, 1991-2006..........81

Figure 5.5. Spatial distribution of highly deprived meshblocks in Wellington, 2006-2013..........82

Figure 5.6. Spatial distribution of highly deprived meshblocks in Wellington, 2006-2013..........83

Figure 5.7. Spatial distribution of highly deprived meshblocks in Wellington, 1991 and 2006 ...84

Figure 5.8. Spatial distribution of highly deprived meshblocks in Wellington, 2006 and 2013 ....85

Figure 5.9. Spatial distribution of highly deprived meshblocks in Auckland, 1991-2006...........85

Figure 5.10. Spatial distribution of highly deprived meshblocks in Auckland, 1991-2006..........86

Figure 5.11. Spatial distribution of highly deprived meshblocks in Auckland, 2006-2013.........87

Figure 5.12. Spatial distribution of highly deprived meshblocks in Auckland, 2006-2013..........88

Figure 5.13. Spatial distribution of highly deprived meshblocks in Auckland, 1991 and $2006 . . .89$

Figure 5.14. Spatial distribution of highly deprived meshblocks in Auckland, 2006 and 2013 ....90

Figure 6.1. Area units for the Wellington Region, 2013 .......................................................97

Figure 6.2. Meshblocks for the urban area of the Wellington region, 2013 ..............................98

Figure 6.3. Location quotients for population in highly deprived meshblocks in Wellington, 1991 2006 and 2013

Figure 6.4. Location quotient for number of individuals with low-income in highly deprived

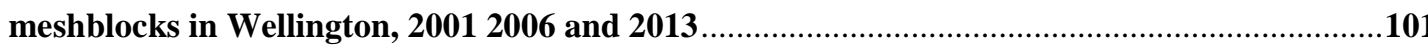

Figure 6.5. Location quotient for number of means tested benefit in highly deprived meshblocks in Wellington, 20012006 and 2013. 102

Figure 6.6. Location quotients for the number of unemployed in highly deprived meshblocks in Wellington, 19912006 and 2013. .103

Figure 6.7. Location quotient for number of one-parent families in highly deprived meshblocks in Wellington (1991, 2006 and 2013).

Figure 6.8. Location quotient for number of households who do not own their dwelling for highly deprived meshblocks in Wellington, 19912006 and 2013. 105

Figure 6.9. Location quotient for number of individuals who do not possess a qualification for highly deprived meshblocks in Wellington, 20012006 and 2013. 106

Figure 6.10. Location quotient for crowding ratio for highly deprived meshblocks in Wellington, 19912006 and 2013.

Figure 6.11. Location quotient for individuals with no access to a vehicle for highly deprived meshblocks in Wellington, 19912006 and 2013.

Figure 6.12. Location quotients for population in highly deprived meshblocks in Auckland, 1991 2006 and 2013. 
Figure 6.13. Location quotient for number of individuals with low income in highly deprived meshblocks in Auckland, 20012006 and 2013.

Figure 6.14. Location quotient for number of means tested benefits in highly deprived meshblocks in Auckland, 20012006 and 2013.

Figure 6.15. Location quotient for number of unemployed in highly deprived meshblocks in Auckland, 19912006 and 2013.

Figure 6.16. Location quotient for number of one-parent family in highly deprived meshblocks in Auckland, 19912006 and 2013

Figure 6.17. Location quotient for number of households who do not own their dwelling for highly deprived meshblocks in Auckland, 19912006 and 2013.

Figure 6.18. Location quotient for number of individuals who do not possess a qualification for highly deprived meshblocks in Auckland, 20012006 and 2013 116

Figure 6.19. Location quotient for crowding ratio for highly deprived meshblocks in Auckland, 19912006 and 2013 117

Figure 6.20 Location quotient for individuals with no access to a vehicle for highly deprived meshblocks in Auckland, 19912006 and 2013

\section{Table of Tables}

Table 3.1: Weight for variables included in the NZDep91

Table 3.2: Variables included in the New Zealand deprivation score, 2006 and 2013

Table 4.1. Population change in disadvantaged locations in $10 \mathrm{~km}$ bands for the five cities, 1986 and 2011.

Table 4.2. Location quotients for disadvantaged populations for the five cities (Adelaide, Brisbane, Melbourne, Perth and Sydney), 1986 and 2011.

Table 4.3. Population change in deprived locations in $10 \mathrm{~km}$ bands for Wellington and Auckland (1991 and 2013) .57

Table 4.4. Location quotients for deprived populations for Wellington and Auckland (1991 and 2013) .58

Table 5.1 Mean and standard deviation of the unemployment rate for Auckland and Wellington, 1987 to 2017 .73

Table 5.2. Population change in deprived locations in $10 \mathrm{~km}$ bands for Wellington and Auckland, 1991 and 2006

Table 5.3. Population change in deprived locations in $10 \mathrm{~km}$ bands for Wellington and Auckland, 2006 and 2013

Table 5.4. Location quotients for disadvantaged populations for Wellington and Auckland, 1991, 2006 and 2013. .79

Table 6.1. Variables included in the New Zealand deprivation score, 2006 and 2013 .93 


\section{Chapter One: Introduction}

\subsection{The problem}

Inequality has emerged as a key issue in contemporary global urban debates. Many developed cities across the world are characterised by growing social-spatial inequalities, housing liberalisation, and gentrification, which limit the housing options of poor households. When the poor have limited housing options, they have to deploy coping mechanisms. There is recent international literature on the suburbanisation of poverty in predominantly European and American cities. The aim of this research is to identify whether - given rising house prices - there has been a shift of the urban poor away from the central cities in New Zealand, towards the middle suburbs and peripheries. Furthermore, this research seeks to observe whether poor populations are becoming more concentrated.

This thesis intends to investigate how the poor adjust to rising demand for access to the central city. This study hypothesises that the poor move down the rent gradient, rather than trade off the quantity (or quality) of housing consumed. If confirmed, this finding would raise questions around market orientated urban growth driving demand for housing in the cities of New Zealand.

\subsection{Outline of thesis}

This thesis spans seven chapters. The first chapter introduces my topic. Chapter two is my literature review and conceptual approach chapter, and chapter three is my methodology chapter. Chapter four is the start of my analysis chapters. In that chapter, I look at the change in the spatial distribution of deprivation. In chapter five, I look at temporal differences across two periods, one characterising a strong macroeconomy and one comprising a weak macro-economy. In my last analysis chapter, chapter six, I look at the individual components that go into the deprivation variable, and whether they are becoming more concentrated in deprived areas. Lastly, in my seventh chapter, I bring all my findings together and discuss what I found, and the relevance of what I found.

In chapter two, I summarise a large portion of literature that addresses the shift of the poor away from the urban centres. The literature shows there is a growing concern 
with geographic inequalities in urban settings. Increasing house prices due to gentrification and the increasing opportunity cost of time for the urban affluent is making the central city unaffordable for the urban poor. A large amount of literature has described or argued that the poor are being displaced or replaced, and that the geographic inequalities are exacerbating.

From this literature, I was able to develop my conceptual approach. I conceptualised the problem by hypothesising that due to rising house prices, poorer households or individuals would need either to move further away from the city centre or adjust their housing consumption. This will help me answer my three research questions.

In chapter three, I outline the steps I will be taking for my analysis, the data I will be using, and the rationale for both. I first describe the data that was available to me. I use data from the New Zealand census and describe how this dataset can be broken down into different geographical levels. Next, I introduce my dependent variable, the New Zealand deprivation score. I then look to previous international studies with a similar geographical focus. I describe their research processes and what can be learnt from their methodologies. Particularly, I look to the 2017 study by Randolph and Tice that looked at the shifting spatial distribution of disadvantage in Australia's five biggest cities. Their research uses a similar variable to my main dependent variable, and Australian cities are occasionally compared to New Zealand cities. Lastly, I describe the methods that I undertake in the three analysis chapters.

In chapter four, I go through Randolph and Tice's 2017 study. My expectation is that because Randolph and Tice found a shift of 'disadvantage' away from the city centre in Australian cities, that I would find a similar pattern. I expect to find a shift away from the city centre of 'deprivation' in New Zealand cities.

In chapter five, I introduce the concept of temporal differences having a part to play in the changing spatial distribution of deprivation. The temporal differences that I compare correspond to changing strengths in macroeconomic conditions. The first period 1991-2006 is a time of economic 'expansion'. The second period I measure, 2006-2013, is a time of economic 'contractiona'. I set up my analysis to see whether these different periods have different experiences in the distribution and concentration of deprivation. 
In chapter six, I analyse the concentration of the different components that make up deprivation in highly deprived meshblocks. The purpose of performing this analysis is to see whether different aspects of deprivation are increasingly becoming more concentrated in highly deprived areas or more dispersed away from deprived areas. The main method of analysis I use is location quotients.

In my seventh and final chapter, I bring together my findings and conclude. I go through each research question, my expectation as to what I thought I would find before the research, how that was set up as a hypothesis, and then what my actual finding was. I relate these findings back to the literature and then relate these findings to how they might be relevant to policy. 


\section{Chapter Two: Literature and conceptual approach}

\subsection{Introduction}

The aim of this research is to identify whether - given the rising demand for access to the central city - there has been a shift of the urban poor away from the centre of cities, towards their peripheries. This chapter reviews existing urban literature as a point of departure for my study and outlines advances this thesis will make relative to the existing research.

\subsection{The problem}

\subsubsection{Suburbanisation of the poor}

The main point I wish to investigate in this chapter concerns the way in which previous authors have analysed continual concentration of income and expenditure in the central city of a metropolitan area and how that might exacerbate social inequality. The primary mechanism considered is the way the spatial concentration of capital at the centre of a city steepens the housing rent gradient, leading to increasing the suburbanisation of the poor. There are different approaches to test and measure this phenomenon.

Both Randolph and Tice (2014), and Cooke and Denton (2015) take a place-based approach, looking as to why there appears to be increasing levels of poverty in the suburbs relative to inner city areas and previous measurements of these suburbs. Randolph and Tice used data from the 1986 and the 2006 Census in Sydney, Australia. The authors looked at both poverty rates in geographical units and at the geographic distribution of incomes. Randolph and Tice observed a reversal of the previous geographic distribution of income across the city. They concluded there had been a marked shift of poverty away from the inner cities and into the middle, and in some cases outer suburbs of Sydney.

Cooke and Denton (2015) aimed to answer whether higher densities could explain increasing poverty in suburban regions, rather than distance to the city centre associating with poverty, i.e. less accessibility to the centre of the city. The authors used data drawn from the 1990 United States Census, as well as the 2007-2011 American Community Survey that provides recent estimates for poverty rates in 
census tracts. From their analysis of the largest 100 metropolitan areas, the authors concluded that poverty is increasing in the low-density suburbs of a handful of the largest metropolitan areas. However, the most definitive trend they found was an increase in poverty in medium-density neighbourhoods at the boundaries of the inner cities.

By contrast, both Hochstenbach and Musterd (2017), and Walker (2017) take a people-based approach, tracking the migratory movements of those with low incomes and other characteristics attributed to poverty, and analysing their movements to see the extent of the so-called suburbanisation. The people-based approach empirically remains a challenge, as few surveys track households across locations or dwellings. Moreover, households move frequently, and households who are genuinely pushed out because of rising rents or market-related evictions are difficult to identify.

Hochstenbach and Musterd (2017) looked at residential movements of low-income households in Amsterdam and Rotterdam. They identified a trend of the suburbanization of poverty toward the urban peripheries and surrounding regions. Their paper argued that the suburbanization of poverty is both a direct process of poor households moving from city to suburb, and a broader indirect process caused by exclusionary mechanisms. However, their analysis did not pay any attention to the low-income households that were staying put in their location. They investigated changes in the residential moves of different low-income households - the working poor, low-to-middle income earners, and unemployed - in the Amsterdam and Rotterdam urban regions for the period 2004 until 2013. While they found a consistent suburbanisation of poverty within Amsterdam, they attributed the trend in Rotterdam to a reaction to the global financial crisis and found this had since regressed to the mean. The authors found low-to-middle income and unemployed households tended to be the groups suburbanising. They concluded that a growing number of working poor households are using coping strategies to remain urbanised, presumably for accessibility to employment opportunities.

Walker (2017) examined the claim that internal migration trends in the U.S. have reached a turning point where migrants increasingly prefer urban residences to suburban locales. To establish whether recent internal migrants in the U.S. are 
choosing closer-in destinations, Walker (2017) drew from microdata samples from the American Community Survey between 2005 and 2011. During this period, the author observed there was an overall trend of migrants in the largest metropolitan areas of the U.S. choosing to migrate closer to the metropolitan core. However, the majority of the migrants classified as high income were moving closer to the core. Lower income internal migrants remain suburban. Overall, this analysis supports the hypothesis that the poor must suburbanise due to higher competition for land closer to the city centre. These studies, along with others, show there is a sufficient body of international evidence to suggest a shift of poverty from the inner-city areas to the middle and outer areas of some cities (Cooke \& Denton, 2015; Randolph \& Tice, 2014; Abrahmson et al., 1995; Stoll \& Raphael, 2010).

\subsubsection{Importance}

Why is testing whether there has been a shift of low-incomes towards the periphery of the city important? Cities are known to promote growth and productivity through agglomeration (i.e. the clustering together of different services) and accessibility to goods and services. Cities are therefore a mechanism for increasing the wellbeing of the residents (World Bank, 2009). There is research that has shown geographic inequalities to be problematic in several ways. Some evidence suggests that the suburban poor face more barriers to much needed services than they would living closer to the central city, suggesting that accessibility is a good in and of itself (Andrulis, Duchon \& Reid, 2004 as cited in Howell and Timberlake, 2013). This further disadvantages the poor and creates a less equal and cohesive society.

In many suburbs the low income health care infrastructure is underdeveloped, and the spatial location of service providers requires significant travel, both of which can be a burden on the poor (Andrulis, Duchon \& Reid, 2004 as cited in Howell and Timberlake, 2013). Low income households generally do not or cannot migrate to more affluent areas (Howell \& Timberlake, 2013; Morrison \& Nissen, 2010), which raises issues of social mobility and entrenching inequitable access to urban amenities if it exists. Furthermore, Clark and Morrison (2012) showed that those leaving very deprived areas are less likely to upgrade their neighbourhood, particularly if they also report relatively low incomes. 


\subsubsection{Rising house prices}

Edlund Machado and Sviatschi (2017) argued that house prices in urban areas have risen over the last three decades predominantly due to rising returns to skill. Skilled workers are increasingly paid more than non-skilled workers are. Skilled jobs such as service-based jobs are highly centralised and concentrated in or around the central business districts. The authors argue that the skilled are working longer hours, which boosts the attractiveness of the city centre, as commute times are shorter.

Subsequently, the skilled outbid the competition, i.e. the poor, for housing in the centre of the city. Access to opportunity, Acolin and Wachter (2017) argue, is inextricably linked with housing affordability. They conclude that access to opportunity, and in particular good education, is important for social mobility between generations. The poor are increasingly being denied access to opportunity because fewer of them now live in the centre city.

Rising house prices are a leading cause of the poor having to shift towards the peripheries. Cox, Pavletich and Hartwich (2017) used historic data to create a 'median multiple' - median house prices divided by median household income. The authors found that housing costs in New Zealand cities had risen at a similar rate to household incomes until recently. Historically, the Median Multiple had remained consistently between 2.0 to 3.0 in New Zealand, Australia, United Kingdom, United States, Canada and Ireland. These were the countries that the authors had longitudinal data for. In recent decades, house prices have escalated far above household incomes in many parts of the world. In some metropolitan markets house prices have doubled, tripled or even quadrupled relative to household incomes (Cox et al., 2017).

Evidence suggests that recent initiatives such as home sharing may further increase rental prices and house prices in urban centres (Horn and Merante, 2017; Barron, Kung and Proserpio, 2017). The primary example of this is Airbnb, a platform that has become hugely popular. Demand for home-sharing increases the rental rates and incentivises property owners to switch from supplying long-term rental accommodation, opting instead for short-term rentals. The increase in rental rates through this channel is then capitalized into house prices. Home-sharing also increases house prices directly by enabling homeowners to generate income from 
surplus housing capacity. This raises the value of owning relative to long-term renting, and therefore increases the price-to-rent ratio directly (Horn and Merante, 2017; Barron, Kung and Proserpio, 2017).

Substantial literature discussed in this section show that rising house prices are becoming unaffordable, especially for poorer households. These house prices are passed on in rental prices, and subsequently, the poor have to adjust their housing consumption or opt to move down the rent gradient.

\subsubsection{Urban housing models}

Rising house prices present an affordability problem. The rich can out-bid the poor for housing, which in turn leaves the poor with little or no choice as to where to live. Urban academics have attempted to develop theories and models that describe ways in which a city's growth can provide housing for both the rich and the poor.

One theory focuses on the concept of filtering. Filtering suggests that as new houses are built and enter the market, older houses deteriorate and decrease in value (Lowry, 1960). The theory posits that wealthier residents tend to relocate to new dwellings, leaving older dwellings available for the less affluent. This filtering is a means of providing affordable housing without the need for state intervention. In this respect, filtering advocates for a free market rather than state supplied solution for housing of the poor. Filtering also dictates the spatial layout and growth of the city. Older dwellings locate near the centre of the city with newer homes being built further away. This results in the rich tending to reside further from the city centre. Filtering has been the subject of substantial debate and its ability to explain housing markets has been criticised (Gray \& Boddy, 1979; Galster \& Rothenberg, 1991).

While not without its criticism, the monocentric city model, developed by Alonso, Mills, and Muth (Alonso, 1960) has been broadly used in the urban literature. The model explains simply why house prices are more expensive towards the centre of cities, and cheaper further out. The model represents the city as a circular residential area surrounding a central business district where all employment is located. The utility of housing is determined by its distance to the CBD, quantity of housing, and price. Rent must be lower at more distant locations, proportional to the increase in transport costs. Urban land prices are driven by transport costs paid by users. These 
transport costs include the opportunity cost of the time spent traveling to work and leisure activities. Transport costs increase with distance from the city centre. The trade-off made by land users between the cost of transport in different locations and their desire to consume land results in land prices decreasing as transport costs increase. Land users react to differences in land prices by consuming less land where land is expensive and more where it is cheaper (Duranton \& Puga, 2015).

Under the monocentric city model, housing location choice is the result of the combined utility gained from housing and transport accessibility (particularly with regard to commute time); the extent to which property values rise in relation to distance to the central city can be viewed as a metric of the value consumers place on transport accessibility and low commute times relative to housing. Lower house prices on centrally located housing in the US between the 1950s and 1990s is evidence of a preference for larger houses over lower transport costs (Mieszkowski \& Mills, 1993).

Using data from the 27 largest US cities, Edlund, Machado, \& Sviathci (2017) argued that while before 2000 rich households tended to locate in suburban neighbourhoods distant from the central city, post 2000 data shows an increasing tendency to locate in the central city. The authors argue that this is due to the increasing opportunity cost of time, especially among rich households.

Trussell (2010) argues that transportation technology decreases the predictive power of the monocentric bid rent gradient, and more variables must be introduced into the model. Bertaud (2014) disagrees, stating that the monocentric model continues to have strong descriptive and predictive power for existing cities, even for polycentric cities (multiple employment centres). This is useful, as Bochnovic (2014) describes how difficult and inconsistent measuring polycentricity is in a given city. The simplicity of the monocentric model, and the relaxed assumptions means the model is still used in many places around the world - including New Zealand and Australia - to explain patterns of land use and urban development (Kulish, Richards, and Gillitzer, 2012; Lees, 2014). Indeed, Arribas-Bel and Sanz-Garcia (2014) showed in their study of 359 U.S. metropolitan areas that despite a new focus on polycentric cities in the literature, a majority of the cities adhere to a monocentric structure. 
Housing costs vary considerably across geographic space, a factor that is both relevant to individual household location choice decisions and government decision making when choosing where to allow future housing development (Bertaud, 2015). When comparing the cost of living in various locations, many analyses have omitted the transport costs associated with living at a given location (e.g. Cox, Pavletich and Hartwich, 2017). Such an approach is problematic as some areas that are considered affordable in terms of housing costs are often less so after accounting for transport costs due to the relative inaccessibility of employment and amenities (Nunns, 2014).

\subsection{The causes of suburbanisation of the poor}

\subsubsection{Gentrification}

Gentrification has been defined in various ways over the last 50 years. However, there are four key aspects that the literature agrees upon (Lees, Slater and Wyly, 2013). Firstly, gentrification involves the reinvestment of capital. Secondly, urban spaces are upgraded, predominantly by the rich. Thirdly, neighbourhoods are changed dramatically because of this reinvestment. Lastly, the process creates displacement of low-income groups who were previously residing in the area (Davison and Lees, 2000 cited in Lees et al., 2013).

While the processes of gentrification have mainly been observed in the urban centres, this is not the only place gentrification occurs. Drawing from the models discussed previously, gentrification is more likely to occur in places that are more accessible to the city centres. These gentrifying locations may come in the surrounding area of transport hubs or efficiently built highways. Many residents who were displaced or pushed to the periphery in the early stages of gentrification may subsequently be displaced or pushed further (Slater, 2011).

\subsubsection{Production and Consumption}

The gentrification process has changed over time and been modified in relation to local contexts. As such, urban scholars often attempt to categorise gentrification in terms of waves: first wave, second wave and third wave. The various stages of gentrification will be discussed in more detail later in this section. Straddling these waves is a key debate amongst gentrification scholars, most notably Neil Smith and David Ley, concerning the significance of production and consumption drivers in 
gentrification processes. Firstly, the production side theory, put forward by Neil Smith in 1987, argues that without upkeep, the quality of a building naturally decays over time, and therefore property prices tend to fall. The depreciated land in the centre of a city is then undervalued - and the people who inhabit the property fall into poverty - causing the price to be significantly cheaper than the potential value the land could allow for (Persky \&Wiewel, 2011). Essentially, buildings depreciate whereas land appreciates in value, creating a rent gap between the potential value of land and the realised price of land, the extent of which depends on how intensified the land is closer to the centre of the city (p. 462).

Secondly, there is the consumption side theory that describes gentrification as the social and spatial manifestation of the transition from an industrial, production-based economy to a post-industrial, service-based economy (Hamnett, 2003). Higher income service-based jobs agglomerate in the central city and are filled by the rich who can outbid the working class for property. As reasoned earlier, the highly skilled want to travel less to work and to leisure. Furthermore, this new group, with more disposable income, are attracted to inner city living due to the consumption and leisure opportunities available in bars, restaurants, theatres and cafes that living within close proximity to the city allows access to (Ley, 1994).

To consider these opposing views, it is important to first ask, who is the gentry? Ruth Glass's (1964) definition claims the gentry is the middle or upper class. However, later definitions have expanded on this and termed this mobile gentry 'the yuppie' (young urban professionals) (Wyly and Hammel, 1999). This group is middle class, usually well educated, and often includes couples that have opted to not have children (Wyly and Hammel, 1999; Lees et al., 2013). While Ley and Smith tend to agree upon who makes up the gentry, the debate in scholarship arises regarding what motivates this group to move to the city.

As mentioned above, Neil Smith (1987) claims gentrification is a movement of capital rather than people. He agrees that the gentrification process is carried out by middle class urban dwellers; however, for Smith this movement is motivated by profit rather than consumer preference. Smith's (1979) rent gap theory explains that once an area of the city is no longer worth investing in, landlords or property owners will simply disinvest and move to other parts of the city that can promise a greater 
return on their investment. This process creates uneven development since services and infrastructure are then channelled to wealthier parts of the city. Since housing is an asset, rich people choose neighbourhoods where property values are likely to increase over time.

Production and consumption processes, it would seem, contribute simultaneously to gentrification. Disinvestment followed by reinvestment in an area by property developers or landlords can attract new interest in the neighbourhood. However, this investment might only become profitable by attracting the middle-class buyers into the area - a chicken and egg situation. Consumption spaces that are desirable to the rich are crucial within the gentrification process for several reasons. Firstly, cafés, restaurants, upmarket shops act to distinguish the neighbourhood as middle class but also to distance the suburb from its former working-class history. Secondly, these new retail spaces play a significant role in the displacement process since as the neighbourhood begins to transform former residents no longer feel at home in the area, thus contributing to indirect displacement (Lees et al., 2013).

\subsubsection{Stages of Gentrification}

If gentrification is a contributor to suburbanising the poor, why has this trend of the poor suburbanising not arisen sooner? It is likely due to the fact gentrification happens in different waves. Across the urban literature, three waves of gentrification have been identified in highly developed western countries (Lees et al., 2013. It is not clear yet if these processes are universal and occur in developing cities. The first wave began approximately in the 1950s and lasted until the mid-1970s (Hackworth and Smith, 2001). The second wave is considered to have been from the midseventies and throughout the 1980s (Hackworth and Smith, 2001). The third wave became prominent in the 1990s (Hackworth and Smith, 2001) and continues to the present time.

The wave model provides a broad explanation for different types of gentrification, although these definitions are often critiqued for being too general and ignoring locally specific contexts (Lees et al., 2013). Nevertheless, the various waves can provide a useful framework from which to further assess case studies. 


\section{First wave}

First wave gentrification describes urban change at the neighbourhood level and has been observed in developed cities as having occurred prior to the mid-seventies (Hackworth and Smith, 2001). This is the type of gentrification that was originally described by Ruth Glass in 1964 (Smith, 2002, as cited in Lees et al., 2013). These changes were carried out by the middle class's buying up of property, which consequently displaced the neighbourhood's previous working-class occupants (Butler and Hamnett, 2009; Lees et al., 2013).

Gentrification during this period was largely carried out by the rich acting individually, and tended to be periodic (Hackworth and Smith, 2001; Lees et al., 2013). As Neil Smith (1987) notes, at this time gentrification was framed as a positive contribution to the urban environment. Poor neighbourhoods were perceived as deteriorating, declining and undesirable places to reside.

While the post-war era saw a movement of the middle classes to the suburbs, gentrification brought the middle classes 'back to the city.' In addition, during this period there was a growing middle class and an overall shift from renting to private property ownership amongst this group (O'Hanlon and Hamnett, 2009). This can be considered in terms of a Keynesian welfare state that prioritised affordable housing for working class families, encouraging class mobility. Reinvesting in inner city urban areas that had deteriorated due to property owners' disinvestment was often cheaper than building or buying new property in the suburbs (Smith, 1987). Alternatively, as Ley (1994) would argue, changes to family structure, more women engaging in paid work and the post-industrial city created the desire for middle class workers to live closer to the city centre.

\section{Second Wave}

During the second wave, gentrification had become commonplace in most developed urban centres (Hackworth and Smith, 2001). The social, political and economic restructuring of cities contributed to this trend (Smith, 1987). The 1970s saw a shift away from manufacturing as the primary industry in many developed urban centres (Butler and Hamnett, 2009; Howe, 2009; Watt, 2013). This shift brought about an increase in service sectors meaning more people were employed in managerial and 
professional roles (Butler and Hamnett, 2009; Smith, 1987; Watt, 2013). Changes to industry consequently brought a change in class structures - this facilitated growth in the middle class (Butler and Hamnett, 2009; O'Hanlon and Hamnett, 2009; Smith, 1996; Watt, 2013). Another factor that contributed to changing class structures was changing gender roles; more women engaging in the paid workforce led to increases in household incomes for some families (Slater, 2011). These changes contributed to cities becoming spaces of consumption rather than production. Cities had now become a more desirable place for middle class workers to reside.

Political resistance and opposition to gentrification was the strongest during the second stage of gentrification (Hackworth and Smith, 2001; Lees et al., 2013). This is perhaps because this phase was more intense than the last one as it brought about high levels of displacement (Forman, 1989). The United States saw an increase in homelessness, making the impact of gentrification more visible (Smith, 1996). While the first wave of gentrification tended to be periodic, by the second wave gentrification had become widespread and is ongoing. Shifting to the urban core became a viable, if not attractive, option for middle class workers.

\section{Third Wave}

The most notable aspect of third wave gentrification is the changing role played by the State (Murphy, 2008; Rérat, et al., 2010; Smith, 2002). Prior to the 1990s the State played a minimal role in gentrification and in fact in many cases prevented areas of the city from becoming gentrified (Watt, 2009). Social housing owned by local and central governments meant desirable parts of the city were kept out of reach of the private market (Watt, 2009).

Policies such as rent control provided a security blanket to poor people living in gentrifying areas. However, free market orientated governance and changes to social welfare meant these properties were now made available to private investors (Watt, 2009; Watt, 2013). Under State-led gentrification, private property developers and local governments work together to facilitate the gentrification of neighbourhoods (Smith, 2002).

Individual actors are still involved in the third stage of gentrification through creating a demand (Rérat et al., 2010). The changing role of the State in the gentrification 
process meant that by the 1990s gentrification strategies had become embedded in local and national urban policy (Smith, 2002). As a result, the third wave of gentrification, unlike previous waves, was more planned (Smith, 2002; van Gent, 2013). As Neil Smith (1996) puts it, although gentrification existed prior to privatisation, the gentrification process thrives in a climate of privatisation.

\subsubsection{Displacement}

A direct result of gentrification is the displacement of a neighbourhood's previous occupants. As Neil Smith $(1987 ; 1996)$ argues the process of gentrification is a movement of capital rather than people. Neil Smith's (1987) rent gap theory is a useful way of thinking about how capital is moved around in the gentrification process. According to Smith (1987), landlords who invest in properties receive a return in the form of rent. In a declining market, landlords will simply disinvest in their properties if the maintenance costs outweigh the rental price (Smith, 1987). This, according to Smith (1987), is when gentrification occurs since land can be sold cheaply and rejuvenated. In some cases, land banking is a viable option, and landlords simply rebuild when the land is worth more. Since gentrification occurs in declining markets, those being displaced tend to be low-income vulnerable groups such as women, sole parents, the elderly, unemployed or underemployed.

As Shaw (2000) argues, there is often also a link to ethnicity. Displacements then act to further marginalise this group since rely particularly on community and social networks for support. Furthermore, the poor have fewer affordable options available to them on the housing market.

Displacement occurs in the gentrification process in several ways and residents can be displaced either directly or indirectly (Watt, 2009). Low income residents may be directly pressured to leave their homes through housing demolitions, increases in rent (or rates), or eviction by the landlord (Atkinson, 2004; Rérat et al., 2010; Watt, 2009; Watt, 2013).

Since gentrification is a process that works its way outwards from the city centre (Smith, 2002) rent and property prices may also increase in neighbouring suburbs (Atkinson, 2004). This makes remaining in the same area difficult for low-income groups. However, displacement may also occur more subtly; when their family and 
friends are priced out of the area, residents may choose to leave due to a loss of sense of community, neighbourhood resources and social networks (Atkinson, 2004; Rérat et al., 2010; Watt, 2009; Watt, 2013).

The latter form of displacement is often referred to as 'displacement pressure' (Atkinson, 2004). This can occur in several ways. Firstly, new shops, businesses and facilities geared towards middle class occupants may make the neighbourhood less liveable for low-income residents (Watt, 2013).

Another aspect that makes displacement less obvious is that it is often mediated by welfare systems in ways that can lessen the severity of gentrification's impacts. This was the case with gentrification in Auckland's inner-city neighbourhoods since the lowest income earners being displaced were often State housing tenants. The State then often assisted with the relocation of this group (Atkinson, 2004; Lees, 2012) moving residents into new social housing built on the periphery.

This is especially true for State-led gentrification since the State's heavy role requires local governments to consider what to do with those displaced (Lees, 2012). However, relocation is often problematic. Firstly, moving residents out of the area means displacement effects such as loss of community, sense of belonging and place are unseen. As previously mentioned, the second wave met the highest level of resistance since it produced an influx of homeless (especially in the United States where there is less social welfare support available) (Atkinson, 2004). However, the State's role in the third wave of gentrification means these social costs can remain hidden to the wider public, and local governments can continue to frame gentrification in a positive light using language such as urban renewal.

\subsection{New Zealand Context}

In 1977, Thorns analysed suburbanisation rates in New Zealand and found a large proportion of rich people were moving to the suburbs. This can be explained largely by New Zealanders' attitudes towards living space, and the "quarter acre kiwi dream" of owning a large section of land. Thorns' study was undertaken before the radical economic policies of the 1980s and 1990s were implemented and before the previously mentioned processes occurred. New Zealand has since seen unprecedented growth in income inequality due to an increasingly larger proportion 
of wealth going to the higher income brackets (OECD, 2015). It is an important job for policy makers to ensure the most disadvantaged are not left behind, especially in New Zealand's two biggest metropolitan areas.

Auckland and Wellington are relatively unique when it comes to their urban topography. Both small by international standards, they are also both constrained by naturally occurring harbours. Both metropolitan areas are technically polycentric, drawing their wider population from four different cities and surrounding districts that have sprawled together due to outward urban growth. However, due to their narrow topography, and relatively low population - by international standards - one might expect the Auckland and Wellington metropolitan areas to experience the models discussed throughout this chapter. I discuss potential problems with treating both cities as monocentric in chapter seven.

Allen (2015) examined how residents make trade-offs between low and higher density housing in Auckland. Qualitative interviews were conducted with 57 residents of medium density housing developments spread throughout the City. In contrast to Haarhoff et al. (2012), when envisioning desired future residential locations, respondents were evenly split between desiring low density and medium density housing. Accessibility to urban amenities was identified as the primary factor for choosing medium density housing. The primary factor in choosing low density housing in the future was not a preference towards low density, but rather other concerns such as build quality, lack of storage, kitchen space, the ability to have pets, and the ability to make renovations.

Yeoman \& Akehurst (2015) examined preferences for dwelling type, dwelling size, and location in Auckland using a stated choice survey. Respondents were recruited via telephone and completed the survey via a web browser. 1,096 responses were received with a response rate of $13 \%$. The survey over-represented higher income individuals, homeowners, and older individuals, and under-represented minority groups and one and two person households. Respondents were asked to choose between four alternatives which varied by the number of bedrooms, number of bathrooms, architectural style, layout, parking, land area, location, and price. Visual aids were provided for the layout, dwelling type, and location. A conditional logit model was constructed using four attributes: housing type, location, number of 
bedrooms, and price. Price was by far the most important variable, followed by dwelling location and then by dwelling type. Dwelling size, measured by number of bedrooms, was not statistically significant at the 5\% confidence level. When making a trade-off between location, type, size, and price, just over half (52\%) of all respondents chose a detached dwelling. This is in contrast to $75 \%$ of dwellings in Auckland currently being standalone dwellings. A significant limitation of the study is that there was a considerable number of variables in the choice task that were not held constant across the alternatives, including architectural style, parking, land area, layout, greenery, and dwelling colour. These variables likely influenced choices but were not incorporated into the modelling exercise.

Auckland's inner-city suburb of Ponsonby provides a useful example of the first wave of gentrification. Prior to World War II Auckland's inner-city suburbs were mostly occupied by white, middle class workers. However, after the war, new motorways and high rates of vehicle ownership accommodated a middle-class shift to the suburbs (Latham, 2000; Lees and Berg, 1995; Friesen, 2009). Those left behind or recently arriving in the city were Māori migrating from rural areas and Pacific Island immigrants, arriving in New Zealand to work in the manufacturing industry (Latham, 2000; Lees and Berg, 1995; Friesen, 2009). Since the 'white flight' of the post war period meant those left in the inner city were usually lowincome working class, Ponsonby shops and houses declined. Smith (1996; 2002) would argue this was a result of disinvestment of capital, subsequently reinvested in outer city suburbs by middle class workers.

However, the 1970s once again brought a shift in the demographic of those living in inner city suburbs such as Ponsonby (Latham, 2000; Lees and Berg, 1995; Friesen, 2009). Throughout the 1970s and 1980s young professionals (or 'Yuppies') were looking at buying their first homes and were attracted to cheap house prices. According to Latham (2000) early migrants to Ponsonby were not the wealthiest group, but rather modest income earners such as nurses, university lecturers, students and architects. These groups were attracted to the inner-city suburbs due to affordable housing prices in addition to an alternative lifestyle from the suburban stereotype. Areas such as Ponsonby appealed to this group due to its proximity to the city centre, which facilitated the consumption culture of restaurants, cafés and bars. 
The gentrification of Auckland's inner-city suburbs occurred gradually throughout the 1970s and 1980s. One by one the houses were bought and renovated by middle class residents moving in. Eventually the landscape reflected this changing demographic with once run-down abandoned shop fronts slowly replaced with trendy cafes, bars and restaurants (Latham, 2000).

Second wave gentrification was most prominent during the 1980s and 1990s, coinciding with welfare reforms that gradually removed the 'safety net' and reduced the State's role in housing provisioning. This meant the State became involved in the gentrification process. As Lees and Berg (1995) point out, Auckland saw an increased spatial polarisation between rich and poor throughout the 1980s and 1990s. Areas of Auckland's inner city such as Ponsonby, Freeman's Bay, Herne Bay and Parnell had been areas that were occupied by State-housing tenants.

During the first wave of gentrification in Auckland, inner city State-housing tenants were protected under security of tenure. However, changes to State-housing policy in the early 1990s introduced market rents. Since the middle-class desire to live close to the city centre had become the norm, this brought about an increase in rents and property prices. Increased rents and rates left those within the lower income bracket, including State housing tenants, the option to relocate or pay more. State housing tenants could receive the accommodation supplement; however, this was not always enough to cover the shortfall in the costs of rents. After the change in government in 1999, income related rents were restored for State tenants.

The demographic of inner-city suburbs was now primarily white middle class while Māori and Pacific Island residents (who during this period were mostly low-wage workers) were pushed to the periphery where market rents and property prices were more affordable. Lees and Berg (1995) explain that between 1986 and 1991 there was an ethnic change within Auckland with Maori and Pacific Island populations moving to then outer city suburbs such as Penrose, Glen Innes, Pt. England, Oranga/Te Papa, Mt Wellington, Tamaki, Otahuhu, Mangere and Wesley, which also saw a related decrease in Pākeha populations.

Auckland's CBD has two current examples of third-wave gentrification. Collins (2010) argues that New Zealand's migration and education policy led to an increase 
in the number of international students in Auckland, which altered the urban landscape resulting in the 'studentification' of the CBD. The influx of international student migration in the early 2000s resulted in the development of low-cost, low quality, high-rise apartment buildings, a growth in educational facilities, and changes to consumption spaces in central Auckland. Auckland Council imposed minimal planning restrictions on these new development projects, thus providing favourable conditions for private developers and international investors in this process (Collins, 2010).

A second example of State-led gentrification is the redevelopment of Auckland's Viaduct Harbour (Murphy, 2008). The gentrification of Auckland's waterfront can be considered an extension of the gentrification of the nearby previously mentioned suburb of Ponsonby (Murphy, 2008). However, in this example the State played an active role in the early stages of the Viaduct's redevelopment. Auckland City invested \$120 million of public funds into redeveloping the Viaduct Harbour to host the America's Cup in the year 2000. The Viaduct Harbour was then transformed into a site of elite consumption, up-market restaurants and tourism. This initial investment by the State stimulated private investment in the Viaduct, which included the development of exclusive apartment buildings (Murphy, 2008).

As Auckland continues to grow outward, areas that were once nearer to the periphery of the city are becoming increasingly desirable for middle class workers. Auckland's inner East suburbs of Glen Innes, Panmure and Point England (suburbs where many of those displaced in the first wave of gentrification retreated to) have become recent desirable places to live due to the proximity to Auckland's city centre. It is reasonable to suspect a similar situation might be occurring in Wellington.

Morrison (2011) argues that the growth of a creative economy in Wellington City and concurrent rise in the central city population has resulted in increased suburbanisation of the poor. It is argued that the benefits of a creative city, including a vibrant central city and a concentration of professional and creative jobs, accrue disproportionately to higher income groups and the well-educated, who are much more likely to live centrally. At the same time, he argues that the creative city results in an increasing rent gradient, which may drive those with lower incomes to live in 
the surrounding region in search of lower housing costs, where they face increased commuting costs.

Wellington city is a highly monocentric city with a concentration of jobs in the central city (Dodge, 2017). Based on the models discussed earlier in this chapter, it is worth investigating the validity of the wider metropolitan area, and in doing so, measure the extent to which there has been a suburbanisation of the poor.

\subsection{Conceptual framework}

One of the relevant questions is whether sensitivity to housing prices rises as incomes fall. If so, the poor will be especially keen to economise on the grounds of price. What I do not know is whether the poor are more sensitive to changes in housing prices relative to other expenditures (such as commuting). My conceptual framework is informed and built from the mechanisms described in this chapter, particularly the bid-rent curve.

The location issue has to do with how the poor economise. Is it by moving down the rent gradient closer to the periphery of the city or is it by reducing the quantity of housing they consume (i.e. reduce housing size per person by crowding or renting or buying smaller places)? Alternatively, do they try to maintain their housing expenditure by adjusting expenditure in some other way (such as eating less or cutting down on holidays or having fewer children etc.)?

To gain some initial traction, I begin with some simplifying assumptions. The first of these is the standard mono-centred city with an accessibility cost surface that increases linearly from the centre. The second assumption, derived from the first, is that rents decline from the single employment centre towards the periphery (the range of the labour catchment). The third assumption is that, apart from land rent (the cost of accessibility), the only other reason housing varies in price is because of the amount consumed.

If I assume that housing quality is uniform throughout the stock, then at any given location only the amount of living space per person determines the amount consumed. By these assumptions at any point in time, the price of housing can be 
varied either by changing location (closer or farther from the CBD along the $\mathrm{X}$-axis) and/or by altering the amount consumed (along the Y-axis).

From these simple assumptions, one can derive several hypotheses about the distributional implications of an externally generated rise in demand for housing. For argument's sake let me assume that price rise is a result of an externally generated surge in immigration. By external, I mean it is generated outside the market, say by government relaxing entry limits. To keep things simple, I assume all households rent their housing, therefore prices are housing rents (as opposed to land rents).

All three assumptions are used to construct Figure 2.1. I assume there are two groups of renters, low income and high income. The former live in smaller housing, along the thin continuous diagonal line of Figure 2.1 (r'), and the latter along the thick top diagonal line (r). These lines are like the bid-rent curves discussed earlier in this chapter.

Figure 2.1. Conceptual framework model



The bid-rent gradient lines are parallel in this scenario by the assumption that they both face the same accessibility cost; in dollar terms, it takes the poor and rich the same time to travel to work at the centre. However, this is often not true. With traffic 
congestion, and public transport stratification, the rich will often locate around highly accessible locations, even if they choose to live further down the rent gradient.

At any time, $t$, I assume that both groups, low and high income, are paying their maximum for housing. My interest is what happens to the renters when there is an exogenous shock to the market, such as a marked rise in immigration. Given the very low elasticity typical of housing supply (a limited number of dwellings can be built in any year); the impact of a surge in demand is to raise the price of all housing. In terms of Figure 2.1, the high-income households will adjust their consumption of housing to accommodate the price rise by consuming less housing (moving to a smaller house) or moving down the rent gradient further from the centre. Since the price rise affects all houses in the local urban market, a shift in the rent surface occurs downwards at all distances, so the lines remain parallel.

I assume, in this short run scenario, that there is no proportionate rise in incomes to counteract the rise in housing prices. To keep consuming the same amount of housing they would also have the option of moving down the rent gradient at time a to time $b$. To maintain the level of expenditure on housing at the same location (that is without moving from a) both high and low income renters must reduce the space they consume; from s to s' and from $r$ to r' in the case of high income households and from s' to s" or r' to r' in the case of low-income households.

Since low income households are also at their maximum when faced with rising prices, they too must adjust their housing consumption in order not to increase their expenditure on housing. As with the high income households, low income households also have two choices, to move further down the rent gradient (from a to $\mathrm{b}$ or reduce their consumption of housing (from r' to r' ') which would allow them to stay at location a.

Such an adjustment for housing consumed could involving sharing the existing space with additional household members to help pay the additional rent (and thereby reduce space per person). Alternatively, they could move into a smaller dwelling with no change in occupants. 
The other alternative (ruled out by my assumptions of equal quality) would be to reduce housing quality while retaining both location and quantity. In a 3D version, adjustments over all three dimensions would be possible.

The first lesson from this theoretical reasoning is that 'suburbanisation', i.e. movement down the rent curve towards the periphery is not the only response available to the poor (or rich) when faced with an externally driven rise in housing costs. The second lesson is that any empirical test of adjustment of the poor must take at least housing size and housing price into account.

As I move to my analysis, I know either I will find a shift of the poor away from the city centre, or I will find no change, or I will find an increase in the poor per square metre. This conceptual framework helps me understand the economic decisions a household might make. Either the poor can move down the rent gradient, i.e. suburbanise, or the poor can decrease housing consumption, i.e. increase crowding.

My thesis has three research questions: has there been a shift in the distribution of the urban poor away from the urban centre, towards the suburbs and periphery of cities?

Do different periods coinciding with both weak and strong macroeconomic conditions show different experiences in the distribution of the urban poor? If and how do the variables that make up the characterisation of urban poor differ in their concentration across a city?

\subsection{Summary}

In this chapter, I have summarised a large portion of literature that addresses the shift of the poor away from the urban centres. The literature shows there is a growing concern with geographic inequalities in urban settings. Increasing house prices due to gentrification and increasing opportunity cost of time is making the central city unaffordable for the urban poor. A large amount of literature has described or argued that the poor are being displaced or replaced, and that the geographic inequalities are exacerbating. However, this literature review cannot capture every concept that could be used to explain these geographic inequalities, and I acknowledge that this therefore narrows the scope of my research significantly. 
From this literature, I was able to develop my conceptual approach. Drawing from the bid-rent curve function, I conceptualised the problem by inducing that due to rising house prices, poorer households or individuals would need either to move further away from the city centre or adjust their housing consumption. This will help me answer my three research questions. 


\section{Chapter Three: Data and Methodology}

\subsection{Introduction}

The methodology and type of data used in a study is incredibly important because it confines a researcher in their findings. In the previous chapter, I reviewed the literature covering the suburbanisation of poverty and gentrification in Western cities around the world. The authors were similarly motivated in their studies to address the changing urban geographies of inequality. However, as I discussed, their methodologies differed. The methodology addresses the way the researcher wishes to frame their questions.

My thesis focuses on the spatial distribution and the spatial concentration of the urban poor. To measure this, I first have to look at the available data. The data I choose to use is the New Zealand census. I then present the variables available within the census that would characterise who I consider the urban poor. Next, I discuss how other studies similar to my own research have taken their methodological approach and the different types of data used. I also discuss how their methodologies have shaped the findings they take away.

\subsection{Data}

My analysis draws primarily from Statistics New Zealand's (StatsNZ) 1991, 2006 and 2013 Census of Population and Dwellings (I hereafter refer to it as the census). The earliest available census data starts from 1991 and takes place every five years. However, due to the February 2011 Christchurch earthquake, StatsNZ postponed the 2011 census until 2013. These data allow me to investigate the geographical and spatial distribution of the poor. I introduce the geographical units and data in turn.

The StatsNZ geographical framework allows the inclusion of a wide range of location specific data. A meshblock is the smallest geographical area for which StatsNZ collects and analyses data. In an urban setting, a meshblock is roughly equivalent to the size of an urban block. In 2013, meshblocks had a median population of 78 persons and a median of 27 households. Meshblocks vary both in the size of their population and the physical area covered. 
Meshblocks cover the whole of New Zealand and derive from population and household data from the census.

There were 38365 meshblocks in 1991, 41,376 meshblocks in 2006 and 46,629 in 2013. StatsNZ's second smallest statistical area is the area unit, which comprises several complete meshblocks that combine into "a single geographic entity with a unique name" (Stats New Zealand, 2011). In urban areas, area units usually contain between 3000 and 5000 individuals.

To illustrate the size, scale, and functionality of the two geographic levels used in my analysis, I will explain and provide an example of the data attributed to each area unit and meshblock. The shapes and population numbers of the different area units and meshblocks can change between census years, as StatsNZ reclassify the areas. An area unit is the second smallest geographical area from StatsNZ, and they make area units from several meshblocks. In an urban context, an area unit is roughly equivalent to the size of a suburb. In 2013, area units had a median population of 1863 persons and median of 681 households. Area units vary both in the size of their population and the physical area covered.

A large part of my analysis involves grouping meshblocks into ten kilometre bands. These bands are concentric, meaning they progressively move further out from a centre point. In the case of both Wellington and Auckland, the centre point is the central train station. Figures 3.1, 3.2 and 3.3 show these concentric distance bands. I chose ten kilometre distance bands because it is a large enough grouping that a few outliers will not affect the overall trends I am measuring, but it is still small enough that I can distinguish subtle details and differences between the groupings.

In total, there are 207 area units in the Wellington region for 2013. Figure 3.1 shows the dispersion and spread of area units across Wellington. The five shaded rings are, as mentioned, concentric rings in ten kilometre bands around the central position of the Wellington train station. From the 207 area units in the region, Figure 3.1 shows the varying degrees in size and shape. Notably, the areas closest to the centre are smaller because they have a higher density of population. 
Figure 3.1: Area units for the Wellington Region, 2013

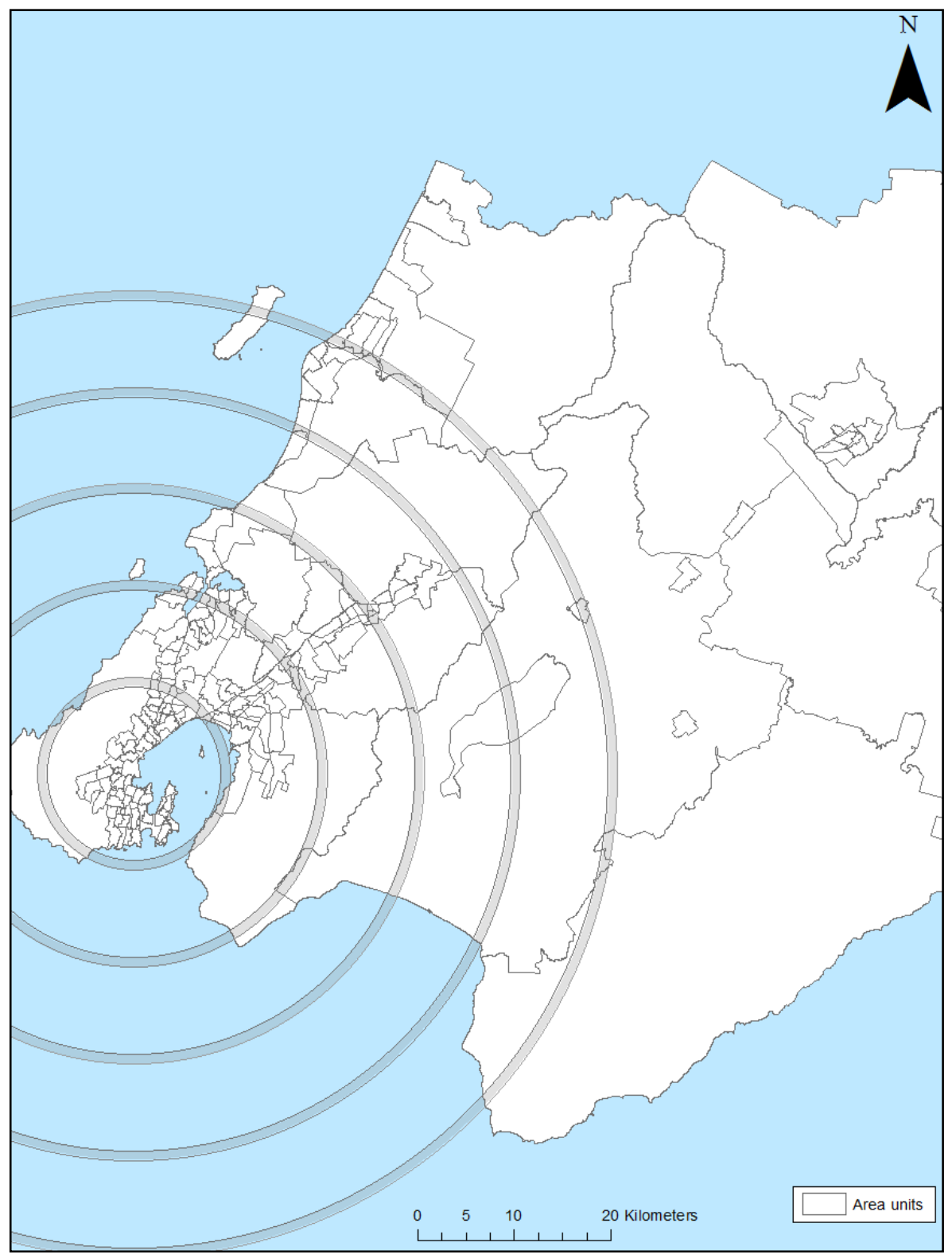

Source: Statistics New Zealand

Inside these area units are meshblocks. In total, there are 5199 meshblocks for the Wellington Region for 2013. Since meshblocks are considerably smaller than area units, I increased the scale size of Figure 3.2 to focus more on just the Wellington urban area. Again, Figure 3.2 shows a large number of small meshblocks. These meshblocks are small because they are densely populated and Statistics New Zealand attempts to limit the variation in population size across this geographic unit. 
Figure 3.2: Meshblocks for the urban area of the Wellington region, 2013



Source: Statistics New Zealand

Next, I will show an example of a specific area unit and a meshblock within that area unit to give an idea of the breadth and depth of data at both geographic levels. First, Figure 3.3 shows the standard deviation of the New Zealand deprivation score in area units in the urban area of Wellington for 2013. I have introduced this variable on the map because I will be discussing the variable in the next section. The darker shades show a higher deprivation score (which would suggest more highly deprived), and the lighter shades show a lower deprivation score (suggesting less deprived). The darkest shades appear in Porirua, located in the northern area of the second distance band, and Lower Hutt, located in the north-eastern area of the second distance band. I will examine one of these area units as an example. 
Figure 3.3: Deprivation Score by area units for the Wellington urban area, 2013

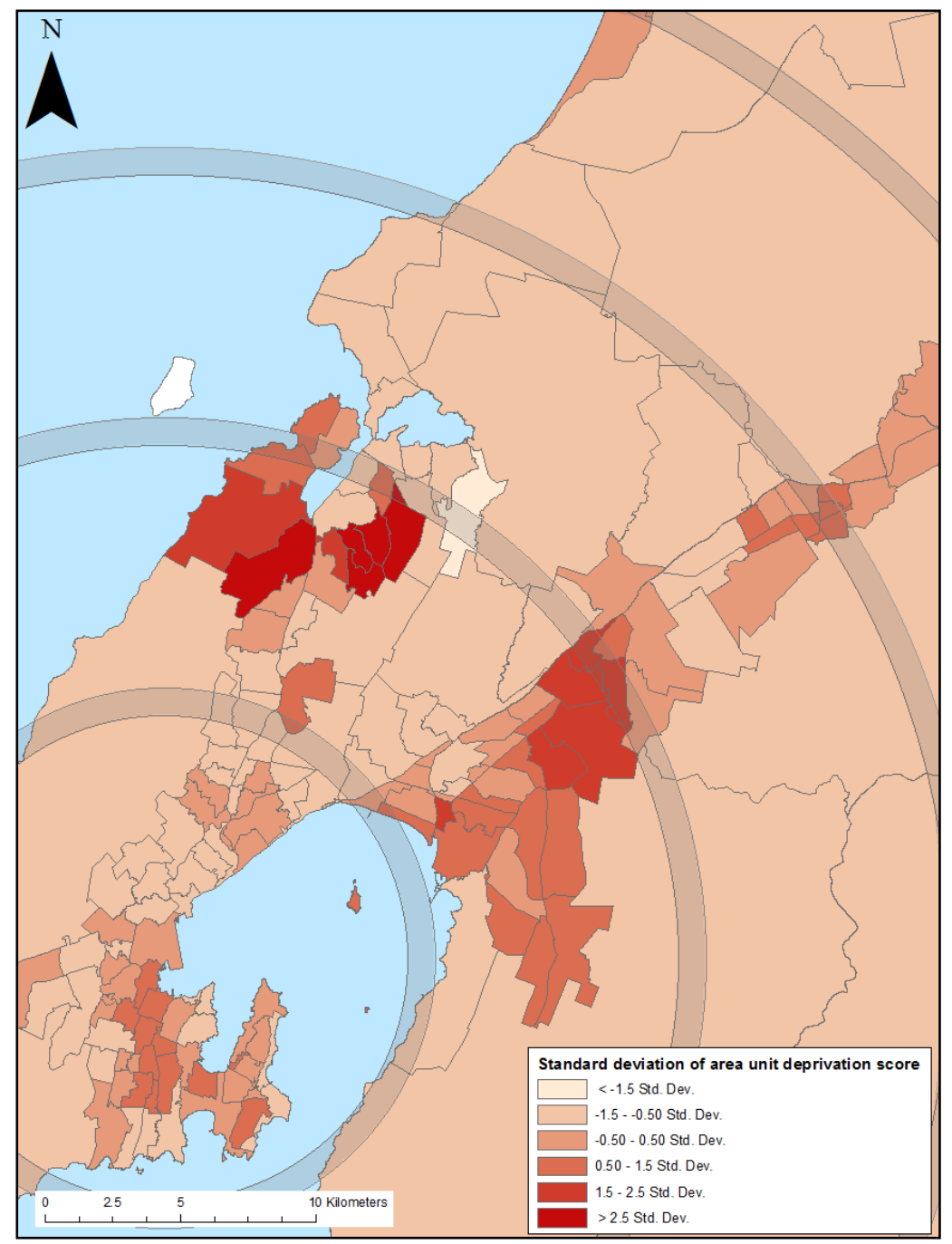

Source: Statistics New Zealand

I have chosen the area unit of Waitangirua as an example to examine. Figure 3.4 shows the geographic location of the area unit. The area unit is home to 1020 households, containing 4020 persons. The area unit of Waitangirua contains 40 meshblocks in 2013. Of these 40, all are classified as highly deprived (at or beyond one standard deviation above the mean New Zealand deprivation score for the country as a whole). Therefore, I know that the population of the area unit in Figure 3.4 must contain a large sum of individuals who are disadvantaged. However, how exactly are the individuals disadvantaged?

Due to the way StatsNZ ask many questions in the census, the data only offers some variables in categories. In 2013, there were 216 households in Waitangirua area unit shown in Figure 3.4 at or below $\$ 30,000$ for their household income, 21.2\% of total 
households in the area unit. The median household income in New Zealand for 2013 was $\$ 63,800$. That means that at least one fifth of the households in the Waitangirua area unit shown in Figure 3.4 were more than fifty percent below the New Zealand median household income. This does not take into account that 372 households did not state their household income. Alternatively, the individuals inside the area unit might be disadvantaged if they are collecting a means-tested benefit.

Figure 3.4: Waitangirua area unit in Wellington, 2013

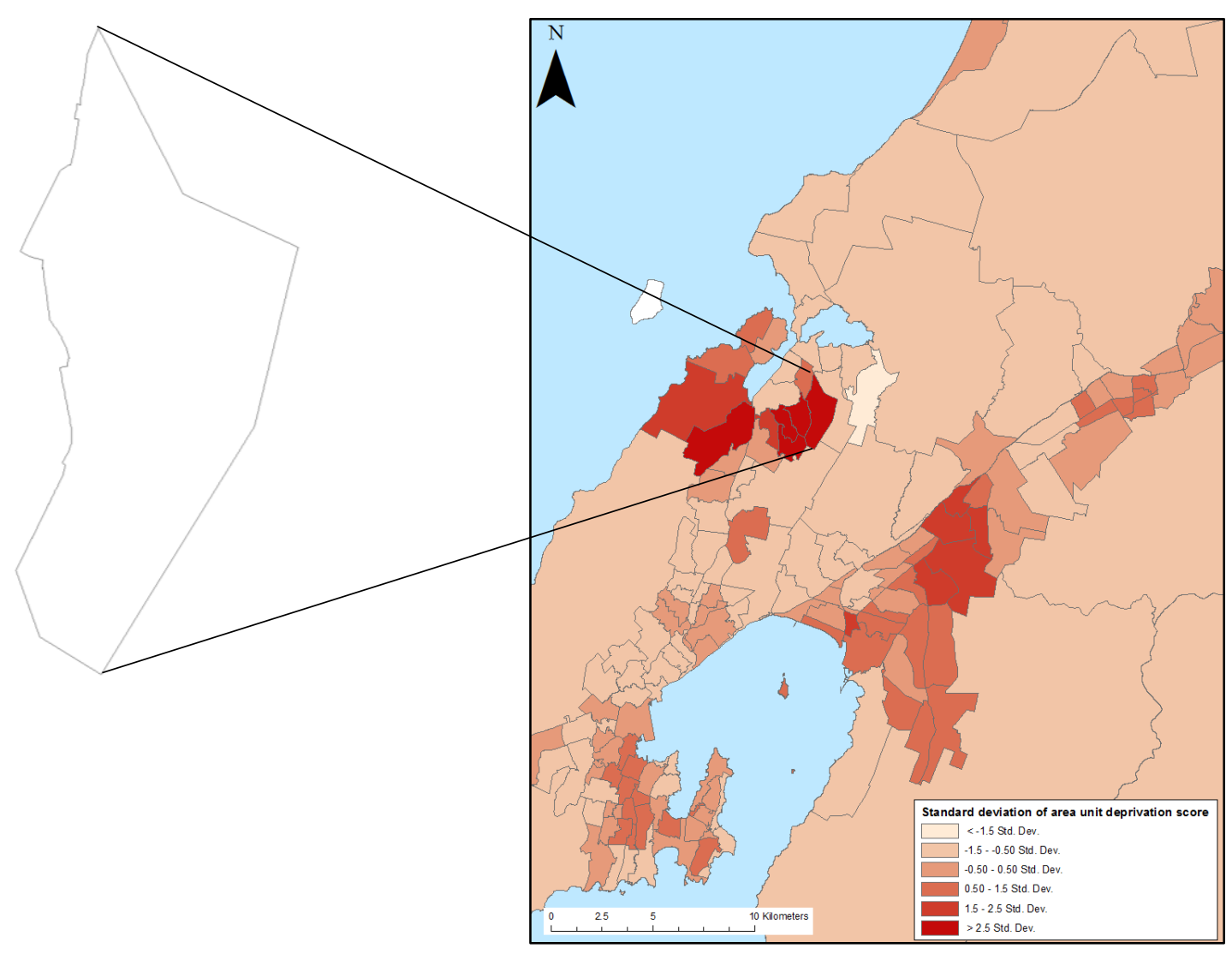

Source: Statistics New Zealand

As mentioned earlier, contained within the Waitangirua 2013 area unit are 40 meshblocks. While they are all considered 'highly deprived', their occupants are likely disadvantaged differently and at different levels. To illustrate this point, I will examine a meshblock within Waitangirua as an example. Figure 3.5 shows the meshblock chosen, and its shape and location within the Waitangirua area unit.

I chose meshblock 2060600 at random from the Waitangirua area unit. Meshblock 2060600 contains 84 individuals who receive some sort of income and are of 
working age. Of these 84,39 receive below $\$ 20,000$ as a personal income. This is approximately $70 \%$ of the median personal income of $\$ 28,500$ for New Zealand. Of these 84, 12 are unemployed and 27 receive a means tested benefit, and 33 do not possess a qualification of any kind.

There are 27 households in meshblock 2060600, of which 21 do not own the dwelling they live in. Only three of these 27 households do not have access to a vehicle. In these 27 households, there are 30 families, of which 15 are one-parent families with child/ren. Lastly, in these 27 households, there are 78 bedrooms in total, and 96 household members in total, resulting in a crowding ratio (household members per bedroom) of 1.23. This crowding ratio might be somewhat misleading, as it is an average for a meshblock, and does not reflect any households with a much larger crowding ratio offsetting households with lower crowding ratios.

Figure 3.5: Meshblock 2060600 within Waitangirua area unit in the Wellington region, 2013

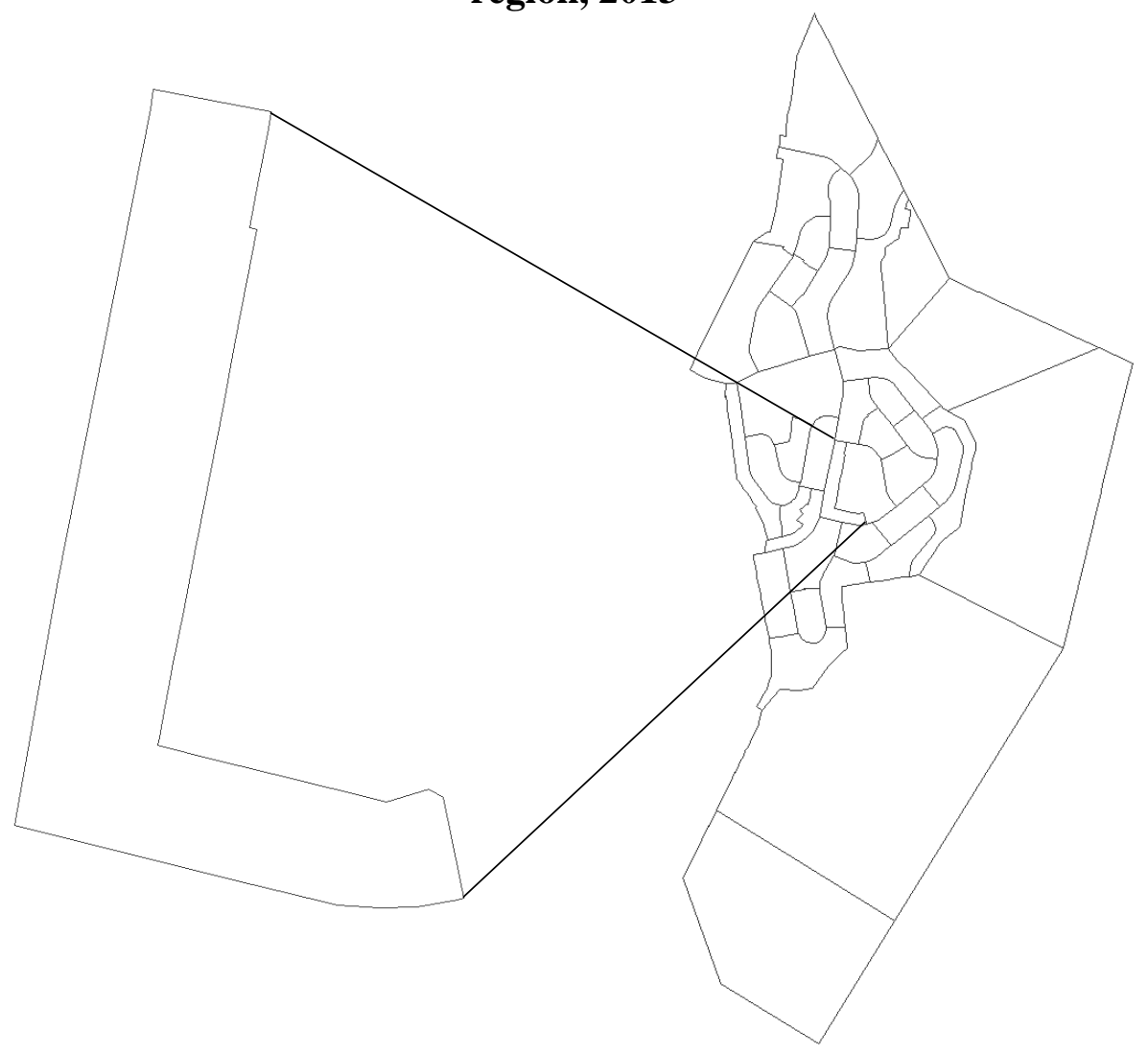

Source: Statistics New Zealand 
In this section, I have broken down the geographic levels that are available in the census and that I use throughout this thesis. This breakdown shows the amount of data available to attempt to investigate the geographic and spatial distribution of the poor in Wellington and Auckland.

\subsection{Variables}

This section will cover the main dependent variable used in this analysis - the New Zealand deprivation score. Deprivation score is an aggregated variable based on census data. In this section, I will discuss measuring socioeconomic position, but particularly the New Zealand deprivation score.

There are two broad approaches to the measurement of socioeconomic position. One is based on the production side of the economic equation and emphasises the differential availability of resources to people. The other is based on the consumption side of the equation, and emphasises the conditions experienced by people. Figure 3.6 summarises the ways in which four key concepts and approaches to the study and measurement of socioeconomic position are aligned with the production and consumption approaches. Figure 3.6 also summarises the factors that are considered when measuring socioeconomic position based on the four key measurement concepts of Class/Socioeconomic status, Income poverty, Living standards, and Deprivation.

Figure 3.6: Some approaches to measuring socioeconomic position

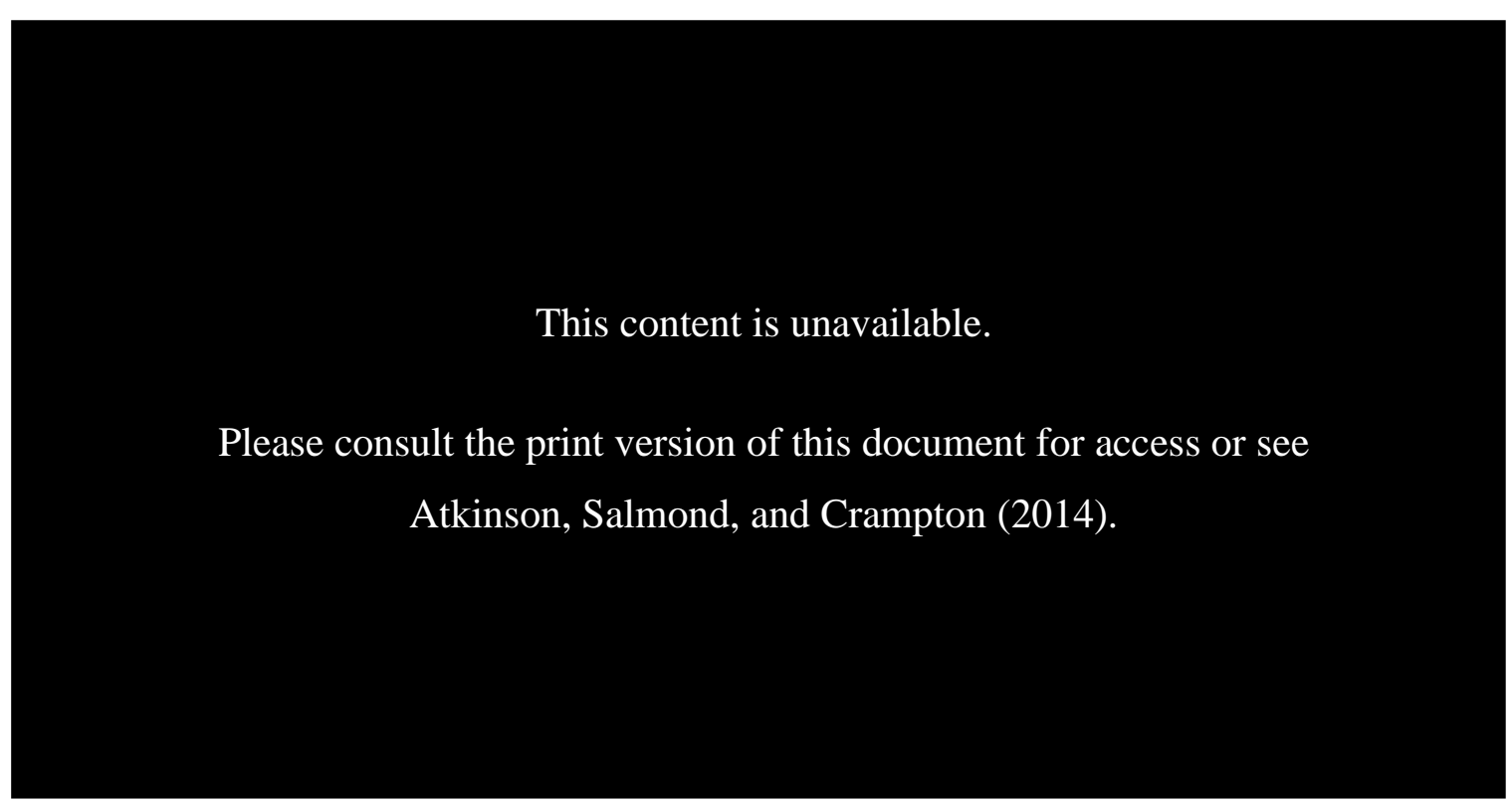

Source: (Salmond, King, Crampton and Waldegrave, 2005) 
Socioeconomic deprivation reflects a 'neo-materialist' standpoint (that places emphasis on relative rather than absolute material conditions), taking the view that people have material, social, cultural and spiritual needs that are linked to the norms of their society and culture, and that it is possible to be deprived in one or more of these respects. Deprivation has been defined as a state of observable and demonstrable disadvantage relative to the local community or the wider society or nation to which an individual, family or group belongs (Townsend, 1987). Townsend distinguishes the concept of deprivation from that of poverty by arguing that while poverty is associated with the availability of resources, deprivation is associated with the conditions experienced. Accordingly, to be in a state of poverty is to lack the resources necessary to avoid material and social deprivation. This means that to be in poverty is, by definition, to be in a state of deprivation. Alternatively, it is possible for a person to be in a state of deprivation, as defined by the conditions they experience, while not being in poverty, if, for example, they have access to the resources necessary to avoid material and social deprivation but chose not to use them.

I utilise data from the New Zealand Ministry of Health and Otago University's New Zealand deprivation score (deprivation score). Deprivation score is an aggregate variable compiled from other individual variables found in the census and applied to a geographic area.

The census is used to calculate the New Zealand Deprivation Index 1991, 1996, 2001, 2006 and 2013, referred to here as the deprivation index. The New Zealand Ministry of Health, in conjunction with Otago School of Medicine Wellington, following each census, calculates the deprivation index. It measures the relative level of socio-economic deprivation of an area and decision makers can use the variable in funding formulas for a range of social services.

A range of variables are used, including the individual and household income, home ownership, family support, employment, qualifications and transport accessibility within a location. Health literature informs the decisions on the weights for each variable, and the authors delicately fine-tune the weights each new census. Table 3.1 shows the variables used to create NZDep91, and the weights of each individual component that went into the deprivation variable. Likewise, Table 3.2 shows the 
weights and variables for both NZDep2006 and NZDep2013. Notice the different input variables between the three census years; being separated or divorced was removed by 2006 and have access to a telephone was implemented instead. By 2013, the authors replaced telephone access with internet access.

\section{Table 3.1: Weight for variables included in the NZDep91}

\begin{tabular}{|c|c|}
\hline $\begin{array}{l}\text { Standardised } \\
\text { proportion of persons }\end{array}$ & $\begin{array}{l}\text { Weight (coefficient in first } \\
\text { principal component) }\end{array}$ \\
\hline $\begin{array}{l}\text { In single parent families and } \\
\text { aged under } 60\end{array}$ & 0.375 \\
\hline $\begin{array}{l}\text { On means tested } \\
\text { benefit and aged 18-59 }\end{array}$ & 0.367 \\
\hline $\begin{array}{l}\text { Below threshold for } \\
\text { equivalised household income }\end{array}$ & 0.364 \\
\hline $\begin{array}{l}\text { Without access to a } \\
\text { car and aged } 18 \text { or over }\end{array}$ & 0.356 \\
\hline $\begin{array}{l}\text { Without qualifications } \\
\text { and aged } 18-59\end{array}$ & 0.342 \\
\hline Unemployed and aged $18-59$ & 0.319 \\
\hline $\begin{array}{l}\text { Separated or divorced } \\
\text { and aged } 18-59\end{array}$ & 0.296 \\
\hline Not in owned home & 0.291 \\
\hline $\begin{array}{l}\text { Below threshold for } \\
\text { equivalised occupancy }\end{array}$ & 0.237 \\
\hline $\begin{array}{l}\text { Separated or divorced and } \\
\text { aged } 60 \text { or over }\end{array}$ & 0.133 \\
\hline
\end{tabular}

Source: (Salmond, Crampton and Sutton, 1998)

Table 3.2: Variables included in the New Zealand deprivation score, 2006 and 2013

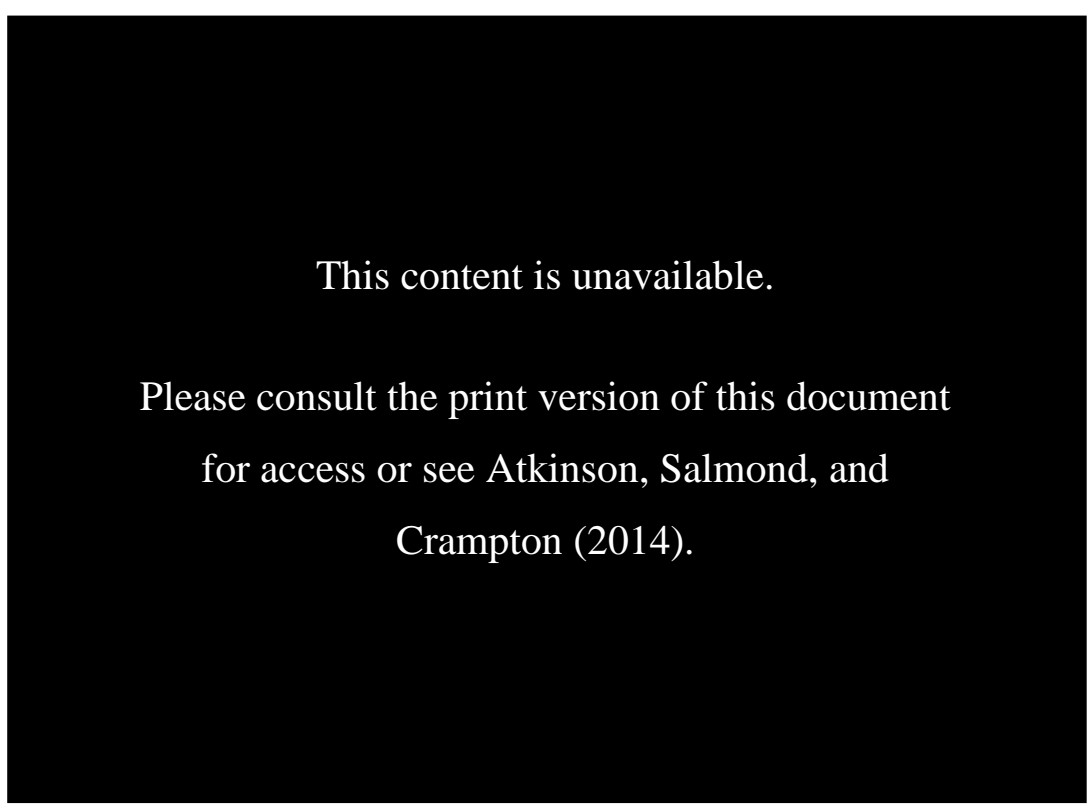

Source: (Atkinson, Salmond, and Crampton, 2014) 
The geographic framework of the deprivation index or deprivation score is built using grouped meshblock data. Statistics New Zealand created 38365 meshblocks in 1991, 41,376 meshblocks in 2006 and 46,629 in 2013. StatsNZ aggregates these meshblocks into small areas specifically for the deprivation score. In 2006 for example, StatsNZ aggregated the meshblocks into 23,786 small areas, each comprising of at least 100 people. Thus, every meshblock has an NZDep score and index value but may share a value with a group of one or more geographically connected meshblocks. The NZDep score values are calculated as follows:

"The NZDep2013 continuous score is a weighted sum of the nine variables created using a principal components analysis. This statistical method identifies weighted sums of variables that progressively account for the overall variation in the data.

"The NZDep2006 index is the first principal component scaled to have a mean of 1000 index points and standard deviation of 100 index points. The index is the weighted sum of the variables that accounts for the most variation. Each variable in the sum is a proportion of people in a small area. Each proportion is standardised in eight age-gender groups (0-17 years, 1839 years, 40-64 years, 65 years and over, for each gender) to the New Zealand population structure. This equivalises the small areas, so that some areas cannot be considered more deprived than others simply because their populations have different age structures." (White et al., 2008, p. 9-10)

As a result, the deprivation score provides a standardised measure of the degree of socio-economic deprivation of small areas, interpreted by some as a neighbourhood. The creators of the variable then index the deprivation score into deciles, with an even number of meshblocks in each index value (1-10). A deprivation index of 1 represents the least deprived, and 10 represents the most deprived. However, Figure 3.7 shows that the deprivation score is not evenly distributed. In fact, deprivation score is right skewed, or skewed to the more deprived. 
Figure 3.7: Distribution of NZDep2013 scores, with the NZDep2013 decile scale superimposed

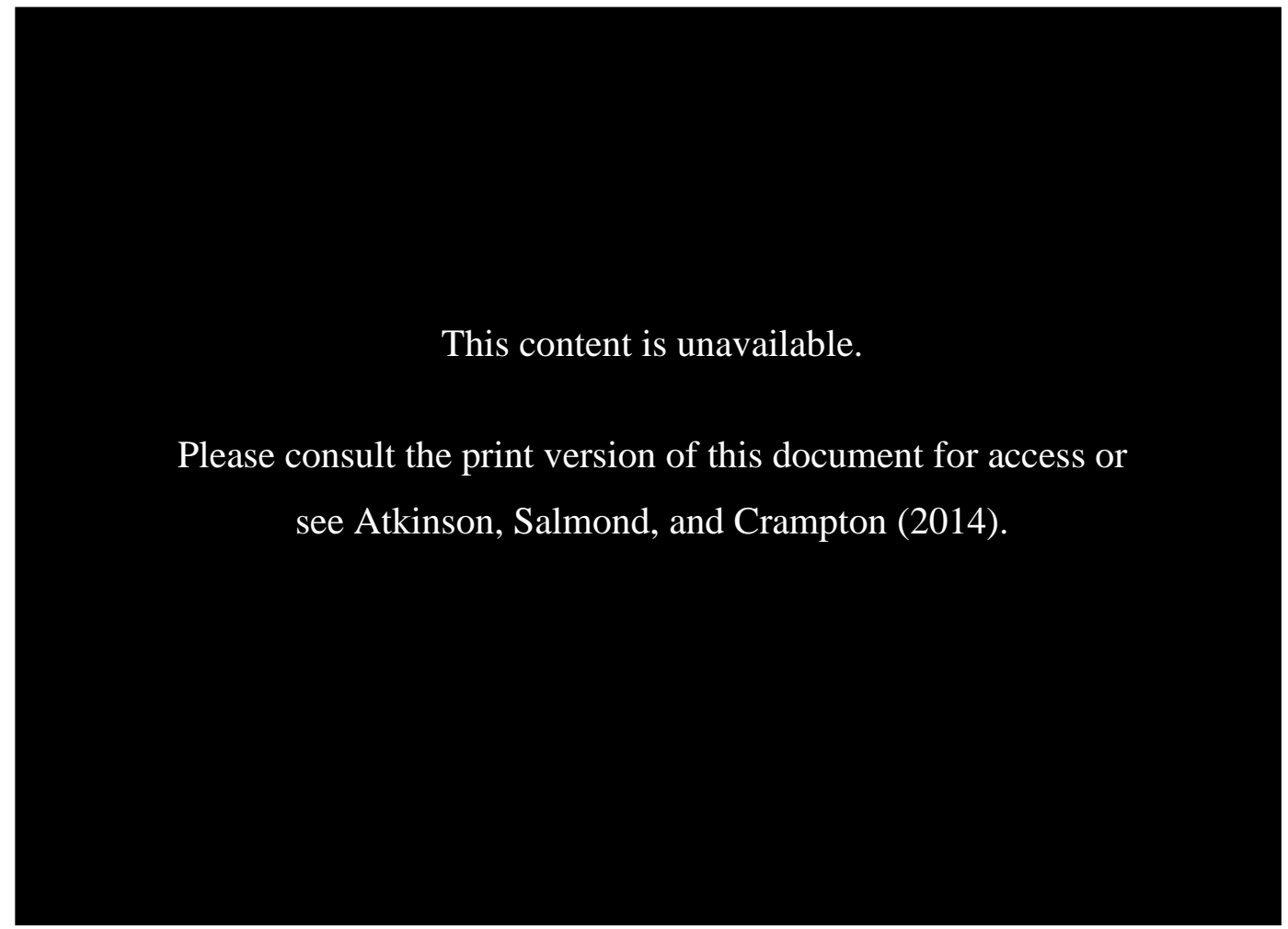

Source: (Atkinson, Salmond, and Crampton, 2014)

I have now shown how deprivation score is calculated, the individual components that make up deprivation score, and how deprivation score is geographically applied. Next, I turn to previous international studies. I discuss their methods, and I identify methods that might be useful and applicable to my own research.

\subsection{Previous studies}

As mentioned in the previous chapter, there are different ways to test and measure a shift in the geographic distribution of deprivation. I separated the different methodologies into two broad categories. The first way is by using fixed geographical units and determining whether there has been a change in the number of areas that a researcher might consider deprived based on a specific metric. I call this the 'place-based approach' to measuring a change in the distribution of deprivation. The second way is by tracing the movements of low-income individuals or households, and identifying the areas that they end up in - a 'people-based approach'. Due to the availability of data, and the questions asked in this thesis, I 
have not included a breakdown of people based approach methodologies. Instead, I focus on the previous studies most relevant to my research.

A study by Randolph and Tice from 2014 that they later updated in 2017 to include a wider array of cities, used a place-based approach. In their study, they used data collated from the Australian Bureau of Statistic's censuses for 1986 and 2011 to look at socio economic disadvantage in Adelaide, Brisbane, Melbourne, Perth and Sydney in Australia. The authors used an indexed variable called the index of disadvantage calculated from 16 other census variables focussing on economic disadvantage at the suburb and collector district geographic scale (Australian equivalents of the area unit and meshblock, respectively). This index is the Australian equivalent of StatsNZ deprivation score, which I previously discussed in this chapter. The Australian variable is derived from variables including number of people unemployed, household income, public housing, low-value rental, no car ownership, Aboriginality, poor English, one-parent families, and low levels of schooling (Australian Bureau of Statistics, 2008 as cited in Randolph and Tice, 2014). The Australian Bureau of Statistics standardised the calculation for the entirety of Australia so that the index varies around a mean of 1000 .

The first part of Randolph and Tice's (2014) analysis was to identify the 'collector districts' (CDs), the smallest geographic units collected by the Australian census, each consisting of on average 220 dwellings, that were at or below one standard deviation of the index. The second part of their analysis was to identify those suburbs (made up of approximately 8 to $12 \mathrm{CDs}$ ) that consisted of at least one $\mathrm{CD}$ that was below one standard deviation of the index. The third part of the author's analysis was to compare changes in occurrences and proportions of disadvantage from 1986 to 2011.

Cooke and Denton (2015) also used a place-based approach. The authors analysed census-tract poverty rates in the 100 largest metropolitan areas in the United States for 1990 and 2007-2011. However, the authors take objection to classifying census tracts as urban or suburban. Instead, they opt to analyse the association between census-tract population density and poverty. They rationalise this by assuming urban areas are generally more densely populated, and suburban areas are less densely populated. The authors hypothesise that the relationship between these two variables 
would traditionally be positive. However, if poverty is suburbanising, then the relationship between census-tract population density and census-tract poverty rates should become less positive over time.

To control for the economic and demographic differences in cities across the United States, Cooke and Denton (2015) standardise the population density to a mean of zero and a standard deviation of one. They then pooled the metropolitan areas into similar groups. From these data, the analysis then estimates the effect standardised population density has on census-tract poverty rates. The analysis selects the best fitting fractional polynomial for the final display of the model.

Kavanagh, Lee and Price (2016) take data from the Scottish Neighbourhood Statistics database and use a place-based approach to look at the four largest cities in Scotland. However, they propose a spatial orientated analysis that takes into consideration spatial autocorrelation. When using geographical areas as a unit for analysis, this raises questions about the data being independent from one another. A fundamental thought in geography is that those closer in geographical location, are more similar in certain aspects than those far away (Tobler, 1970 as cited in Kavanagh, Lee and Price, 2016). The authors hypothesise that spatial autocorrelation is likely to be present, thus violating basic assumptions for a normal mode of analysis.

The studies I have discussed have shown me different ways to approach the central thesis. Of importance is the way in which I think about the dependent variable and its relationship to determinants. Moreover, the difference between people and placebased methods, the way I choose to define suburban and urban, and the controlling variables I put in place are in need of attention.

To identify the changing distribution of the poor across cities in New Zealand, I analyse a sample of smaller geographical areas in the cities I am studying for the census years 1991, 2006 and 2013. I study the deprivation. I introduce the data that I use, outline the dependent and independent variables and the possible methods of analysis. 


\subsection{Methods}

My analysis spans three chapters, to answer three research questions, and uses three main methods. The first method is a spatial distribution plot showing highly deprived meshblocks against distance from city centre. The second method is mapping the locations of the highly deprived meshblocks. The third method is using population data to create a location quotient. My first and second analysis chapters (chapter four and chapter five) use all three methods. My third analysis chapter (chapter six) uses just location quotients as my main tool of analysis.

The first method I utilise is a spatial distribution plot showing the proportion of highly deprived meshblocks (meshblocks at or beyond one standard deviation of the national mean deprivation score) against distance from the city centre. I break the distance bands into $10 \mathrm{~km}$ groupings to gain a wider understanding of the spatial distribution of deprivation in the two cities, Wellington and Auckland. I also break the distance bands into $1 \mathrm{~km}$ groupings to gain a more subtle idea of the spatial distribution of deprivation.

The second method I use is visual mapping. I am able to take the meshblocks, and assign the deprivation and other associated census variables to them. The meshblocks and area units are geocoded, and this method gives the distance for the spatial distributions in the first method. The strength of this method is that it provides the geographical element of this research. That is, it allows me to identify the areas in which highly deprived meshblocks are reducing and increasing.

The third method I utilise is adopted from Randolph and Tice's (2017) analysis. They use location quotients to identify the proportion of the population in highly deprived CDs across the different 10km distance bands. I adopt their methods and extend the location quotient defined in this chapter to include all the individual components that make up deprivation score, such as number of low-income earners or number of individuals on a mean-tested benefit. The purpose of using this method is that it allows me to determine if individuals with deprived characteristics are concentrating more or less in deprived areas. It can also help explain the changing spatial distributions of highly deprived meshblocks. 
A location quotient (LQ) is a ratio that compares the proportion of a variable at a certain geographic level with the proportion of that variable at a larger geographic level, shown in equation 1 . Suppose $\mathrm{X}$ is the number of people with some characteristic in a geographic level (e.g., population within highly deprived meshblocks in a $10 \mathrm{~km}$ band), and $\mathrm{Y}$ is the total population in that geographic level. $\mathrm{X} / \mathrm{Y}$ is then the geographic level's "concentration" of the population in that area. If $\mathrm{X}^{\prime}$ and $\mathrm{Y}^{\prime}$ are the same variables for some larger reference region (like a region or large city), then the LQ or relative concentration of that variable in the geographic level compared to the region is $(\mathrm{X} / \mathrm{Y}) /\left(\mathrm{X}^{\prime} / \mathrm{Y}^{\prime}\right)$.

$$
L Q=\frac{(X / Y)_{\text {distance band }}}{\left(X^{\prime} / Y^{\prime}\right)_{\text {region }}}
$$

\subsection{Summary}

In this chapter, I have outlined the steps I will be taking for my analysis, the data I will be using, and the rationale for both. I first described the data that was available to me. The New Zealand census of population and dwellings is a relatively comprehensive snapshot of the population of New Zealand. The census provides a rich source of demographic information to do with the population's living situations and their material wellbeing. I also describe how this dataset can be broken down into geographical components. Next, I introduce the New Zealand deprivation score, a variable based on the available data in the census. I put forward this variable as my main dependent variable through my analysis chapters. I then look to previous international studies with a similar geographical focus. I describe their research processes and what I can learn from their methodologies. Particularly, I look to the 2017 study of Australia's five largest cities by Randolph and Tice. Their research uses a similar variable to my main dependent variable, and Australian cities are occasionally compared to New Zealand cities. Lastly, I describe the methods that I undertake in the following three analysis chapters. Specifically, I describe the location quotients and spatial distribution graphs that form a large part of my analysis. 


\section{Chapter Four: The distribution of deprivation in Wellington and}

Auckland

\subsection{Introduction}

There is a growing focus in the literature on the suburbanisation of the poor, or is more popularly coined, 'the suburbanisation of poverty'. However, these studies focus on the shift in income, or lack thereof, away from the city centres and into the middle and peripheral suburbs. Very little research focuses on the wider implications of individuals' socio-economic status, and how that might affect the location where they reside. Randolph and Tice (2017), however, use an aggregated variable to encompass the socio-economic disadvantage that the poor experience. I will use their study as a point of departure for my own analysis.

I will now describe and interpret Randolph and Tice's 2014 and 2017 papers on relocating and suburbanisation of disadvantage in Australian cities. The purpose of doing this is to understand their data, methods, and results with the intent to replicate their analysis for a New Zealand context. This chapter will break down their analysis, and pull out parts that are similar or achievable for my own analysis. I then replicate their processes.

Randolph and Tice had two objectives from this analysis. First, to explore the location where the low-income groups or the 'disadvantaged' are situated and how that has changed over time. Secondly, to investigate the concentration of these groups and how this may have changed over time. They argue that the geographical distribution of these groups is likely further away from city centres towards the suburbs and urban peripheries, and they are more concentrated. The reasons for this trend, they suggest, are an increase in income inequality and an increasing reliance on the market to deliver housing opportunities for all households. Their analysis focuses on the five main cities in Australia.

\subsection{Methods}

Randolph and Tice use data sourced from the Australian censuses for 1986 and 2011. The authors sought to analyse the location of those deemed to be "disadvantaged" or deprived, based on certain socio-economic factors collected in the census. 
Furthermore, the authors concern focused largely on how those locations may have changed over the period and the extent to which they are concentrating.

Randolph and Tice chose the index of relative socio-economic disadvantage (referred to hereafter as disadvantage or disadvantage index) for their analysis, which I explained in the previous chapter. The Australian Bureau of Statistics (ABS) weights these variables accordingly, and standardise the collated variable around a mean of 1000. Areas with indexes sitting below this mean indicate a higher level of disadvantage.

The New Zealand equivalent of this statistic is the New Zealand deprivation score. Statistics New Zealand create the deprivation score the same way, taking certain variables from the census, weighting them, and standardising them around a mean of 1000. However, in the New Zealand case, a score above the mean indicates higher deprivation. A more in-depth comparison of the two variables is available to read in my methodology chapter.

Randolph and Tice gathered this disadvantage index for five major Australian cities: Adelaide, Brisbane, Melbourne, Perth and Sydney. They used the disadvantage index at the collector district (CD) level, small geographic areas containing approximately 220 households, and suburb level, a slightly larger geographic area made up of 8 to 12 CDs. These two geographic areas closely resemble the meshblock and area unit in New Zealand.

The first step of their analysis was to identify CDs lying at or beyond one standard deviation of the mean disadvantage index for 1986 and 2011 in all five cities. They argue that these CDs represent the most highly disadvantaged CDs in each city, and will therefore best illustrate the location and concentration of disadvantage. Using this information, the authors could identify suburbs with at least one $\mathrm{CD}$ at or beyond one standard deviation of the mean disadvantage index.

The next step of their analysis was to construct a distance variable to show the location of disadvantage. To standardise distance across the five cities, they focussed only on disadvantage occurring within $50 \mathrm{~km}$ from the city centre in each city. They calculated distance as a linear Euclidean ("as the crow flies") measure from the 
geometric centroid of the geographical unit to the city's central post box. Once this distance variable is calculated, the authors banded these distances together so that they could calculate the proportions of disadvantaged CDs at different distance ranges. This analysis comes in both table and graphic form, and both are useful in identifying where disadvantage is located.

Lastly, the authors used maps to accompany the graphical analysis. A visual illustration is useful when interpreting trends and patterns, and they allow the reader to understand exactly where a certain trend may be occurring. The authors displayed the disadvantaged areas, firstly, on a map of Sydney for 1986 and 2006, and then for all five cities for 1986 and 2011. What follows is their analysis.

\subsection{Suburbanisation of disadvantage in Australian cities}

The authors started out in 2014 by looking at Sydney. At the time, only data from the 2006 Australian census was available. As mentioned, their first step was to identify the CDs that were at or beyond one standard deviation of the mean of the index of relative disadvantage. These CDs would be deemed 'highly disadvantaged'. While they did not provide the total numbers of the CDs identified, they did provide the numbers of suburbs containing at least one highly deprived CD.

In 1986, they found there were 216 suburbs containing at least one highly disadvantaged CD. Of these 216 suburbs, " $10 \%$ contained highly disadvantaged CDs that accounted for $80 \%$ or more of the total suburb's population" (Randolph and Tice, 2014, p. 390). This must mean 21 or 22 suburbs had more than $80 \%$ of the CDs that make them deemed highly disadvantaged. The use of the words "suburb's population" is important to note, as the authors assume CDs have constant population. However, they make explicit in their approach and data section, that the number of $d$ wellings is approximately 220 across CDs, with no mention of the population.

By 2006, the number of suburbs containing at least one highly disadvantaged CD had fallen to 197 . Of these $197,17 \%$ contained highly disadvantaged CDs that accounted for more than $80 \%$ of the CDs in the suburb. This must mean 33 or 34 suburbs had more than $80 \%$ of the CDs contained within those deemed highly disadvantaged. 
This change over the 20 -year period is approximately a $70 \%$ increase in the number of suburbs with at least $80 \%$ of the containing CDs deemed highly disadvantaged. This finding suggests that, through whatever mechanisms, the incidence of severe disadvantage appears to have become more concentrated.

So far, their analysis has only focussed on the concentration, and not on the geography or location of disadvantage. Next, the authors plot the previously acquired suburb data on two maps of Sydney, one each for 1986 and 2006. Figure 4.1 shows Sydney in 1986 with a relatively dispersed level of disadvantaged, with darker shaded patches indicating higher concentrations of highly disadvantaged CDs. There is certainly shading in the central area of Sydney, as well as in the middle suburbs and outer suburbs to the west and south-west.

By 2006, Figure 4.2 shows there to be a dramatic reduction in the shading occurring near the central city. Instead, there is a darkening in the middle suburbs of Sydney, just west of the centre of the city. The outer western and south-western suburbs still appear to have similar levels of disadvantaged CDs in their suburbs.

Figure 4.1. Proportion of highly disadvantaged CDs in suburbs, Sydney 1986.

This content is unavailable.

Please consult the print version of this document for access or see Randolph and Tice (2014). 
Figure 4.2. Proportion of highly disadvantaged CDs in suburbs, Sydney 2006.

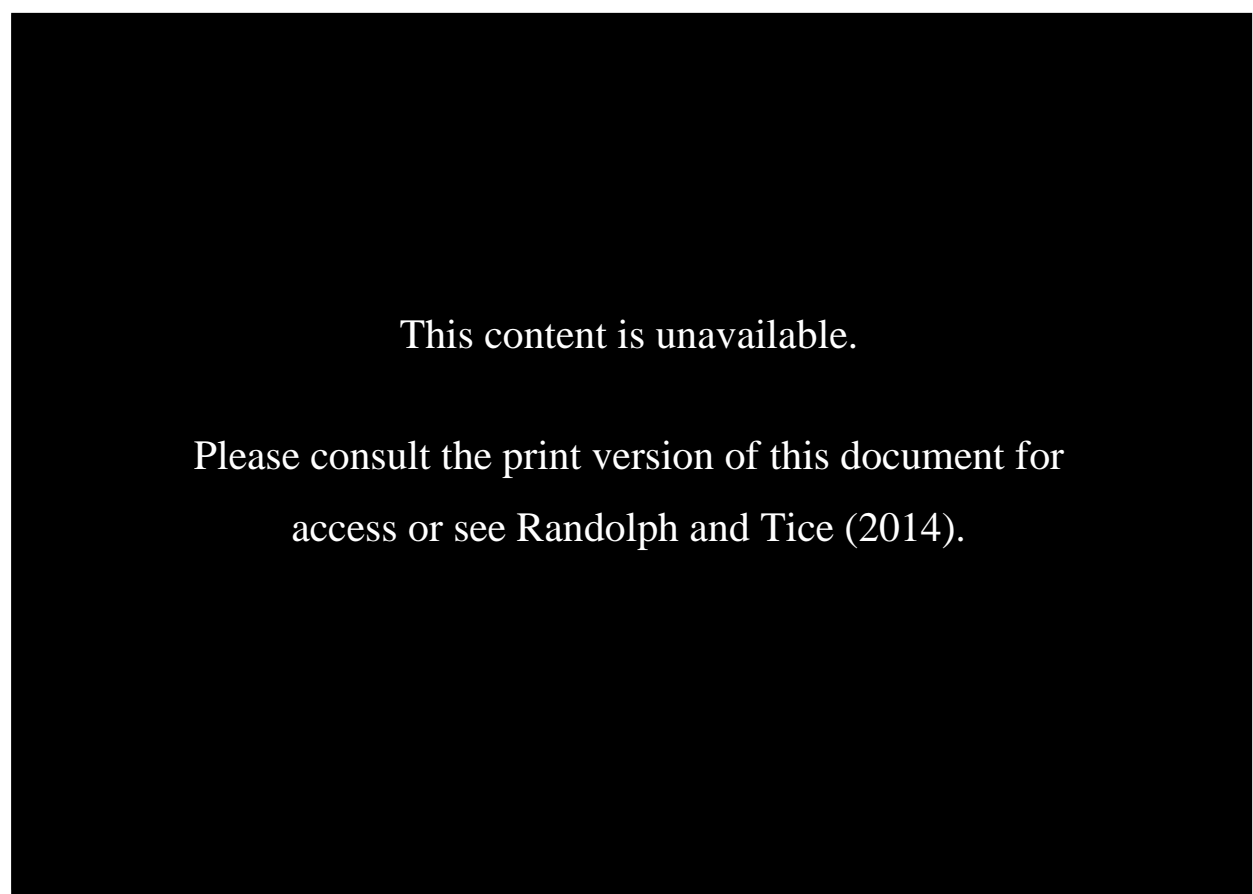

Next, Figure 4.3 illustrates the outward shift of disadvantage in Sydney graphically.

The authors have plotted the location of each disadvanataged CD in distance from their geometric centroids to the centre of Sydney (in this case it is the GPO building). These distances are separated into 1 kilometre bands, and alternate in their display between the two years, e.g. within the first 10 kilometres, there are 20 data points.

Figure 4.3 shows a dramatic decrease from 1986 to 2006 in the number of highly disadvantaged CDs within $13 \mathrm{~km}$ from the city centre, a trend I identified in Figure 4.1 and 4.2 . After $13 \mathrm{~km}$, almost every $1 \mathrm{~km}$ band saw an increase in the percentage of all disadvantaged CDs in Sydney. Particularly, the 20km range and 30-38km saw large increases in the percentage of all disadvantaged CDs. 
Figure 4.3. Distribution of disadvantaged locations, Sydney 1986 and 2006.

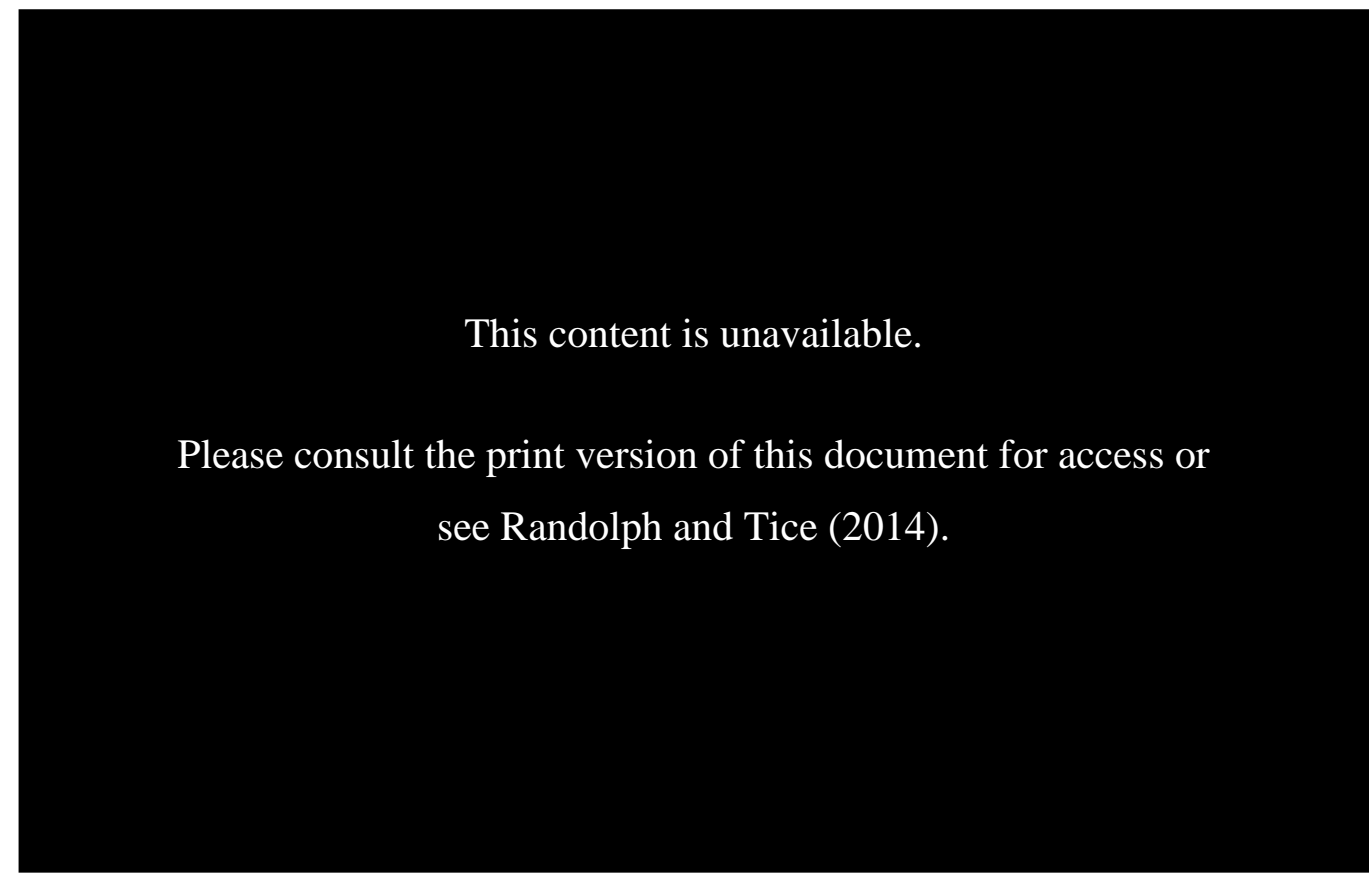

Based on this analysis, the authors found a shift of the highly disadvantaged CDs in Sydney away from the city centre. This shift is quite clear for Sydney. Next, Randolph and Tice (2017) extended their analysis to incorporate the next four largest cities in Australia. The authors also extended their period of analysis, as new census data became available.

Table 4.1 shows the population contained within all disadvantaged CDs for Adelaide, Brisbane, Melbourne, Perth and Sydney. The authors split the population into bands of $10 \mathrm{~km}$. This table is useful because it not only tells us the spatial spread of highly disadvantaged population, but also the concentration of the highly disadvantaged population.

In 1986, I see Adelaide, Brisbane, Melbourne and Sydney all have their largest portion of the population within highly disadvantaged CDs for the first $10 \mathrm{~km}$. Perth has similar numbers for the first and second bands.

By 2011, none of the five cities had the first $10 \mathrm{~km}$ containing the most or second most population within highly disadvantaged CDs. In fact, apart from the first $10 \mathrm{~km}$ band, every city had a positive absolute change over time of population within highly disadvantaged CDs. The exception was Perth, which also had a negative absolute change in population within highly disadvantaged CDs for the second band too. 
Table 4.1. Population change in disadvantaged locations in $10 \mathrm{~km}$ bands for the five cities, 1986 and 2011.

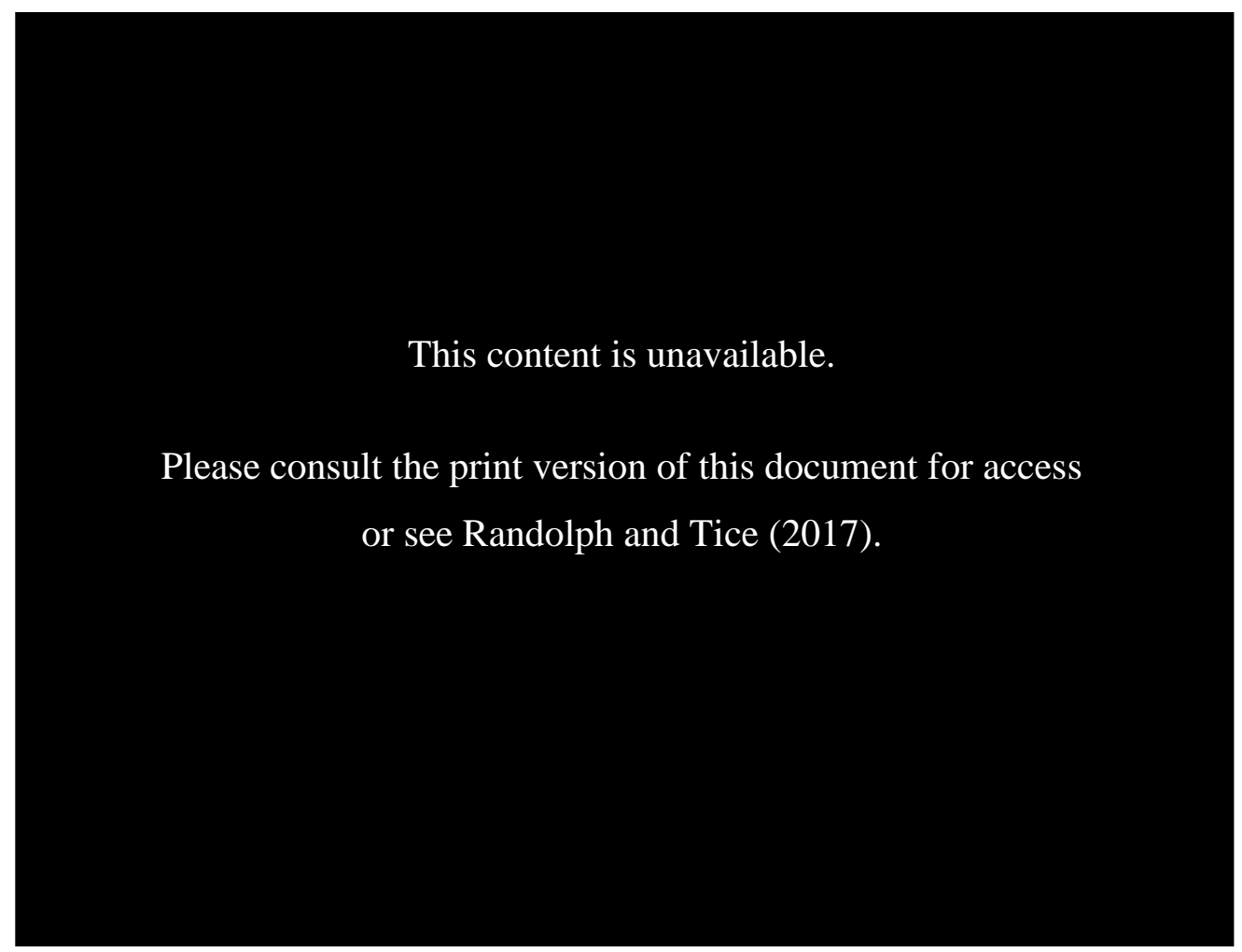

Table 4.2 shows a breakdown of the distribution of disadvantage expressed as location quotients. The location quotient represents the ratio of the percentages of population in disadvantaged CDs for each distance band (in each city) against the overall percentage of the population in disadvantaged CDs. Ratios of one indicate near parity between these values, values of less than one a lesser presence and greater than one a larger presence.

In 1986 , the $0-10 \mathrm{~km}$ band of all the five cities had ratios greater than one, indicating a higher proportion or overrepresentation of disadvantaged populations. Similarly, all cities registered values below one throughout all the suburbs 10-19 km (the second band) out from the inner city locations. Adelaide, and to a lesser extent Brisbane, had higher ratios in the 20-29 km band. Perth, and again to a lesser extent Sydney, recorded higher ratios in the 30-39 km band, with Sydney registering a further overrepresentation in the outlying fifth band, $40-49 \mathrm{~km}$ from the centre. Therefore, even in 1986, only Melbourne presents a situation where disadvantaged locations were disproportionally concentrated within inner city locations in comparison to its suburban counterpart. The other four cities, on this assessment, show a varied pattern 
of greater dispersion with evidence of suburban concentrations of disadvantage present. Sydney, however, stands out with near comparable levels of disadvantage occurring in suburban locations and in the inner city.

By 2011, all cities registered a reversal of the level of disadvantaged locations within their first band, inner city locations, with Adelaide registering the lowest fall in ratio. Brisbane in particular stands out. Over the 25-year period, the presence of disadvantaged locations in this city's inner suburbs fell to a very low ratio. In Melbourne, there was a marked increase in suburbs immediately beyond the inner city. In Sydney, the ratio increased for the four non-central distance bands. Brisbane saw a decrease in the first two bands $(0-20 \mathrm{~km})$ and an increase in the three furthest bands $(21-50 \mathrm{~km})$.

\section{Table 4.2. Location quotients for disadvantaged populations for the five cities} (Adelaide, Brisbane, Melbourne, Perth and Sydney), 1986 and 2011.

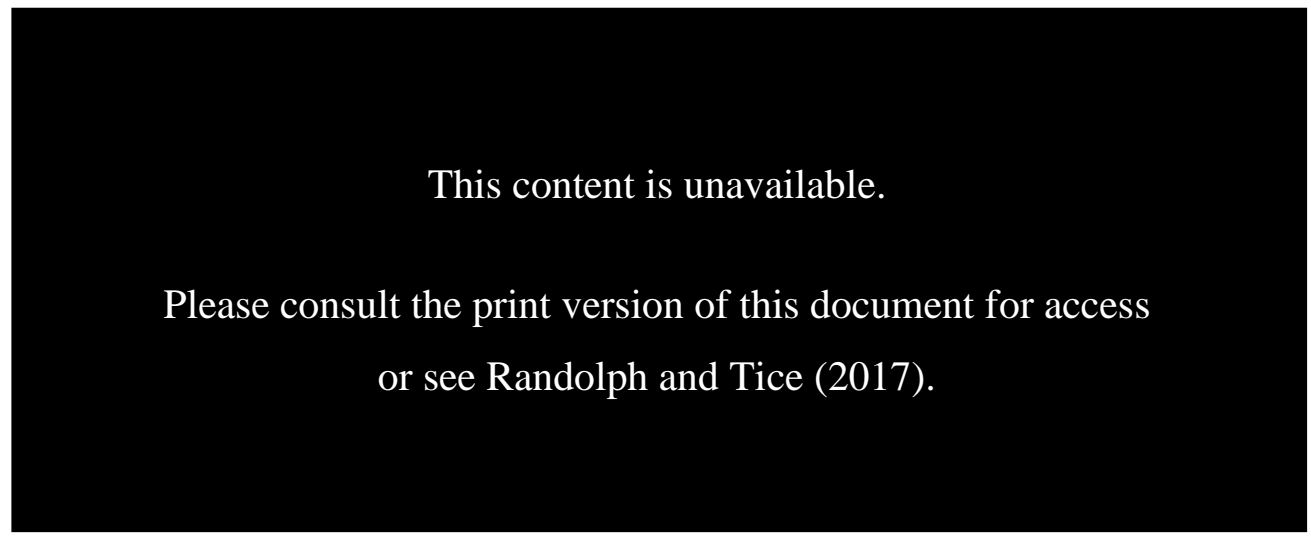

Perhaps a better way to show the changing distribution is through a graph. Figure 4.4 through Figure 4.8 show the percentage of all highly disadvantaged CDs against distance from city centre, broken into $1 \mathrm{~km}$ bands for all five cities.

Figure 4.4 shows a decrease in highly disadvantaged CDs in the first five kilometres for Adelaide. There appear to be slight increases in the occurrence of highly disadvantaged CDs for all other distant groupings, however, there is not a large amount of change beyond $30 \mathrm{~km}$. 
Figure 4.4. Distribution of disadvantaged locations for Adelaide, 1986 and 2011.

This content is unavailable.

Please consult the print version of this document for access or see Randolph and Tice (2017).

Figure 4.5 tells largely the same story for Brisbane; however, it extends the prevalence of the highly disadvantaged CDs to the $20-45 \mathrm{~km}$ range. In 1986, Brisbane had most disadvantaged CDs within the first 10km. By 2011, almost all of those highly disadvantaged CDs have disappeared, with a more even dispersion out away from the city centre.

Figure 4.5. Distribution of disadvantaged locations for Brisbane, 1986 and 2011.

This content is unavailable.

Please consult the print version of this document for access or see Randolph and Tice (2017). 
Figure 4.6 shows a remarkable shift of the highly disadvantaged CDs out of the first $10 \mathrm{~km}$ and into the second and third $10 \mathrm{~km}$ bands for Melbourne.

Figure 4.6. Distribution of disadvantaged locations for Melbourne, 1986 and 2011.

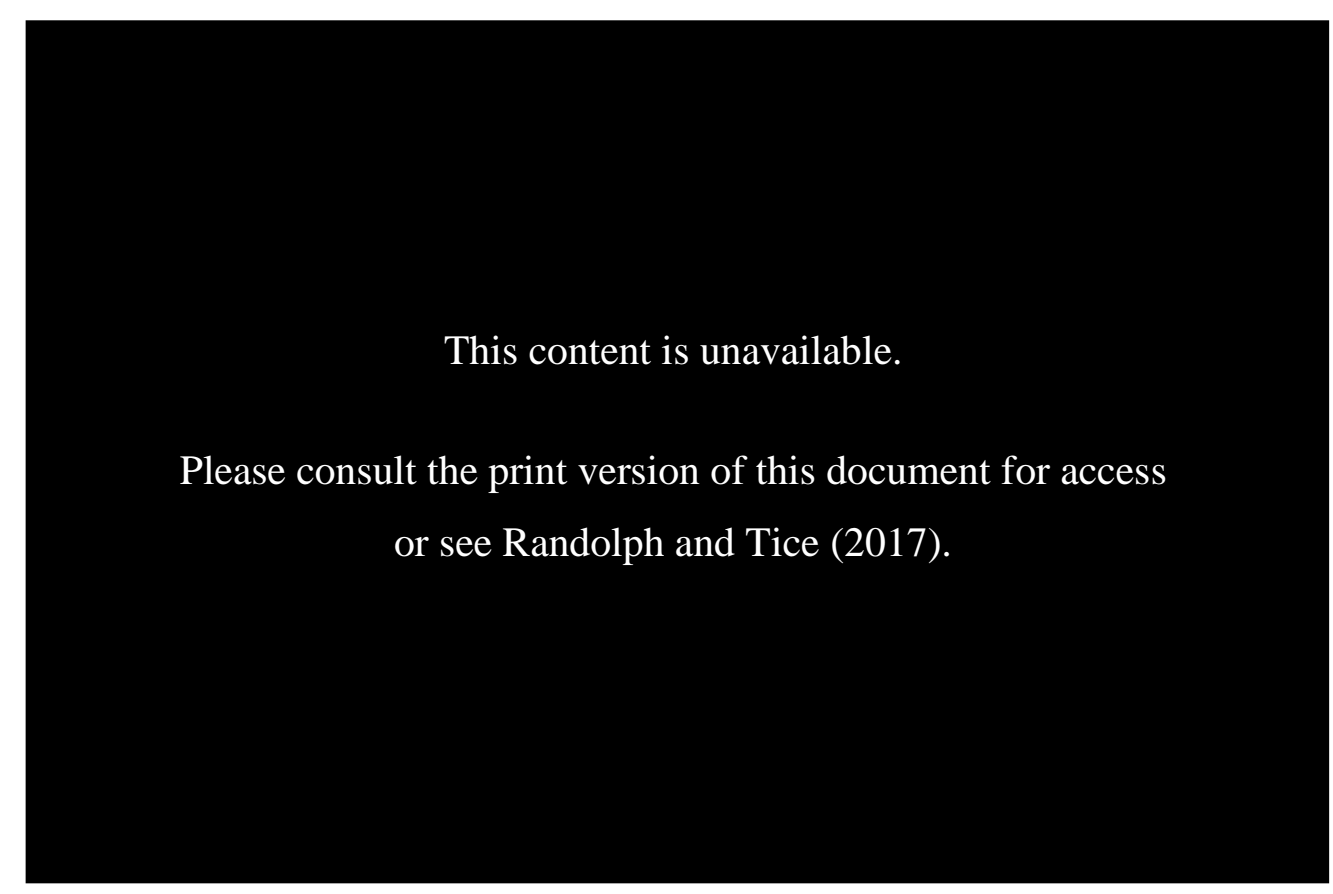

Perth sees a large reduction in the highly disadvantaged CDs occurring in the first $10 \mathrm{~km}$ band and sees large increases in the other bands that were not present previously. 
Figure 4.7. Distribution of disadvantaged locations for Perth, 1986 and 2011.

This content is unavailable.

Please consult the print version of this document for access or see Randolph and Tice (2017).

Lastly, Sydney sees large decreases in highly disadvantaged CDs in the first $10 \mathrm{~km}$, mirrored with a large increase in the middle $10-30 \mathrm{~km}$ suburb range.

Figure 4.8. Distribution of disadvantaged locations for Sydney, 1986 and 2011.

This content is unavailable.

Please consult the print version of this document for access or see Randolph and Tice (2017).

What follows next in Figures 4.9 through 4.13 are maps displaying the geography of disadvantage. Concentric bands from the city's central post office disperse outwards in $10 \mathrm{~km}$ intervals, up to $50 \mathrm{~km}$, to provide a consistent scale and complement the 
information in figures 4.4 through 4.8 and table 4.1 and 4.2. The grey shading indicates the extent of the city's urban area. The dark points the maps are displaying are the locations of the highly disadvantaged CDs. These points are shaded according to the population contained within, although the methodology behind the level of shading is not discussed. When there is a clustering of the data points, the points overlap and display an altogether darker shade. This indicates a clustering of disadvantaged communities. These maps are useful in identifying where exactly the highly disadvantaged are centring. Observing the specific locations of the highly disadvantaged complements the raw distance to centre numbers used so far.

Figures 4.9 shows two maps of Adelaide, 1986 on the left, and 2011 on the right. While I can see a reduction in the highly deprived close to the centre, there appears to be a high number within the whole band, particularly slightly north of centre. There is a large increase in the number of highly disadvantaged CDs in the second ring north of the centre. Figure 4.6 is very useful in determining an accurate picture of the geography of the highly disadvantaged because there is a large increase around the $20 \mathrm{~km}-30 \mathrm{~km}$ zone both north of centre and south of centre. This subtlety is something not registered in the previous analysis.

Figure 4.9. Spatial distribution of disadvantage for Adelaide, (a) 1986 and (b) 2011.

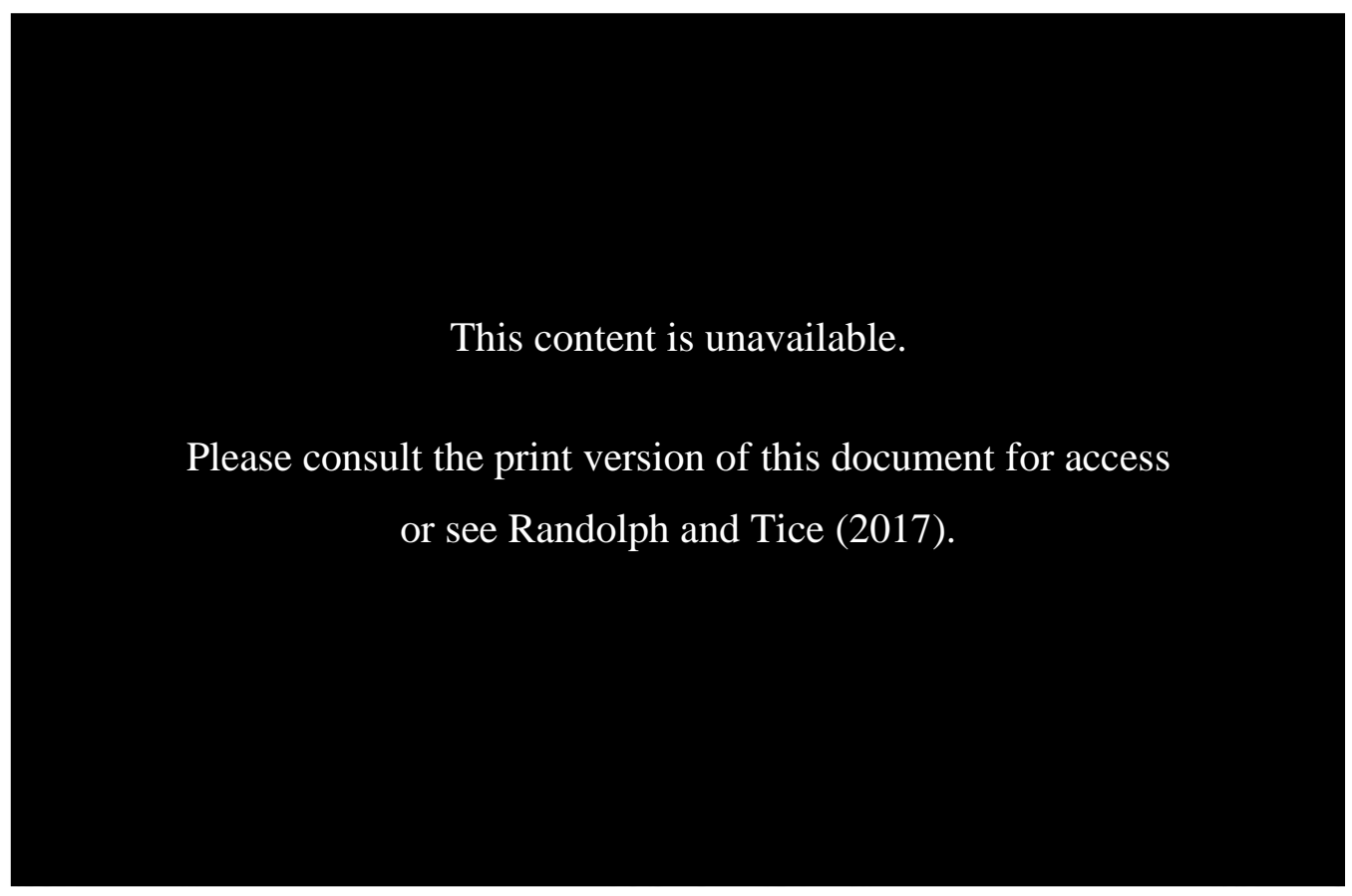


Figure 4.10 shows highly disadvantaged CDs in Brisbane, with the 1986 map on the left and the 2011 map on the right. I see a large decrease of the highly disadvantaged CDs in the first concentric circle. Again, I see an outward dispersion of the highly disadvantaged CDs, but in different directions. New clusters appear in the north fourth band, the west third and fourth bands, and the south third and fourth bands.

Figure 4.10. Spatial distribution of disadvantage for Brisbane, (a) 1986 and (b) 2011.

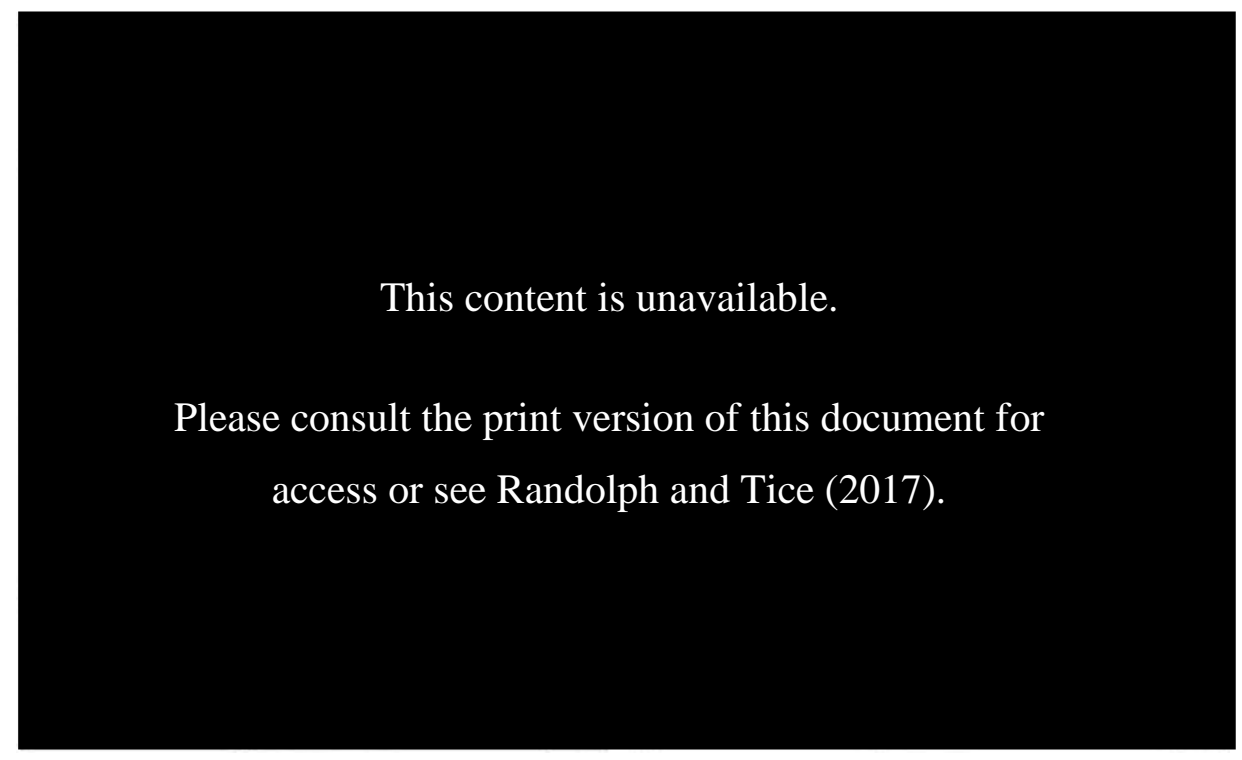

Figure 4.11 shows the city of Melbourne, 1986 map on the left, and 2011 map on the right. In 1986, a large proportion of the highly disadvantaged CDs are located with the first concentric band. By 2011, some of that proportion had shifted out of the centre into the second band $(10-20 \mathrm{~km})$ in the west and north, and the third band in the south-east. 
Figure 4.11. Spatial distribution of disadvantage for Melbourne, (a) 1986 and (b) 2011.

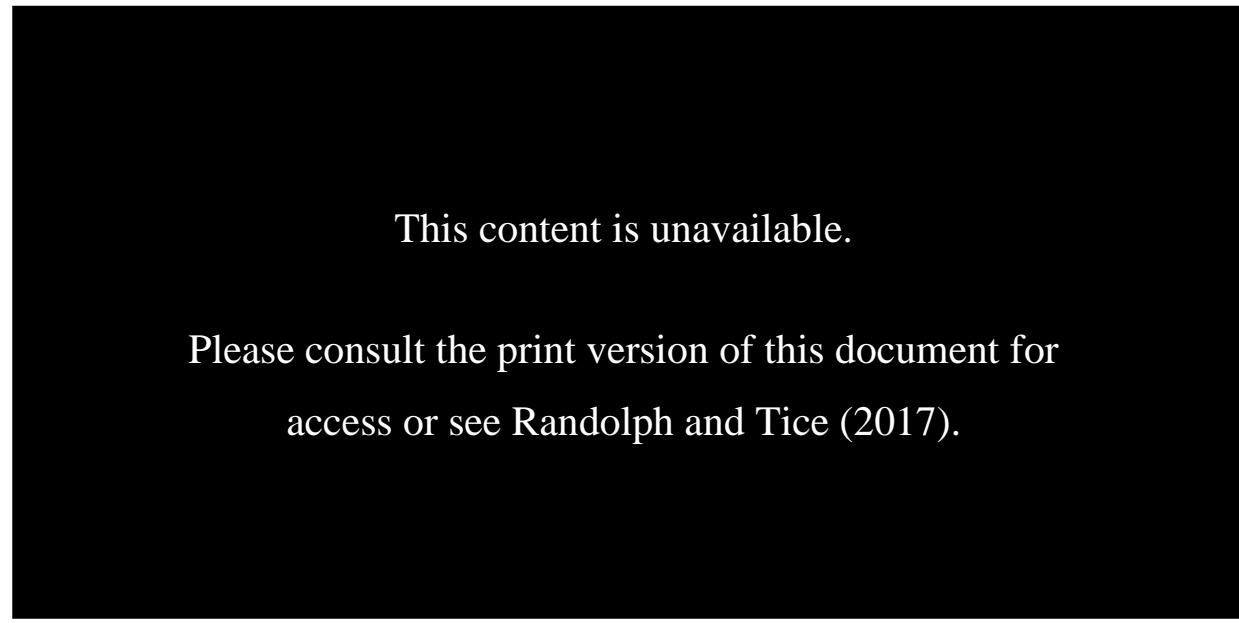

Figure 4.12 shows two maps of Perth, for 1986 and 2011. There is a large reduction highly disadvantaged CDs within the first concentric band over this period, and in the second band to the south west. This is matched with an increase in clusters in the second band to the north, and the emergence of highly disadvantaged CDs in the south-east.

Figure 4.12. Spatial distribution of disadvantage for Perth, (a) 1986 and (b) 2011.

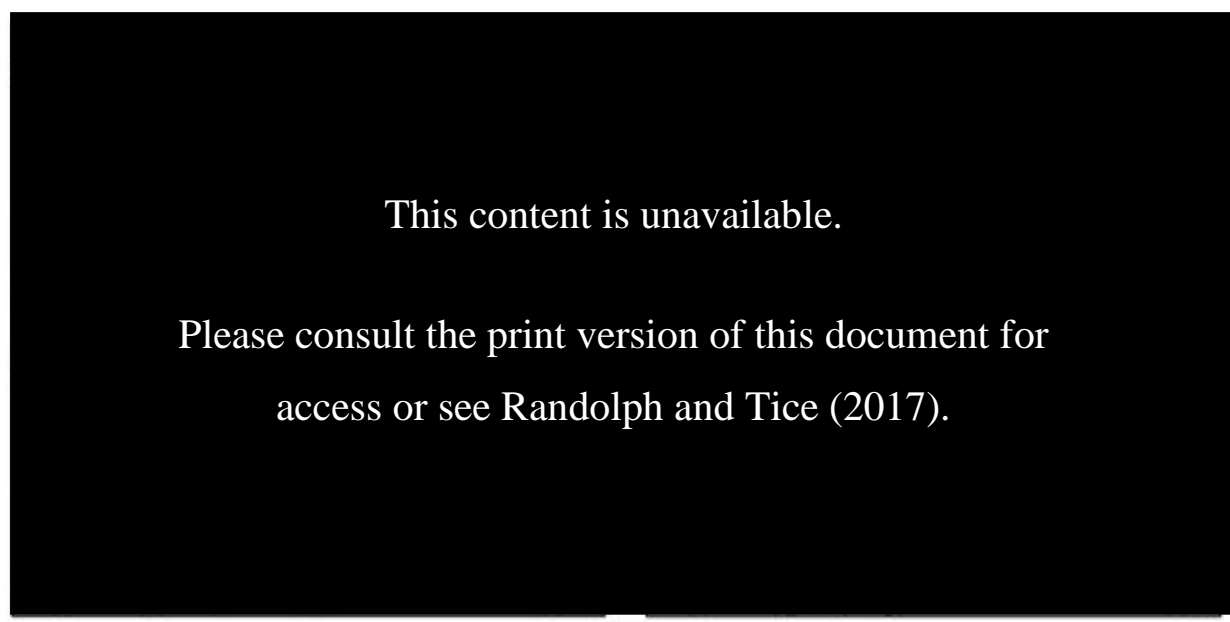

Sydney is an interesting case as observed in my previous analysis. Figure 4.13 shows two maps, the first in 1986, the second in 2011. Being Australia's largest city, it also appears Sydney has the largest number of highly disadvantaged CDs. There appears to be large clusters in the centre in 1986, as well as in the second and third bands west of centre. By 2011, most highly disadvantaged CDs had disappeared out of the 
first band. At the same time, the large clusters in the second and third bands west of centre had increased in size. Small clusters approximately $40 \mathrm{~km}$ west also emerged.

Figure 4.13. Spatial distribution of disadvantage for Sydney, (a) 1986 and (b) 2011.

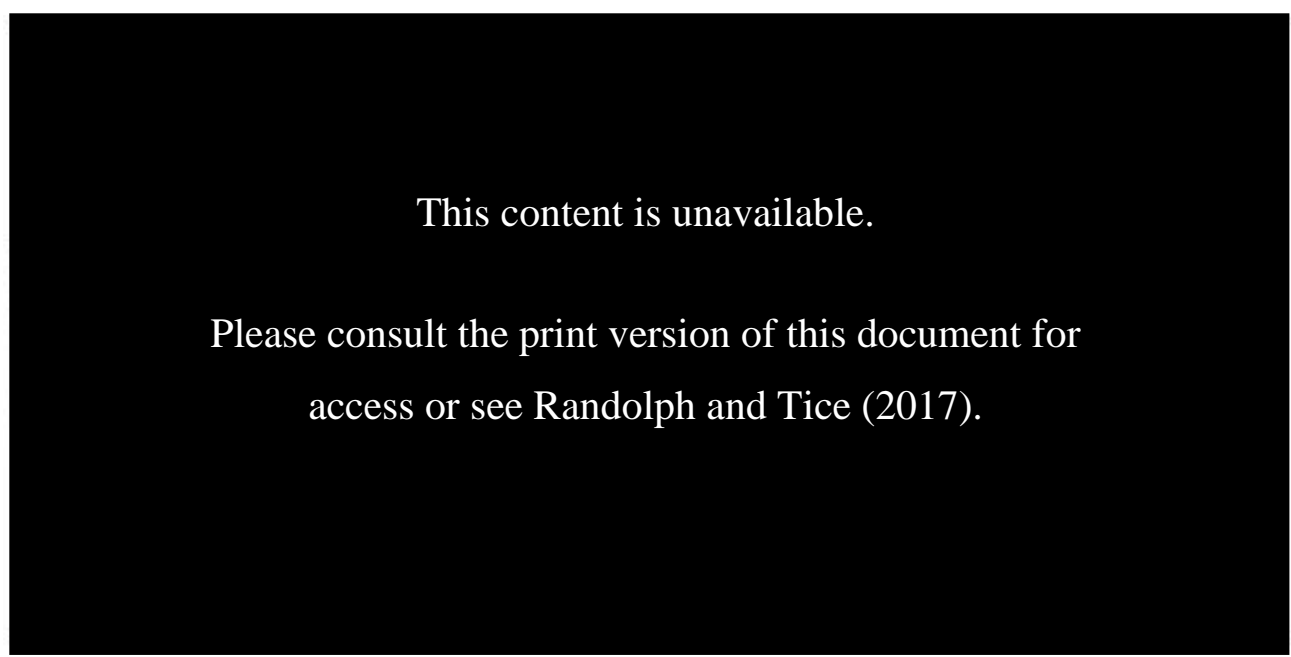

\subsection{The New Zealand comparison}

Next, I turn to Wellington and Auckland to see whether this same shift holds true in New Zealand's two biggest cities. As mentioned previously, I use the deprivation score instead of the disadvantage index. This could be slightly problematic for comparisons, as they are both aggregated variables with different weightings that could yield different results. The creators of both the Australian index of relative disadvantage and the New Zealand deprivation score did not design the variables with the purpose of comparing them. However, deprivation score is -like disadvantage - standardised around a mean of 1000, and one would presume a broadly similar distribution. For the sake of comparability to Randolph and Tice, I categorise 'highly deprived meshblocks', as meshblocks at or beyond one standard deviation above the mean of the New Zealand deprivation score.

First, I look at the population for both Auckland and Wellington, and how it has changed over time. The data points in Figure 4.14 show the usual resident population of these two cities from the past five censuses. Auckland's population has grown more than Wellington and at a faster rate. This makes sense, as Auckland is New Zealand's largest city, and now gets more migrants. 
Figure 4.14. Population for Auckland and Wellington, 1991-2013

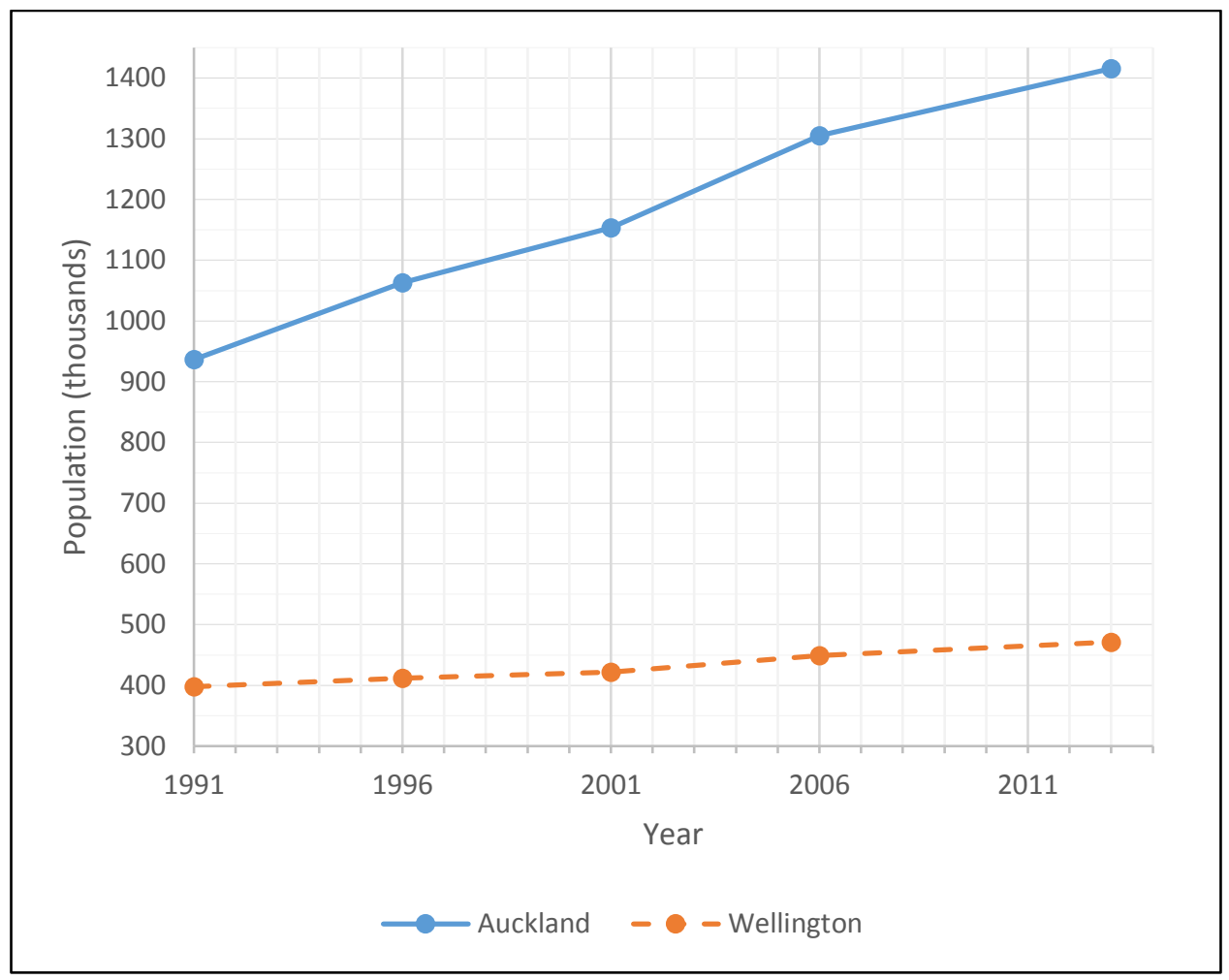

Figure 4.15 confirms that Auckland has grown at a faster rate than Wellington over this period. However, both cities have shown similar expansions and contractions of population growth in these two cities. Of note is the narrowing of the gap between growth rates of the two cities. Over the 1991-1996 period, Auckland was growing at almost $2.7 \%$ p.a. growth rate, while Wellington was growing at almost a $0.7 \%$ p.a., a difference of 2. By the 2006-2013 period, the gap had narrowed to almost 1.25 for Auckland, and 0.75 for Wellington, a difference of 0.5 . 
Figure 4.15. Average annual population growth for Auckland and Wellington, 1991-2013

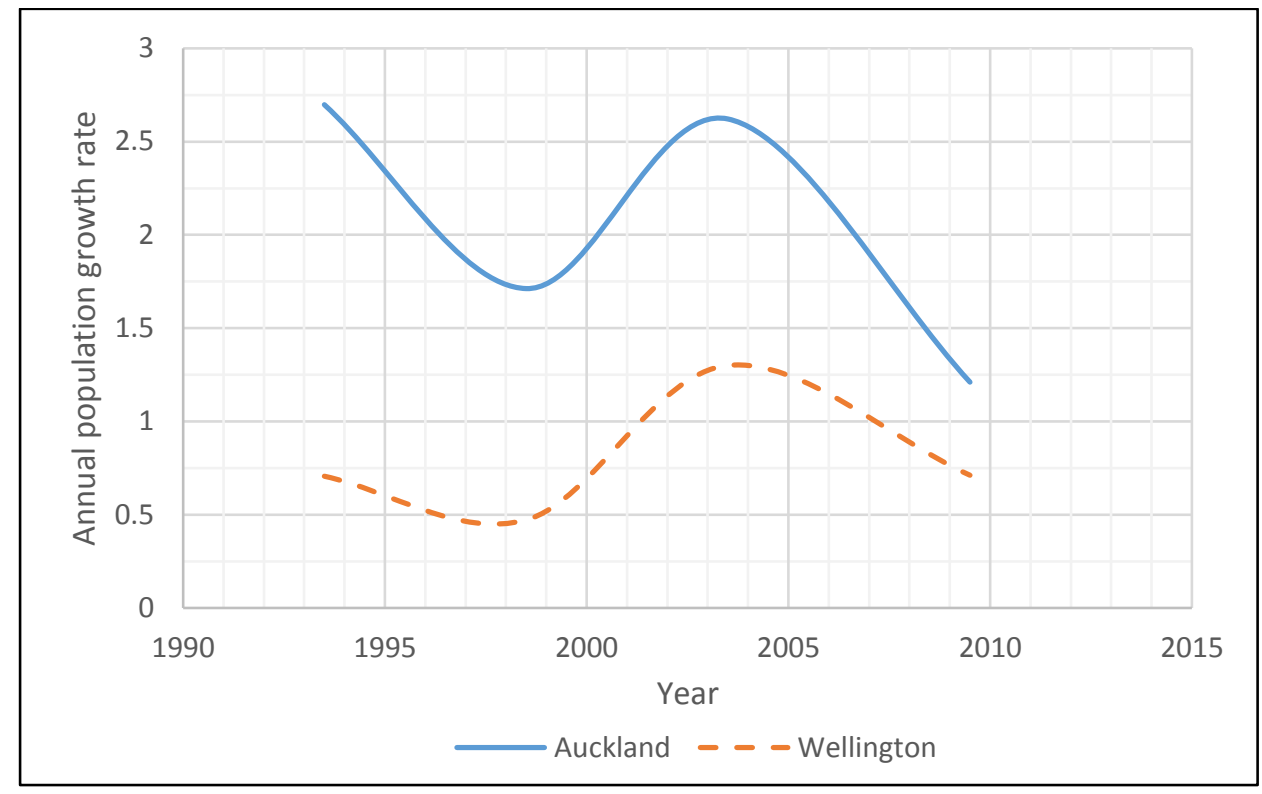

Next, I look at the population of the highly deprived meshblocks (at or beyond one standard deviation in deprivation score), and how they are distributed from the city centre.

Table 4.3 shows a comparable table to Table 4.1. The population contained within highly deprived meshblocks has been split into $10 \mathrm{~km}$ bands from the city centre. In 1991, for both Wellington and Auckland the largest portion of the highly deprived population is contained within the second band (10-19km). By 2013, both cities show a negative absolute change in population for the first $10 \mathrm{~km}$ band. Wellington sees a decrease in the second band too, paired with increases in population across the three further bands. Auckland sees large increases in all but the first band. 
Table 4.3. Population change in deprived locations in $10 \mathrm{~km}$ bands for Wellington and Auckland (1991 and 2013)

\begin{tabular}{|c|c|c|c|}
\hline Distance band & Wellington & Auckland & Total \\
\hline \multicolumn{4}{|l|}{1991} \\
\hline$<10 \mathrm{~km}$ & 8802 & 54438 & 63240 \\
\hline $10-19 \mathrm{~km}$ & 35853 & 73461 & 109314 \\
\hline $20-29 \mathrm{~km}$ & 1908 & 27048 & 28956 \\
\hline $30-39 \mathrm{~km}$ & 270 & 3033 & 3303 \\
\hline $40-49 \mathrm{~km}$ & 591 & 2427 & 3018 \\
\hline Total & 47424 & 160407 & 207831 \\
\hline \multicolumn{4}{|l|}{2013} \\
\hline$<10 \mathrm{~km}$ & 8577 & 53520 & 62097 \\
\hline $10-19 \mathrm{~km}$ & 35277 & 113958 & 149235 \\
\hline $20-29 \mathrm{~km}$ & 3255 & 59916 & 63171 \\
\hline $30-39 \mathrm{~km}$ & 837 & 4488 & 5325 \\
\hline $40-49 \mathrm{~km}$ & 1506 & 4626 & 6132 \\
\hline Total & 49452 & 236508 & 285960 \\
\hline \multicolumn{4}{|l|}{$1991-2013$} \\
\hline \multicolumn{4}{|l|}{ Absolute } \\
\hline$<10 \mathrm{~km}$ & -225 & -918 & -1143 \\
\hline $10-19 \mathrm{~km}$ & -576 & 40497 & 39921 \\
\hline $20-29 \mathrm{~km}$ & 1347 & 32868 & 34215 \\
\hline $30-39 \mathrm{~km}$ & 567 & 1455 & 2022 \\
\hline $40-49 \mathrm{~km}$ & 915 & 2199 & 3114 \\
\hline Total & 2028 & 76101 & 78129 \\
\hline \multicolumn{4}{|l|}{ Percent } \\
\hline$<10 \mathrm{~km}$ & -2.56 & -1.69 & -1.81 \\
\hline $10-19 \mathrm{~km}$ & -1.61 & 55.13 & 36.52 \\
\hline $20-29 \mathrm{~km}$ & 70.60 & 121.52 & 118.16 \\
\hline $30-39 \mathrm{~km}$ & 210.00 & 47.97 & 61.22 \\
\hline \multirow[t]{2}{*}{$40-49 \mathrm{~km}$} & 154.82 & 90.61 & 103.18 \\
\hline & 4.28 & 47.44 & 37.59 \\
\hline
\end{tabular}

A location quotient (LQ) is a ratio that compares the proportion of a variable in a wider context at a geographic level with the proportion of that variable in a wider context at a larger geographic level. Refer to the previous chapter for a more comprehensive explanation. Table 4.4 shows the results.

$$
L Q=\frac{(X / Y)_{\text {distance band }}}{\left(X^{\prime} / Y^{\prime}\right)_{\text {region }}}
$$

Both Wellington and Auckland do not contain disproportionate numbers of the population within highly deprived meshblocks in the first $10 \mathrm{~km}$ from the city centre. Even so, across the period measured, there is a reduction in the number of people living within highly deprived meshblocks in the first band. Both the second band for Wellington, and the second and third band for Auckland contain the most 
disproportionate numbers of highly deprived dwellers. Across the period measured, these bands become even more disproportionate. This suggests that in both cities, the concentration of highly deprived population is occurring.

Table 4.4. Location quotients for deprived populations for Wellington and Auckland (1991 and 2013)

\begin{tabular}{|cccc|}
\hline Distance band & Wellington & Auckland & Total \\
\hline 1991 & & & \\
$<10 \mathrm{~km}$ & 0.47 & 0.84 & 0.76 \\
$10-19 \mathrm{~km}$ & 2.06 & 1.12 & 1.32 \\
$20-29 \mathrm{~km}$ & 0.32 & 1.34 & 1.11 \\
$30-39 \mathrm{~km}$ & 0.12 & 0.60 & 0.45 \\
$40-49 \mathrm{~km}$ & 0.18 & 0.54 & 0.37 \\
& & & \\
2013 & & & \\
$<10 \mathrm{~km}$ & 0.40 & 0.61 & 0.56 \\
$10-19 \mathrm{~km}$ & 2.21 & 1.14 & 1.30 \\
$20-29 \mathrm{~km}$ & 0.54 & 1.82 & 1.63 \\
$30-39 \mathrm{~km}$ & 0.41 & 0.59 & 0.54 \\
$40-49 \mathrm{~km}$ & 0.37 & 0.61 & 0.49 \\
& & & \\
\hline
\end{tabular}

Next, I move to take a closer look at the case of Wellington. Wellington has an unusual topography and geography. There are many hills, slopes, valleys and bodies of water that restrict the outward development of the wider metropolitan region. The city is also located on a rather narrow body of land that means outward growth is bidirectional. This is helpful in a sense, because it means measuring the spatial distribution has less of a directional effect and more of a distance effect.

Like Randolph and Tice (2014), I first look at how the number of highly deprived meshblocks has changed from 1991 to 2013. Overall, in 1991 there were 623 meshblocks above one standard deviation in deprivation score for the Wellington region, out of 4183 in total. This is a proportion of $14.89 \%$ meshblocks considered to be highly deprived.

There were 74 area units out of 178 containing at least one highly deprived meshblock, or $41.47 \%$ of all area units in Wellington. Of these 74 area units, 9 
contained highly deprived meshblocks that accounted for at least $80 \%$ or more of the area unit. This is a proportion of $5.06 \%$ of the total area units containing at least $80 \%$ highly disadvantaged meshblocks.

By 2013, the number of meshblocks above one standard deviation in deprivation score for the Wellington region had risen slightly to 630 of 4902 in total. However, this is a decrease in the proportion of all meshblocks to $12.83 \%$.

There were 80 area units containing at least one highly deprived meshblock from 204 in total, or $39.21 \%$ of all area units in Wellington. Of these 80 area units, only six contained highly deprived meshblocks that accounted for at least $80 \%$ or more of the total meshblocks within that area unit. That translates to a proportion of $2.94 \%$ of the total area units containing highly deprived meshblocks that accounted for at least $80 \%$ or more of the area unit's population.

In other words, the areas of most concentrated deprivation had decreased in spatial extent, with a $42 \%$ reduction in the number of area units where highly deprived meshblocks accounted for $80 \%$ or more of the area unit.

Perhaps a better way of visualising this reduction is looking at the change in proportion of deprived meshblocks. Figure 4.16 shows the spatial distribution of all highly deprived meshblocks for 1991 and 2013 in 1km bands. From 1991 to 2013, there is a noticeable fall around the $15-20 \mathrm{~km}$ range, with small increases across the rest of the city. Figure 4.17 simplifies this pattern by increasing the bands to that of $10 \mathrm{~km}$. Figure 4.17 is also extended to show further out into the region, where a dramatic decrease in deprivation is seen (in the Wairarapa and Otaki areas). Both Figure 4.16 and Figure 4.17 show that the $10-19 \mathrm{~km}$ band is still by far the location of the most deprived. I show Wellington out to $85 \mathrm{~km}$ because the city only expands beyond $10 \mathrm{~km}$ in two directions, due to the shape of the land and typography of the region. 
Figure 4.16. Distribution of highly deprived meshblocks in Wellington, 1991 and 2013

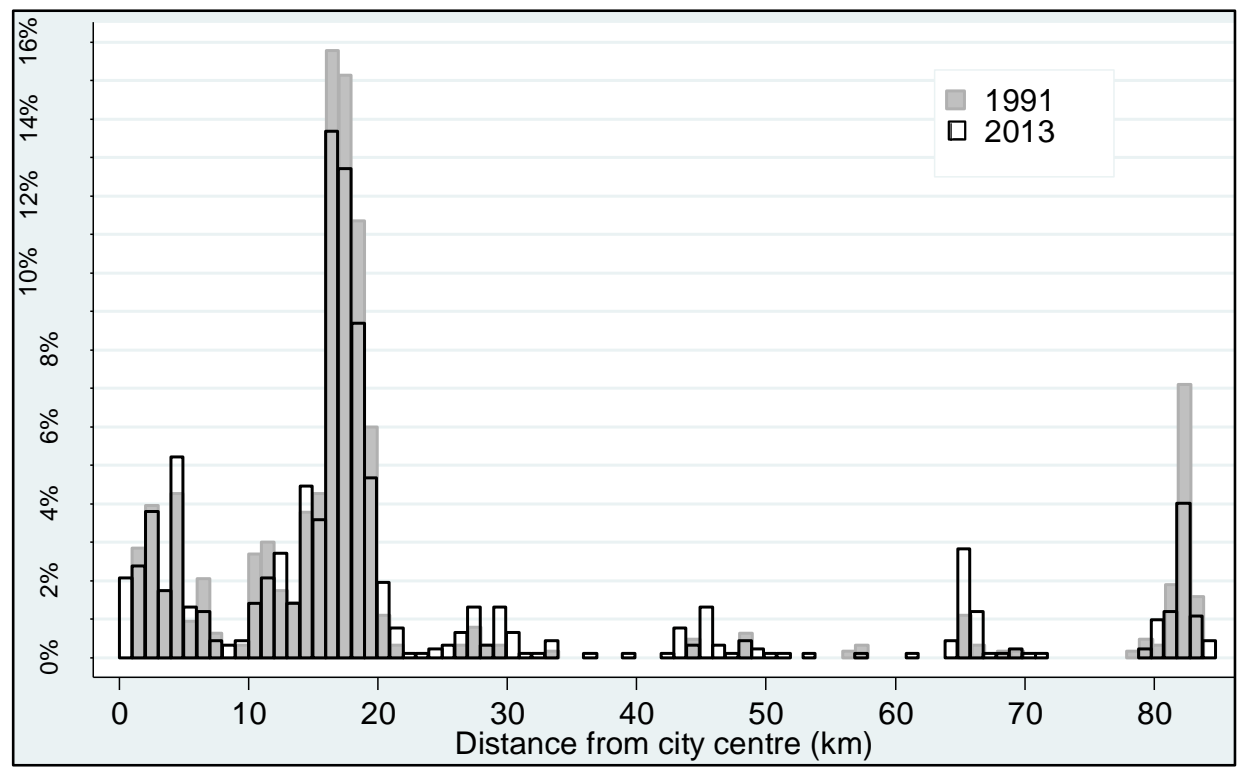

Figure 4.17. Distribution of highly deprived meshblocks in Wellington, 1991 and 2013

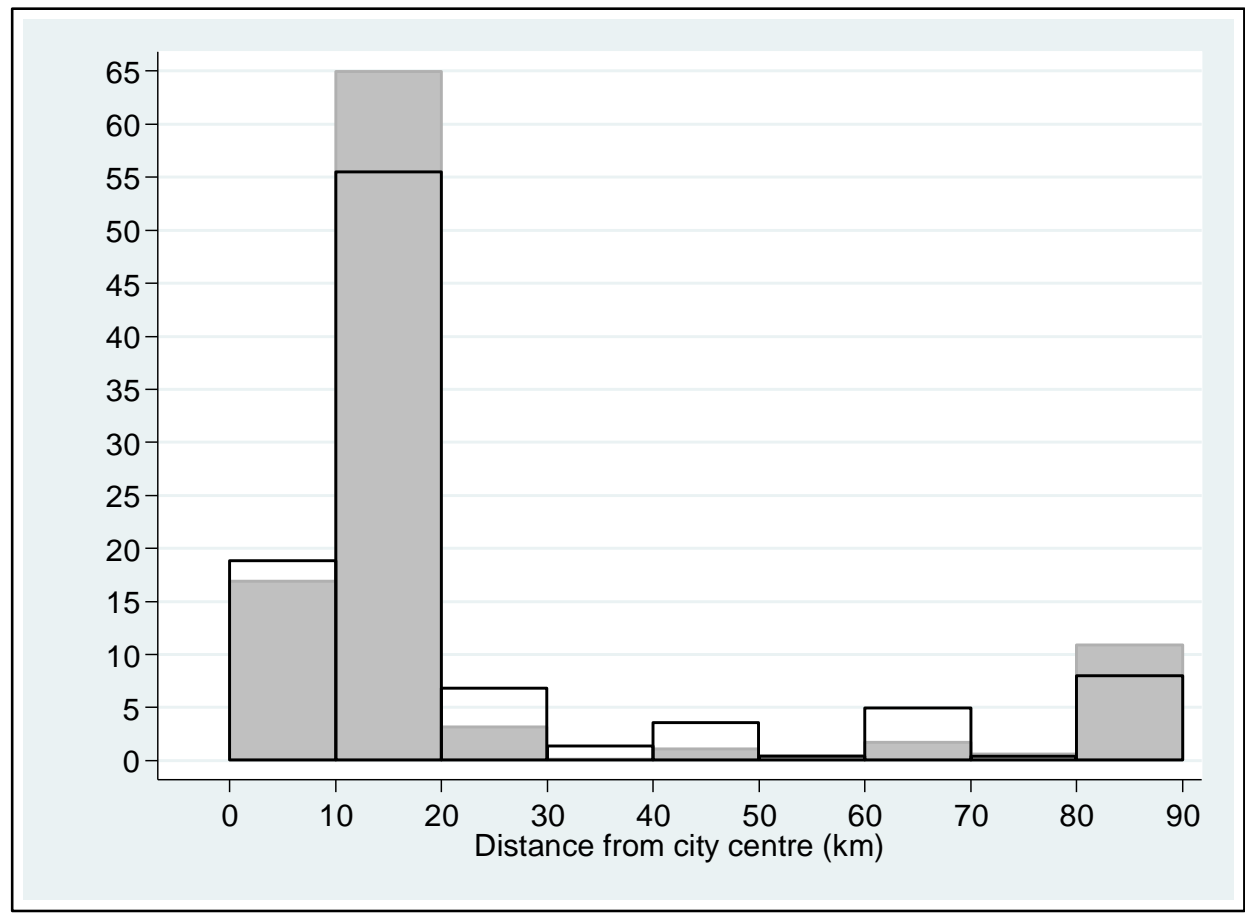

Figure 4.18 illustrates this reduction in deprived areas. Figure 4.18 plots area units in 1991 and 2013. The shading of each area unit indicates the proportion of meshblocks contained with the area unit that I have deemed highly deprived (at or beyond one standard deviation above the mean New Zealand deprivation score). When comparing 2013 with 1991 there is a reduction in deprivation (a lighter shade) in the 
$10-19 \mathrm{~km}$ band for both Porirua (northern area of the band) and Lower Hutt (eastern area of the band). This reduction does not lead to a large increase in many other areas.

Figure 4.18. Proportion of highly deprived meshblocks in area units, Wellington 1991 and 2013

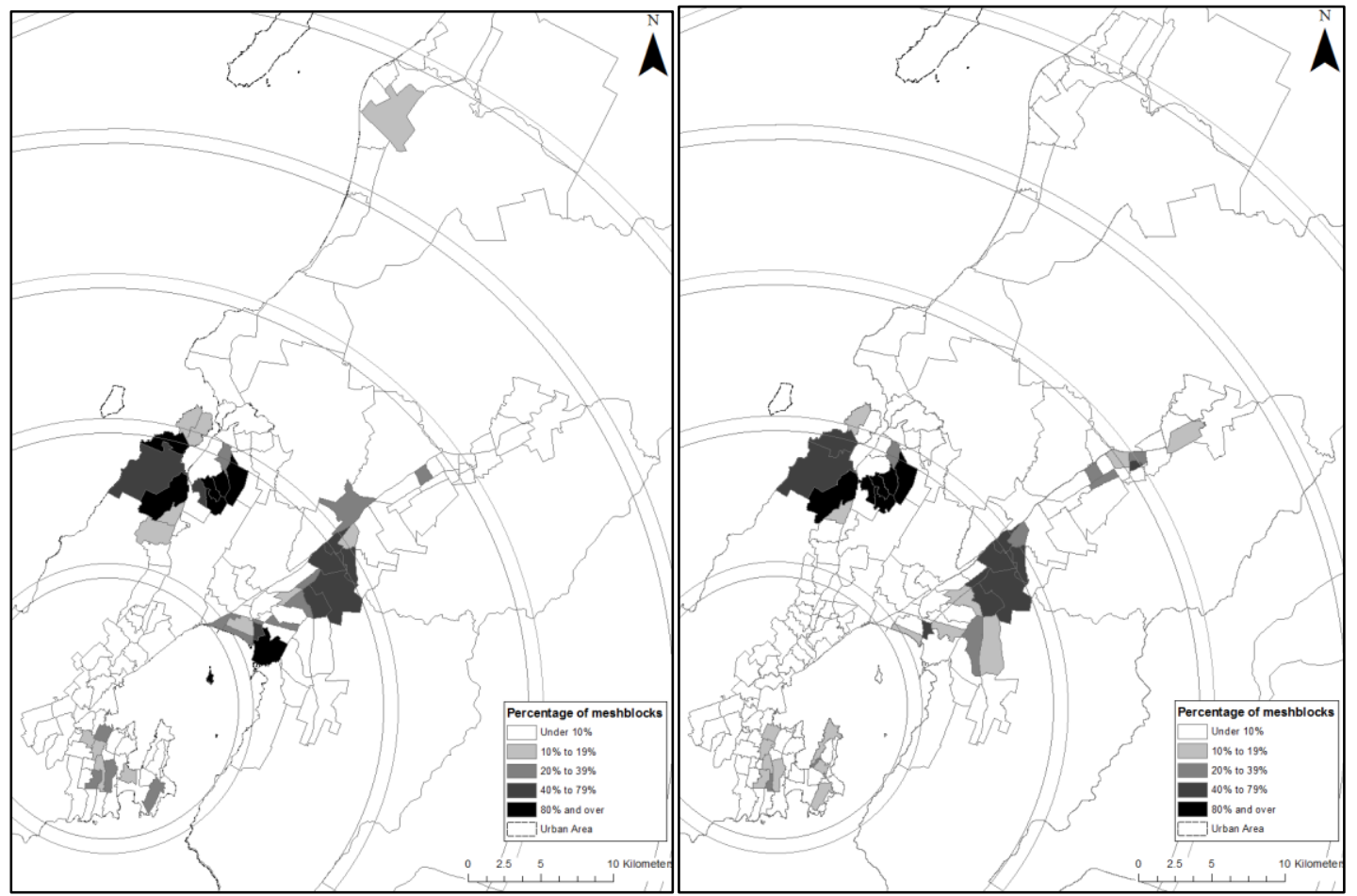

Figure 4.19 plots the individual meshblocks that I have classified as highly deprived for 1991 and 2013. The shading was normalised to the population contained within each meshblock. The intended effect of this technique is to illustrate the concentration within highly deprived meshblocks.

In 1991, there is a large population within highly deprived meshblocks in the second band, mainly in Porirua and Lower Hutt. By 2013, the population within highly deprived meshblocks in the second band has decreased (indicated by the lightening in shade of some areas). However, there is a reduction within the first $10 \mathrm{~km}$ band, close to the city. Additionally, there is a reduction in the prevalence of highly deprived meshblocks in Petone, the area by the harbour close in the second band close to the first band limit. 
Figure 4.19. Spatial distribution of highly deprived meshblocks, Wellington 1991 and 2013



In Wellington, my analysis in Figure 4.16 showed there was a slight increase in the proportion of highly deprived meshblocks (that is, meshblocks at or beyond one standard deviation about the mean New Zealand deprivation score) within the first $10 \mathrm{~km}$ of the city centre. However, the maps show a slightly different story, with Figure 4.19 a large number of highly deprived meshblocks in 1991 in the first band.

Next, I turn to Auckland. Auckland is a more populous city than Wellington and has a more even spread and topography. Originally, Auckland consisted of four different cities and seven districts. In 2010, these cities and districts amalgamated into one. However, the region or city has traditionally acted as one large metropolitan area, and my assumption is that the amalgamation will not affect the analysis.

First, I look at the distribution of highly deprived meshblocks, and how their distribution may have changed. Overall, in 1991 there were 1265 meshblocks above one standard deviation in deprivation score for Auckland, of 7583 in total. Represented as a proportion, this means $16.68 \%$ of all meshblocks in Auckland can be considered to be highly deprived. 
There were 154 area units out of 327 containing at least one highly deprived meshblock or $47.09 \%$ of all area units in Auckland. Of these 154 area units, 13 contained highly deprived meshblocks that accounted for at least $80 \%$ or more of the area unit. This is a proportion of $3.98 \%$ of the total area units containing at least $80 \%$ highly disadvantaged meshblocks.

By 2013, the number of meshblocks above one standard deviation in deprivation score for the Auckland had risen to 1712 of 11,244 in total. However, as a proportion of all meshblocks, the number of highly deprived meshblocks had decreased to $15.23 \%$.

There were 170 area units containing at least one highly deprived meshblock from 405 in total, or $41.98 \%$ of all area units in Auckland. Of these 170 area units, 27 contained highly deprived meshblocks that accounted for at least $80 \%$ or more of the total meshblocks within that area unit. That translates to a proportion of $6.67 \%$ of the total area units containing highly deprived meshblocks that accounted for at least $80 \%$ or more of the area unit.

In other words, the areas of most concentrated deprivation had increased in spatial extent, with a $68 \%$ increase in the number of area units where highly deprived meshblocks accounted for $80 \%$ or more of the area unit.

Figure 4.20 shows the distribution of highly deprived meshblocks for Auckland, for 1991 and 2013. I have split the distribution into $1 \mathrm{~km}$ bands, with 2013 overlaid on the top to determine the change at each kilometre between the two years. In 1991, I initially see a large portion of the highly deprived distributed in the first ten kilometres from city centre, and a large portion in the $13-18 \mathrm{~km}$ range. I can then see a decrease by 2013 in highly deprived meshblocks 3-11km from city centre. Over this same period, there are large increases in highly deprived meshblocks $12-15 \mathrm{~km}$ from city centre and $21-30 \mathrm{~km}$ from city centre. 
Figure 4.20. Distribution of highly deprived meshblocks in Auckland, 1991 and 2013



I have constructed Figure 4.21 in the same way as Figure 20; however, instead I have split the distribution into $10 \mathrm{~km}$ bands. The $10 \mathrm{~km}$ bands serve to illustrate the shift of highly deprived meshblocks from the first 10km. Although Figure 4.21 still contains the second most highly deprived meshblocks, the first $10 \mathrm{~km}$ from city centre shows a large decrease of about $18 \%$ of all highly deprived meshblocks in Auckland. The 10$20 \mathrm{~km}$ band sees an increase of 5\% and by 2013 has the most highly deprived meshblocks. There was also a $10 \%$ increase in the $20-30 \mathrm{~km}$ band of all highly deprived meshblocks.

Figure 4.21. Distribution of highly deprived meshblocks in Auckland, 1991 and 2013

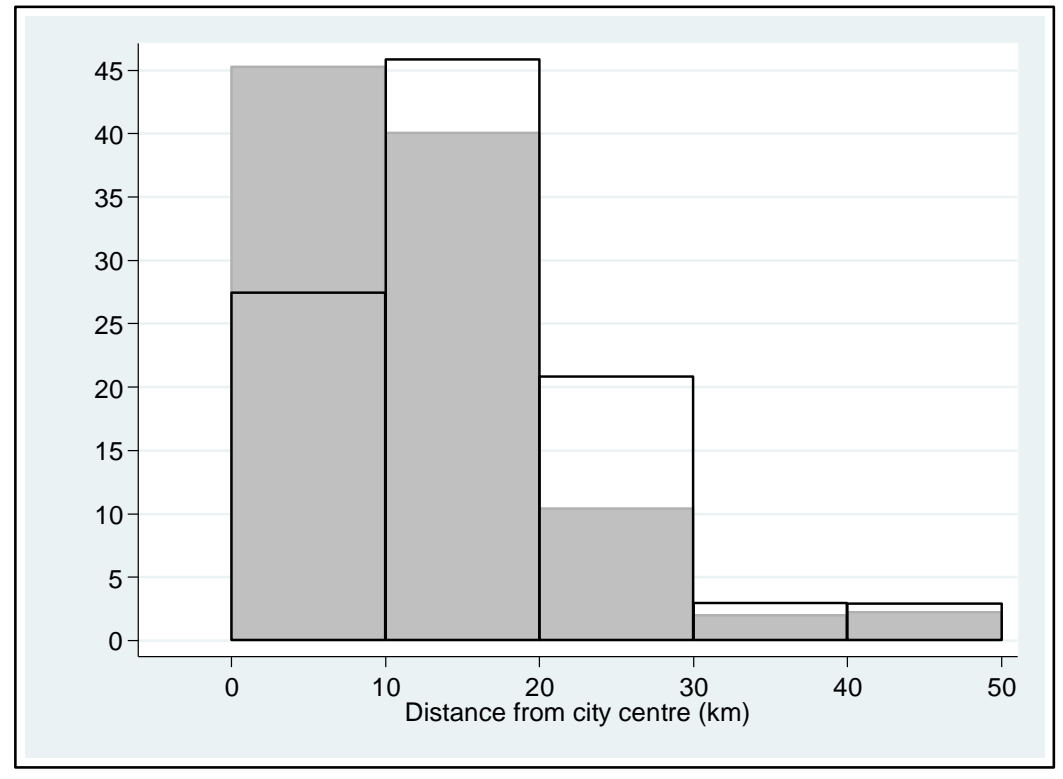


Figures 4.22 and 4.23 illustrate this increase in deprived areas and show where the increases and decreases occur. When comparing 2013 with 1991 for Figure 4.22, there is an increase in deprivation (a darker shade) in the 10-19km band for both South Auckland and West Auckland. There also appears to be an increase in deprivation (or darker shading) in the $20-29 \mathrm{~km}$ band towards the south. This increase in both those bands mirrors the reduction in deprivation in the $0-10 \mathrm{~km}$ band.

Figure 4.22. Proportion of highly deprived meshblocks in area units, Auckland 1991 and 2013

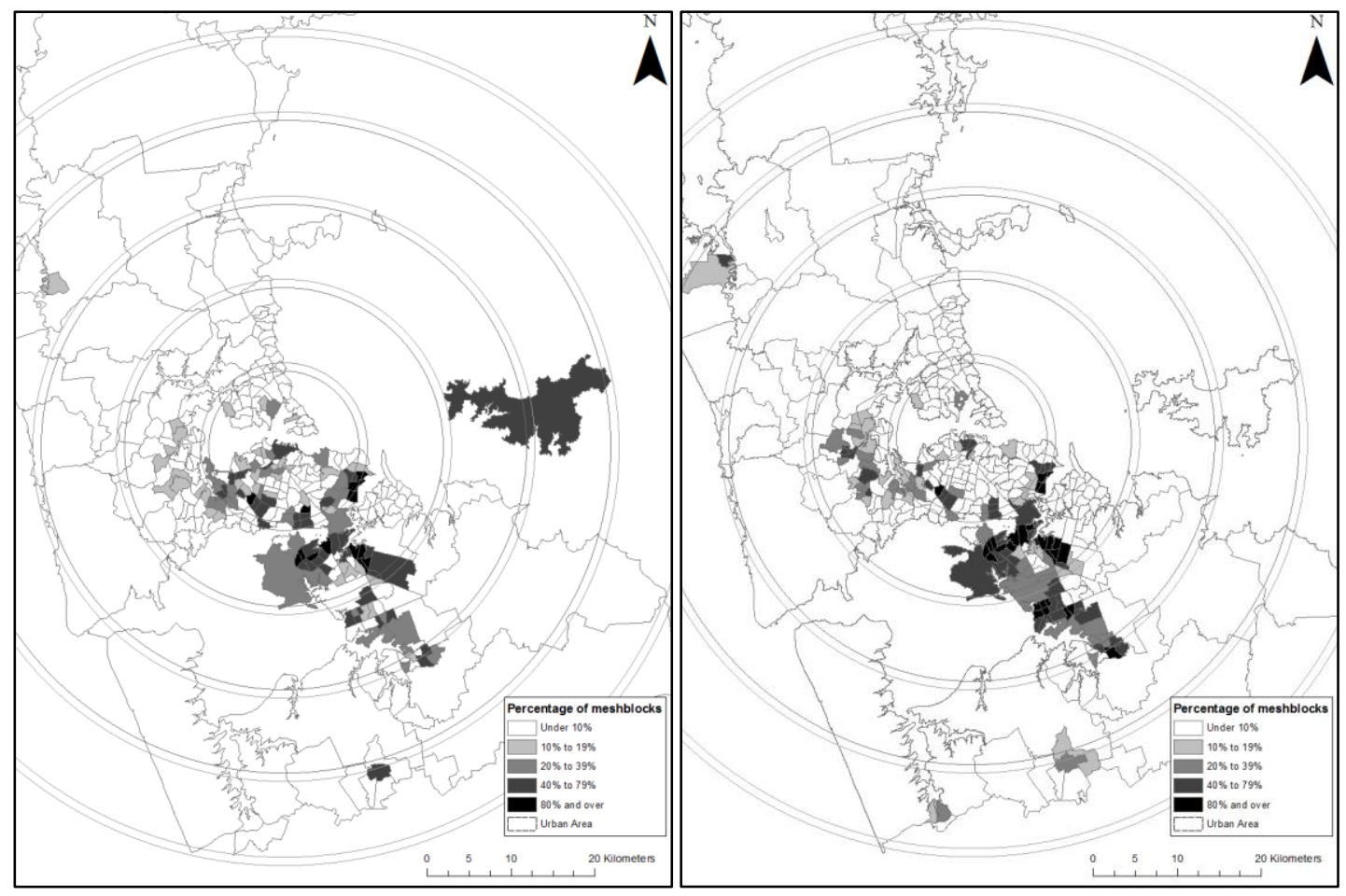

Figure 4.23 shows the highly deprived meshblocks for both 1991 (left) and 2013 (right) in Auckland. Like Randolph and Tice's Figure 4.4-4.8, I have normalised the shading of highly deprived meshblocks to indicate the level of population contained within.

Looking at 1991, I can see the majority of the highly deprived meshblocks are in South Auckland. There were highly deprived meshblocks within the centre, and to the west of centre, as well as on Waiheke Island, the island in third and fourth bands to the east to and from which some people catch a ferry, to commute. By 2013, the highly deprived meshblocks had decreased near the centre, and on Waiheke Island, and become more prevalent in the second and third bands in the south. 


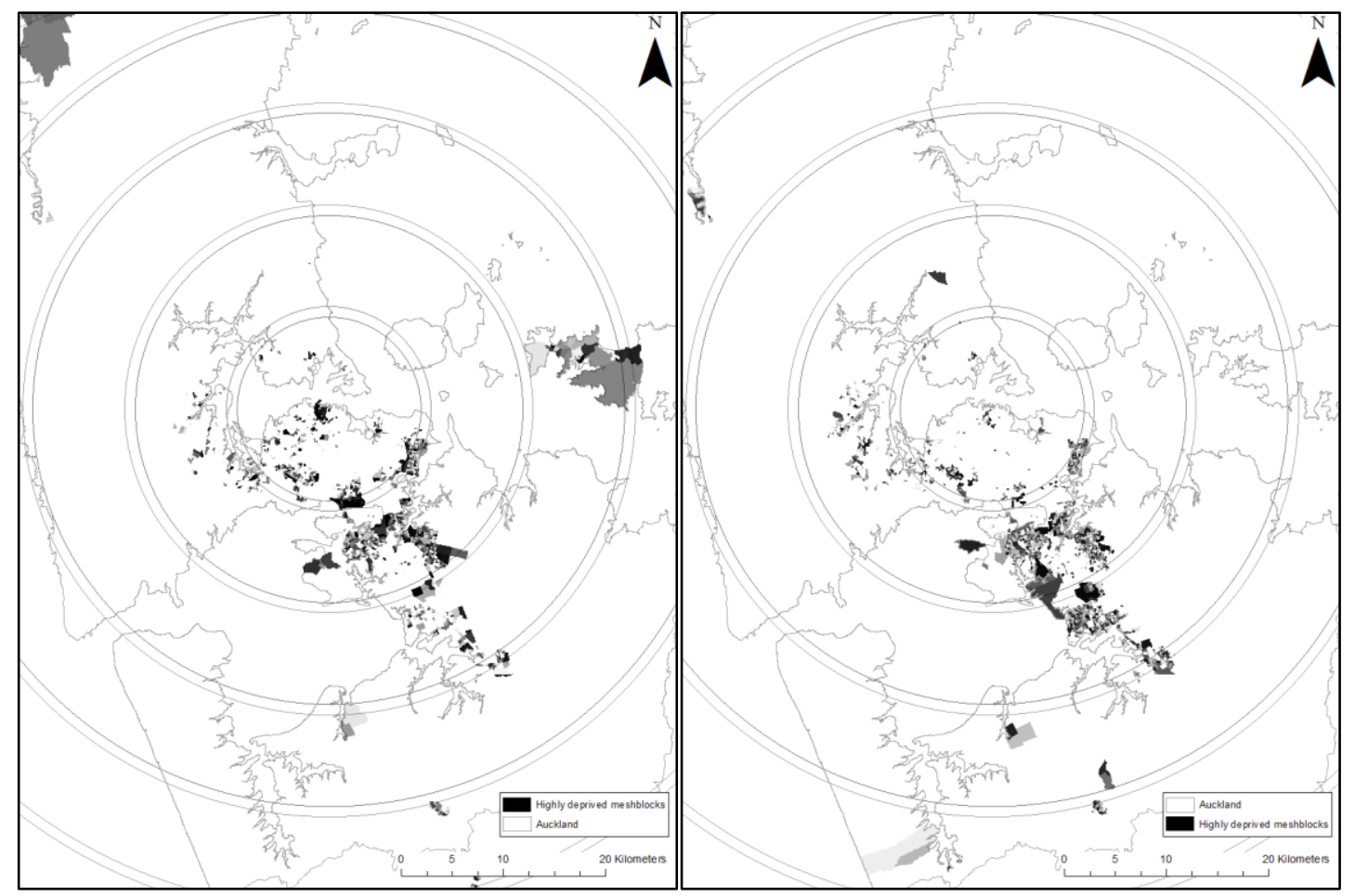

What can I conclude from this analysis? Auckland appears to follow the same trend as the five Australian cities. Looking at meshblocks at and beyond one standard deviation of deprivation score for Auckland, over a 22-year period, there is a measureable shift away from the city centre. In Wellington, the shift is not so clear. In fact, there was a marginal increase of highly deprived meshblocks within the first $10 \mathrm{~km}$ from the city centre (within Wellington City itself) and decreases within the second 10km band (Porirua and Lower Hutt Cities). However, looking at the table 4.3 shows that there was a total decrease in population within the first and second $10 \mathrm{~km}$ bands. This does not match the Australian evidence outlined previously by Randolph and Tice. It also suggests that the highly deprived are either not clustering or concentrating in Wellington as they are in the bigger cities of Australia and Auckland. Alternatively, the highly deprived might be employing other coping mechanisms not captured by the deprivation score.

What are the possible reasons for this mismatch? As Mare, Mawson and Timmins (2001) observe, the population within a highly deprived geographical area may not all be highly deprived. Likewise, not all the highly deprived population is contained within highly deprived meshblocks. It is quite possible that across this 22-year 
period, there is a wider dispersion of highly deprived individuals not within highly deprived meshblocks in Wellington. By focussing on geographic areas categorised as containing a highly deprived population, Randolph and Tice (and also my own analysis) may be ignoring those that are highly deprived but are, through whatever mechanisms, living in areas not deemed to be highly deprived.

It also follows that in times of economic hardship, highly deprived populations would locate in highly deprived areas because highly deprived areas are cheaper. Those that are highly deprived have less choice when it comes to how they locate because they cannot outcompete those that are less deprived. It is quite possible that as the macro-economy has oscillated between strong and weak periods, there has been a concentrating, and then a deconcentrating, of the highly deprived into and then out of highly deprived areas. Twenty-two years is a long enough period to contain more than one cycle of expanding and contracting in the macro economy.

It might also be possible that my monocentric assumptions are affecting my analysis. Wellington is to some extent a polycentric metropolitan area, with Porirua, Lower Hutt and Upper Hutt all standalone cities, alongside Wellington city. Across the 1991-2013 period, I see a decrease in the proportion of highly deprived meshblocks in the second distance band. This second distance band is where Porirua City and Lower Hutt are located. Certainly, in areas closer to the waterfront such as Petone, the maps confirm that there is a decrease in the concentration of highly deprived meshblocks from this area and anecdotal confirmation of gentrification. These two cities' development might be an explanation for the perceived lack of a shift from the city centre.

I should also note that I see in Wellington increases in the proportion of highly deprived meshblocks and the proportion of population concentrated within these areas to be increasing over this period in the distance bands beyond the $10-20 \mathrm{~km}$ range. This supports the hypothesis that the poor are suburbanising. However, it does not fully support the hypothesis of this particular chapter that there is a shift away from the centre of the city and into the middle and outer suburbs. 


\subsection{Summary}

In this chapter, I introduced the 2017 study by Randolph and Tice that looked at the shifting spatial distribution of disadvantage in Australia's five biggest cities. I started with this study as a departure point for my own analysis because it was the only study that I found using an aggregate variable that measures multiple facets of the poor, and not just income related variables. Additionally, studies have not often compared Australian cities to New Zealand; however, they share similar histories in their establishments and developments. It is interesting to compare the similarities and differences between the two New Zealand cities, and the five Australian cities.

Next, I started my analysis based on Randolph and Tice's methodology. My expectation was that because Randolph and Tice found a shift away from the city centre of 'disadvantage' in Australian cities, that I would find a similar pattern. I expected a shift away from the city centre of 'deprivation' in New Zealand cities. In my analysis of Auckland, I confirmed this expectation. However, in my analysis of Wellington, the shift was not so clear. There was a shift in the proportion of population concentrated in highly deprived areas, but there was an increase in the number of highly deprived areas within the first $10 \mathrm{~km}$ of the city centre. This finding for Wellington went against my expectations and against the Australian evidence discussed previously in the chapter. However there a few explanations offered. In this next two analysis chapters, I hope to tease out the subtleties that characterise Wellington. 
Chapter Five: Temporal differences in the distribution of deprivation in Wellington and Auckland, New Zealand 1991-2006 and 2006 -2013.

\subsection{Introduction}

In times of economic downturn, households must make tough decisions with their spending choices. Housing expenditure, which is already a proportionately high cost in a household's budget, can increase even more in real terms. Households, particularly poor households, must choose between decreasing their housing consumption (especially space) or their housing location. One way to achieve this is by moving into areas that are deprived, as they are cheaper areas to live in. In times of economic upturn, households can locate away from deprived areas because they can afford to. Of course, economic upturn can complicate houses choices too. For example, during economic upturn, there may be increases in immigration which can push up house prices and/or rents. However, Stillman and Mare (2008) found no evidence to suggest an inflow of foreign-born immigrants to an area are positively related to local house prices in New Zealand.

In this chapter, I will investigate how the spatial distribution and concentration of deprivation differ between strong and weak macroeconomic periods.

In the previous chapter, between 1991 and 2013, I found that in Auckland there was a decrease in the percentage of meshblocks within $10 \mathrm{~km}$ of the city centre considered 'highly deprived'. By 'highly deprived', I mean that meshblocks had a deprivation score at or beyond one standard deviation above the mean score for New Zealand. Simultaneously, I found that across this same period, there was an increase in the percentage of highly deprived meshblocks in the middle and outer distance bands $(10-50 \mathrm{~km})$. This was matched with an increase in the proportion of population within these highly deprived meshblocks. By that, I mean the population change between 1991 and 2013 concentrated proportionately more in highly deprived meshblocks, than non-deprived meshblocks.

However, I found that, between 1991 and 2013, Wellington saw an increase in the percentage of meshblocks within $10 \mathrm{~km}$ of the city centre considered 'highly 
deprived'. I also found that Wellington saw a decrease in the percentage of highly deprived meshblocks between $10-20 \mathrm{~km}$ and saw an increase $20-50 \mathrm{~km}$ out.

In this chapter, I will go into detail and investigate the changes in deprivation for Wellington and Auckland across two different periods. The purpose of this next step is to characterise whether varying strengths in the economy have changed the concentration of disadvantaged populations. The previous chapter looked at levels of deprivation at the start point and end of a twenty-two year period. This chapter makes the argument that there is likely to be fluctuations in these levels mirroring changes in the economy.

The strength (or lack of strength) of the economy is an important aspect to consider because it contextualises the decisions households make. This chapter comes in three sections. First, this chapter argues conceptually why there might be differing levels in the concentration of deprivation at different points in time across a longer period. Second, this chapter contextualises the national, regional and urban variations in economic structure for Wellington and Auckland. Third, this chapter empirically analyses the differences between two periods deemed to have different economic contexts.

\subsection{Conceptualising the problem}

The relevant question for this chapter is whether the deprived reduce their sensitivity to concentrating in deprived areas as the strength of the macro-economy falls. If so, we would see an increase in the proportion of deprived people living within deprived areas. Alternatively, do the deprived increase their sensitivity to concentrating in deprived areas when the macro-economy is strong. At times of economic strength, we would see a greater dispersion of the deprived, and presumably a lower proportion of the deprived living in deprived areas.

In the previous chapter, we have already observed that there has been a change in the distribution of deprived areas over a twenty-two year timeframe. Deprived areas are deemed deprived because of who is contained within them, namely deprived people. However, the concentration of these deprived people within these deprived areas may also differ. 
The logic follows that at times of economic hardship, the deprived have very limited options in terms of the decision on where they locate. The least expensive locations are the areas where the deprived will tend to locate. However, in times of relative economic strength, the deprived have more options for where they locate.

A strong national economy is one that is growing and absorbs labour and lowers the unemployment and underemployment rate. A weak national economy is the reverse; its growth slows, employers can lay people off, and the amount of work available shrinks. These are important distinctions because people must adjust to these conditions by moving location (among other things). The deprived are more sensitive to these macroeconomic fluctuations than most and therefore the deprived areas they live in see a higher level of turnover when the economy is shrinking (relatively).

The proxy I use to determine macro-economic strength might come in several forms. The national or regional unemployment rate (see Figure 5.1), the employment rate, the underutilisation rate or the labour force participation rate are all commonly used measures when talking about the strength of the economy.

\subsection{Temporal context}

It is important to situate the concentration of deprived populations within their specific urban and regional housing contexts. National and regional variations in economic condition, combined with differences in neighbourhood history, development, and population composition, make it difficult to identify an increase or decrease in not only the concentration, but the distribution of deprived areas and the populations contained within them.

The onset of the 2008 global financial crisis (GFC) was a crucial event that has played a key role in exacerbating existing inequalities and creating new ones. However, it is unclear how this has played out in the space of urban centres, specifically in relation to urban poverty or deprivation. Various patterns are possible. The expanding and contracting periods - both preceding and following the start of the GFC - may be characterised by substantial shifts in deprivation or urban poverty. These changes could also either be accelerating or slowing down. Alternatively, urban trends occurring during the boom period may see a reversal or annihilation during the bust period. 
During expanding periods, gentrification generally progresses the most vigorously, while the process slows during economic contracting periods. The GFC exacerbated inequalities and it is likely to have had a profoundly negative effect on the housing position of various population groups, in particular, the growing group of those hit by unemployment, precarious employment situations, and growing household debt. This group faces decreasing access to homeownership and depends on a shrinking affordable social rental sector, or increasingly costly private rental housing.

At the level of the neighbourhood, this may have several consequences. The most affordable neighbourhoods in an urban-regional system may increasingly serve relatively low-income residents, thus amplifying already existing trajectories of neighbourhood decline (Zwiers, Bolt, Van Ham, \& Van Kempen, 2016).

\section{Figure 5.1. Male unemployment rate for New Zealand, 1987 to 2017}

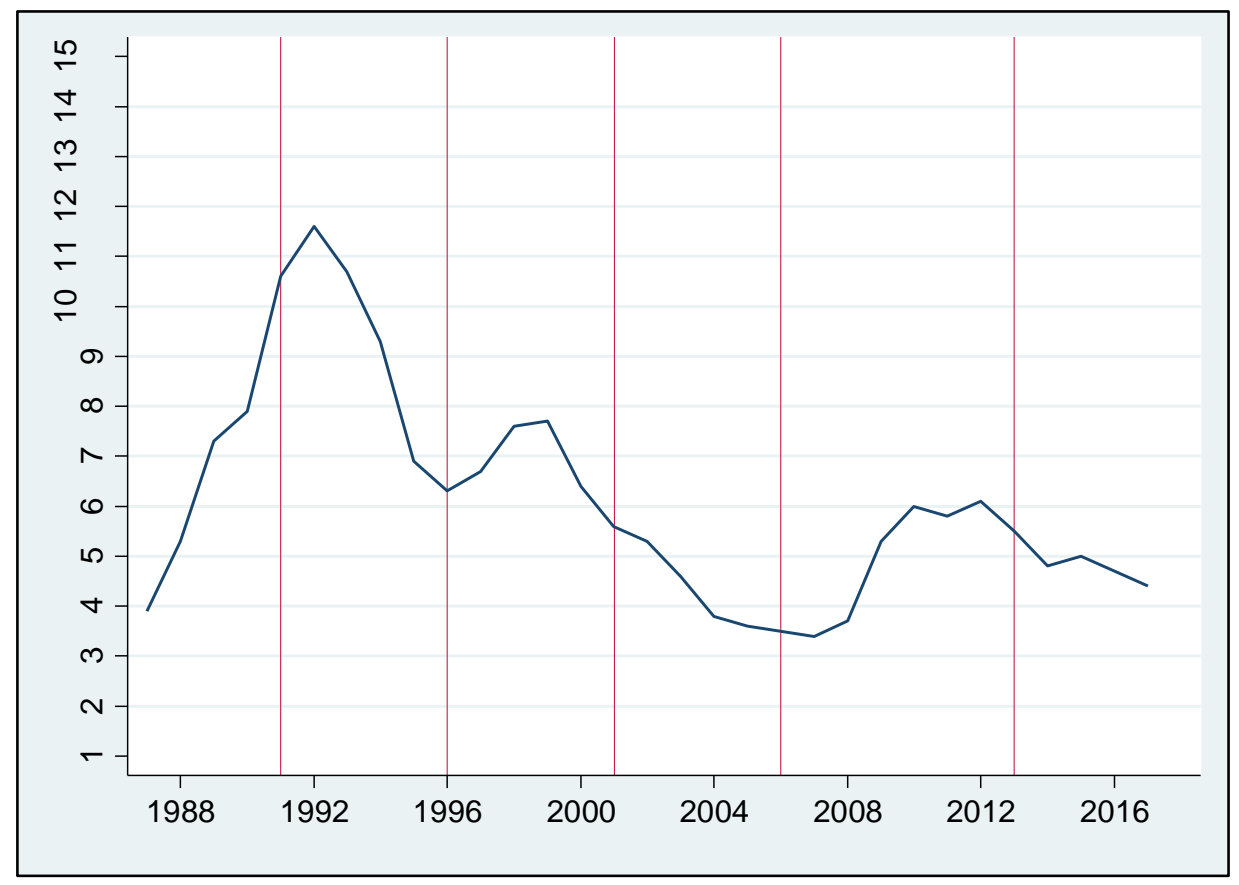

Figure 5.2 shows the male unemployment rate for the Auckland and Wellington Regions, with the red lines depicting the census dates (data starting from 1987, with census on 1991, 1996, 2001, 2006, 2013). It suggests that Auckland's labour force is more sensitive to changes in labour demand. The amplitude of the male unemployment rates is greater as the following figures show (the standard deviation 
is much higher in Auckland) and average unemployment rate over the 31 years is also higher.

Table 5.1 Mean and standard deviation of the unemployment rate for Auckland and Wellington, 1987 to 2017.

\begin{tabular}{|c|c|c|c|c|c|}
\hline Variable & Obs & Mean & Std. Dev. & Min & Max \\
\hline $\begin{array}{l}\text { Unemployment } \\
\text { rate Auckland }\end{array}$ & 31 & 5.983871 & 2.509063 & 2.7 & 13.2 \\
\hline $\begin{array}{c}\text { Unemployment } \\
\text { rate Wellington }\end{array}$ & 31 & 5.874194 & 1.871357 & 2.8 & 10.4 \\
\hline
\end{tabular}

The higher average and amplitude of unemployment in the Auckland labour market was especially noticeable during the recession of the early 1990s when the Auckland unemployment rate was almost three percent higher than Wellington's. Again, during the $2008-2010$ recession the Auckland rate was almost two percent higher at its widest point.

Figure 5.2. Male unemployment rate for Auckland and Wellington, 1987 to 2017

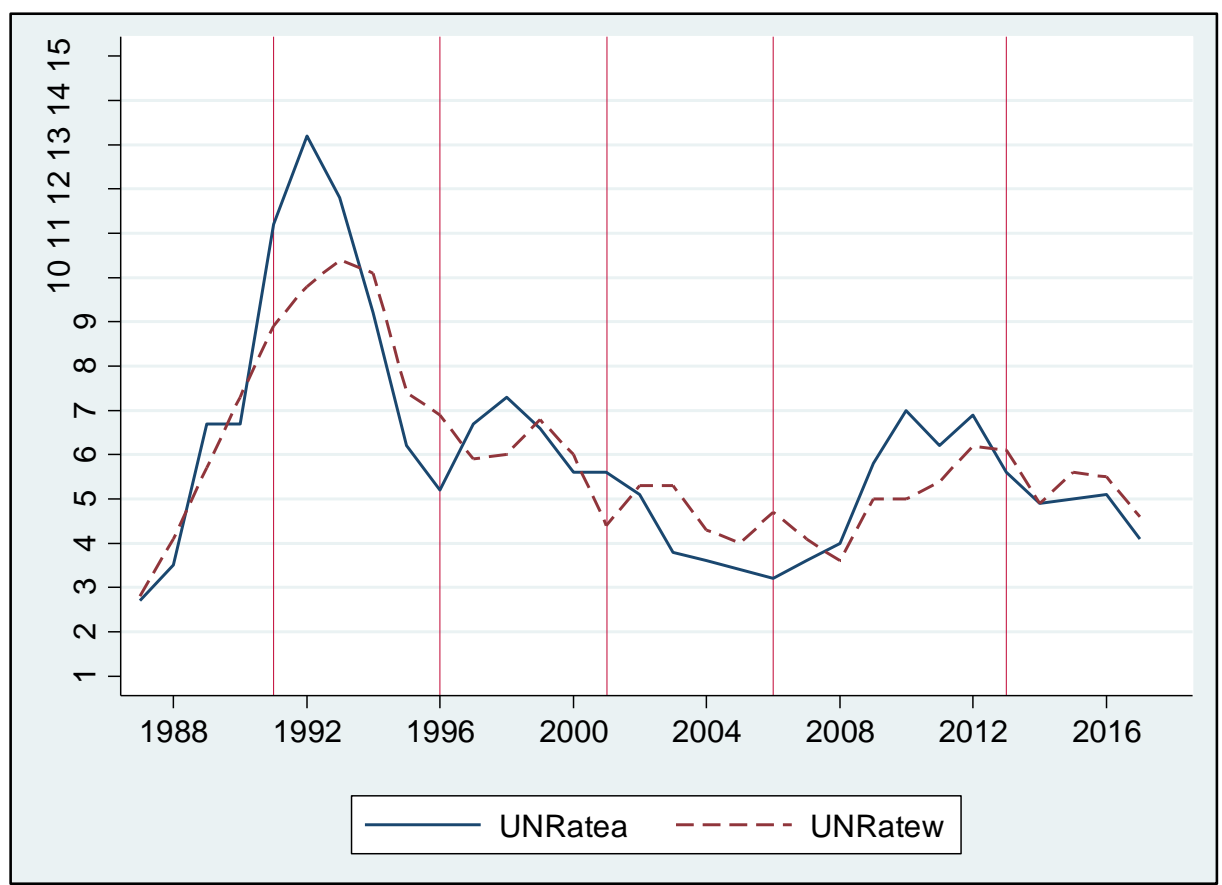




\subsection{Distribution of deprivation in Wellington and Auckland}

We now turn our focus to analysing the change in highly deprived areas in

Wellington and Auckland for two different periods. The first period chosen is 19912006. This period was chosen for two reasons. First, 1991 is the date of the earliest publicly available data for deprivation in New Zealand. Second, as observed in the previous section, the 1991 census corresponded with indicators such as unemployment pointing to a weak macro economy. Conversely, 2006 corresponded with indictors pointing to a strong macro economy. This period is the "expanding" economy period that I am testing.

The second period chosen is directly after the first period, 2006-2013. The GFC occurred shortly after the 2006 census. This crisis corresponded with a sharp increase in adverse macro indicators such as the unemployment rate. Unfortunately, the 2011 census was cancelled due to the Canterbury earthquake. This would have provided a clearer look at how the distribution and concentration of deprived areas responded directly after a "contracting" period, without time for the economy to recover. 2013 was the next census and was also the latest publicly available data for deprivation in New Zealand.

As in the previous chapter, I first want to know how the population in highly deprived areas has changed, by now focussing on our boom and bust periods. Tables 5.2 and 5.3 below were constructed from the overall population contained within highly deprived meshblocks. This population data was then separated into $10 \mathrm{~km}$ bands, out to a maximum of $50 \mathrm{~km}$. This separation allows me to observe large scale changes in the levels of population contained within highly deprived meshblocks.

Table 5.2 shows the first period I am observing, 1991-2006. Going from a weak macro economy in the early 1990s to a strong macro economy in the mid-2000s, I would expect to see a reduction of population in deprived areas that had previously contained high populations.

There are three important observations to note. First, there is an increase in the population within highly deprived areas for every $10 \mathrm{~km}$ band, and in total, for both Wellington and Auckland. The only exception to this is within the first $10 \mathrm{~km}$ band in 
Auckland. Second, due to the constrained spread of the Wellington region, there is a population in highly deprived areas of about 6000 outside of the first $50 \mathrm{~km}$ from the city centre in 1991 and increases to 7300 by 2006. Third, Wellington sees a $33.84 \%$ increase of population in highly deprived meshblocks within the first $10 \mathrm{~km}$, whereas Auckland sees a $0.11 \%$ decrease in this same distance band.

Table 5.2. Population change in deprived locations in $10 \mathrm{~km}$ bands for Wellington and Auckland, 1991 and 2006

\begin{tabular}{|c|c|c|c|}
\hline Distance band & Wellington & Auckland & Total \\
\hline \multicolumn{4}{|l|}{1991} \\
\hline$<10 \mathrm{~km}$ & 8802 & 54438 & 63240 \\
\hline $10-19 \mathrm{~km}$ & 35853 & 73461 & 109314 \\
\hline $20-29 \mathrm{~km}$ & 1908 & 27048 & 28956 \\
\hline $30-39 \mathrm{~km}$ & 270 & 3033 & 3303 \\
\hline $40-49 \mathrm{~km}$ & 591 & 2427 & 3018 \\
\hline Total & 47424 & 160407 & 207831 \\
\hline $\begin{array}{c}\text { Total in region } \\
\mathbf{2 0 0 6}\end{array}$ & 53229 & 161088 & 214317 \\
\hline$<10 \mathrm{~km}$ & 11781 & 54378 & 66159 \\
\hline $10-19 \mathrm{~km}$ & 37836 & 99636 & 137472 \\
\hline $20-29 \mathrm{~km}$ & 2340 & 46635 & 48975 \\
\hline $30-39 \mathrm{~km}$ & 651 & 4053 & 4704 \\
\hline $40-49 \mathrm{~km}$ & 873 & 4815 & 5688 \\
\hline Total & 53481 & 209517 & 262998 \\
\hline \multicolumn{4}{|l|}{ 1991-2006 } \\
\hline \multicolumn{4}{|l|}{ Absolute } \\
\hline$<10 \mathrm{~km}$ & 2979 & -60 & 2919 \\
\hline $10-19 \mathrm{~km}$ & 1983 & 26175 & 28158 \\
\hline $20-29 \mathrm{~km}$ & 432 & 19587 & 20019 \\
\hline $30-39 \mathrm{~km}$ & 381 & 1020 & 1401 \\
\hline $40-49 \mathrm{~km}$ & 282 & 2388 & 2670 \\
\hline Total & 6057 & 49110 & 55167 \\
\hline Total in region & 7383 & 50250 & 57633 \\
\hline \multicolumn{4}{|l|}{ Percent } \\
\hline$<10 \mathrm{~km}$ & 33.84 & -0.11 & 4.62 \\
\hline $10-19 \mathrm{~km}$ & 5.53 & 35.63 & 25.76 \\
\hline $20-29 \mathrm{~km}$ & 22.64 & 72.42 & 69.14 \\
\hline $30-39 \mathrm{~km}$ & 141.11 & 33.63 & 42.42 \\
\hline $40-49 \mathrm{~km}$ & 47.72 & 98.39 & 88.47 \\
\hline Total & 12.77 & 30.62 & 26.54 \\
\hline Total in region & 13.87 & 31.19 & 26.89 \\
\hline
\end{tabular}


Table 5.3 shows the second period I am observing, 2006-2013. Going from a strong macro economy in the mid-2000s to a weaker macro economy in the early 2010s, I would expect to see an increase of population in areas that had previously contained highly deprived populations.

There are two major observations to note. First, there is a big difference in the experiences of Wellington and Auckland. Wellington sees an overall reduction in population contained within highly deprived meshblocks, while Auckland sees an increase in this population over the period. However, both see increases of population contained with highly deprived meshblocks in the middle-distance bands; for Wellington, increases in population for the $20-50 \mathrm{kms}$ bands, and for Auckland, increase in the $10-40 \mathrm{~km}$ bands. Second, Auckland sees both large absolute and percentage increases in the $10-30 \mathrm{~km}$ range, distances which had previously contained almost three quarters of the population in highly deprived meshblocks. Conversely, Wellington saw reductions in the $0-20 \mathrm{~km}$ distance bands; distances that had previously contained more than $80 \%$ of the population in highly deprived meshblocks. 
Table 5.3. Population change in deprived locations in $10 \mathrm{~km}$ bands for

Wellington and Auckland, 2006 and 2013

\begin{tabular}{|c|c|c|c|}
\hline Distance band & Wellington & Auckland & Total \\
\hline \multicolumn{4}{|l|}{2006} \\
\hline$<10 \mathrm{~km}$ & 11781 & 54378 & 66159 \\
\hline $10-19 \mathrm{~km}$ & 37836 & 99636 & 137472 \\
\hline $20-29 \mathrm{~km}$ & 2340 & 46635 & 48975 \\
\hline $30-39 \mathrm{~km}$ & 651 & 4053 & 4704 \\
\hline $40-49 \mathrm{~km}$ & 873 & 4815 & 5688 \\
\hline Total & 53481 & 209517 & 262998 \\
\hline $\begin{array}{c}\text { Total in region } \\
2013\end{array}$ & \multicolumn{2}{|c|}{2013} & 271950 \\
\hline$<10 \mathrm{~km}$ & 8577 & 53520 & 62097 \\
\hline $10-19 \mathrm{~km}$ & 35277 & 113958 & 149235 \\
\hline $20-29 \mathrm{~km}$ & 3255 & 59916 & 63171 \\
\hline $30-39 \mathrm{~km}$ & 837 & 4488 & 5325 \\
\hline $40-49 \mathrm{~km}$ & 1506 & 4626 & 6132 \\
\hline Total & 49452 & 236508 & 285960 \\
\hline $\begin{array}{c}\text { Total in region } \\
\mathbf{2 0 0 6 - 2 0 1 3}\end{array}$ & 57444 & 237831 & 295275 \\
\hline \multicolumn{4}{|l|}{ Absolute } \\
\hline$<10 \mathrm{~km}$ & -3204 & -858 & -4062 \\
\hline $10-19 \mathrm{~km}$ & -2559 & 14322 & 11763 \\
\hline $20-29 \mathrm{~km}$ & 915 & 13281 & 14196 \\
\hline $30-39 \mathrm{~km}$ & 186 & 435 & 621 \\
\hline $40-49 \mathrm{~km}$ & 633 & -189 & 444 \\
\hline Total & -4029 & 26991 & 22962 \\
\hline Total in region & -3168 & 26493 & 23325 \\
\hline \multicolumn{4}{|l|}{ Percent } \\
\hline$<10 \mathrm{~km}$ & -27.20 & -1.58 & -6.14 \\
\hline $10-19 \mathrm{~km}$ & -6.76 & 14.37 & 8.56 \\
\hline $20-29 \mathrm{~km}$ & 39.10 & 28.48 & 28.99 \\
\hline $30-39 \mathrm{~km}$ & 28.57 & 10.73 & 13.20 \\
\hline $40-49 \mathrm{~km}$ & 72.51 & -3.93 & 7.81 \\
\hline Total & -7.53 & 12.88 & 8.73 \\
\hline Total in region & -5.23 & 12.54 & 8.58 \\
\hline
\end{tabular}

Next, I introduce the location quotient to see how the proportion of population is concentrating in highly deprived areas. Refer to the fifth section in chapter three for a more comprehensive breakdown on the variable.

$$
L Q=\frac{(X / Y)_{\text {distance band }}}{\left(X^{\prime} / Y^{\prime}\right)_{\text {region }}}
$$


A location quotient can show the concentration of the population in highly deprived areas controlling for where the general population is concentrated. In other words, I can see if different distance bands contain disproportionate number of people in highly deprived meshblocks, rather than just looking at areas that contain most of the population.

Regarding Table 5.4, there are a few important observations. First, across two time periods, the first distance band does not contain disproportionate numbers of the population within highly deprived meshblocks for either city. However, while in the case of Auckland where there is a decrease in the location quotient ratio for this first distance band across both periods, Wellington sees an increase in the proportion of population in highly deprived meshblocks for the first period, and a decrease for the second period.

Secondly, for both periods, Wellington sees increases in the proportion of population in highly deprived meshblocks for all distance bands except the first distance band in the second period. For the first period, this observation suggests that while there was an increase in the population within highly deprived meshblocks, the increase was relatively widely dispersed in and away from the city centre (i.e. not concentrated in one general area). In the second period, I see a decrease in the location quotient for the first distance in Wellington but increases in the next four distance bands. Furthermore, I see a decrease in the first $50 \mathrm{~km}$ distance band. This indicates that there has been an increase in the population of highly deprived meshblocks outside the first $50 \mathrm{~km}$ of the region.

Third, across both periods in Auckland, the distance band with the biggest proportional increase is the third distance band, with the second distance band stable. The fourth and fifth distance bands stay relatively similar across both periods. 
Table 5.4. Location quotients for disadvantaged populations for Wellington and Auckland, 1991, 2006 and 2013.

\begin{tabular}{|c|c|c|c|}
\hline Distance band & Wellington & Auckland & Total \\
\hline \multicolumn{4}{|l|}{1991} \\
\hline$<10 \mathrm{~km}$ & 0.47 & 0.84 & 0.76 \\
\hline $10-19 \mathrm{~km}$ & 2.06 & 1.12 & 1.32 \\
\hline $20-29 \mathrm{~km}$ & 0.32 & 1.34 & 1.11 \\
\hline $30-39 \mathrm{~km}$ & 0.12 & 0.60 & 0.45 \\
\hline $40-49 \mathrm{~km}$ & 0.18 & 0.54 & 0.37 \\
\hline First $50 \mathrm{~km}$ & 1.01 & 1.00 & 1.01 \\
\hline \multicolumn{4}{|l|}{2006} \\
\hline$<10 \mathrm{~km}$ & 0.52 & 0.69 & 0.65 \\
\hline $10-19 \mathrm{~km}$ & 2.14 & 1.13 & 1.31 \\
\hline $20-29 \mathrm{~km}$ & 0.36 & 1.63 & 1.40 \\
\hline $30-39 \mathrm{~km}$ & 0.29 & 0.60 & 0.52 \\
\hline $40-49 \mathrm{~km}$ & 0.20 & 0.63 & 0.46 \\
\hline First $50 \mathrm{~km}$ & 1.01 & 1.01 & 1.01 \\
\hline \multicolumn{4}{|l|}{2013} \\
\hline$<10 \mathrm{~km}$ & 0.40 & 0.61 & 0.56 \\
\hline $10-19 \mathrm{~km}$ & 2.21 & 1.14 & 1.30 \\
\hline $20-29 \mathrm{~km}$ & 0.54 & 1.82 & 1.63 \\
\hline $30-39 \mathrm{~km}$ & 0.41 & 0.59 & 0.54 \\
\hline $40-49 \mathrm{~km}$ & 0.37 & 0.61 & 0.49 \\
\hline First $50 \mathrm{~km}$ & 0.97 & 1.00 & 1.00 \\
\hline
\end{tabular}

Observing both periods for both cities tells a complicated story. It also shows how the experiences of Wellington and Auckland are different. This may be related to how sensitive each city is to changes in the macro economy. As I observed in the previous section, I expect Wellington to be less sensitive to changes in labour demand than Auckland is.

\subsubsection{Wellington}

Based on the analysis in my previous chapter, I found that Wellington saw a very slight increase in the percentage of highly deprived meshblocks (meshblocks at or beyond one standard deviation above the national mean deprivation score) within the first 10km between 1991 and 2013. This was opposite to my expectation. I also found a decrease in the proportion of the population in those meshblocks when compared with the general population. Based on this finding, I was curious to know 
whether this increase in percentage of highly deprived meshblocks was a linear transition, or whether there were fluctuations over this period.

This analysis that follows looks at the period from 1991 to 2006, and then 2006 to 2013. These periods chosen are closest to matching changes in the macroeconomic conditions of the country. The period 1991 to 2006 is when the economy is in a state of "expanding", and I would therefore expect there to be a lower proportion of the population concentrating in the highly deprived meshblocks. I would also expect that the number of highly deprived meshblocks would decrease nearer the city.

I calculated highly deprived meshblocks as meshblocks at or beyond one standard deviation of the national mean deprivation score. Figure 5.3 plots the percentage of all highly deprived meshblocks in Wellington across $1 \mathrm{~km}$ bands for 1991 and 2006, up to a maximum of $50 \mathrm{~km}$. I chose $50 \mathrm{~km}$ as the maximum distance in this chapter, for easy comparability between Wellington and Auckland. In Figure 5.3, it looks like there is a decrease in the proportion of highly deprived meshblocks over $2-12 \mathrm{~km}$, with very tiny increases from $13-20 \mathrm{~km}$.

Figure 5.4 also illustrates these findings, where it plots the percentage of all highly deprived meshblock in Wellington in 10km bands for 1991 and 2006, up to a maximum of $50 \mathrm{~km}$. There is about a $4 \%$ point decrease in the first $10 \mathrm{~km}$ and a slight increase in the second band. However, the second distance band, $10-20 \mathrm{~km}$, is still home to the majority of highly deprived meshblocks. 
Figure 5.3. Spatial distribution of highly deprived meshblocks in Wellington, 1991-2006.

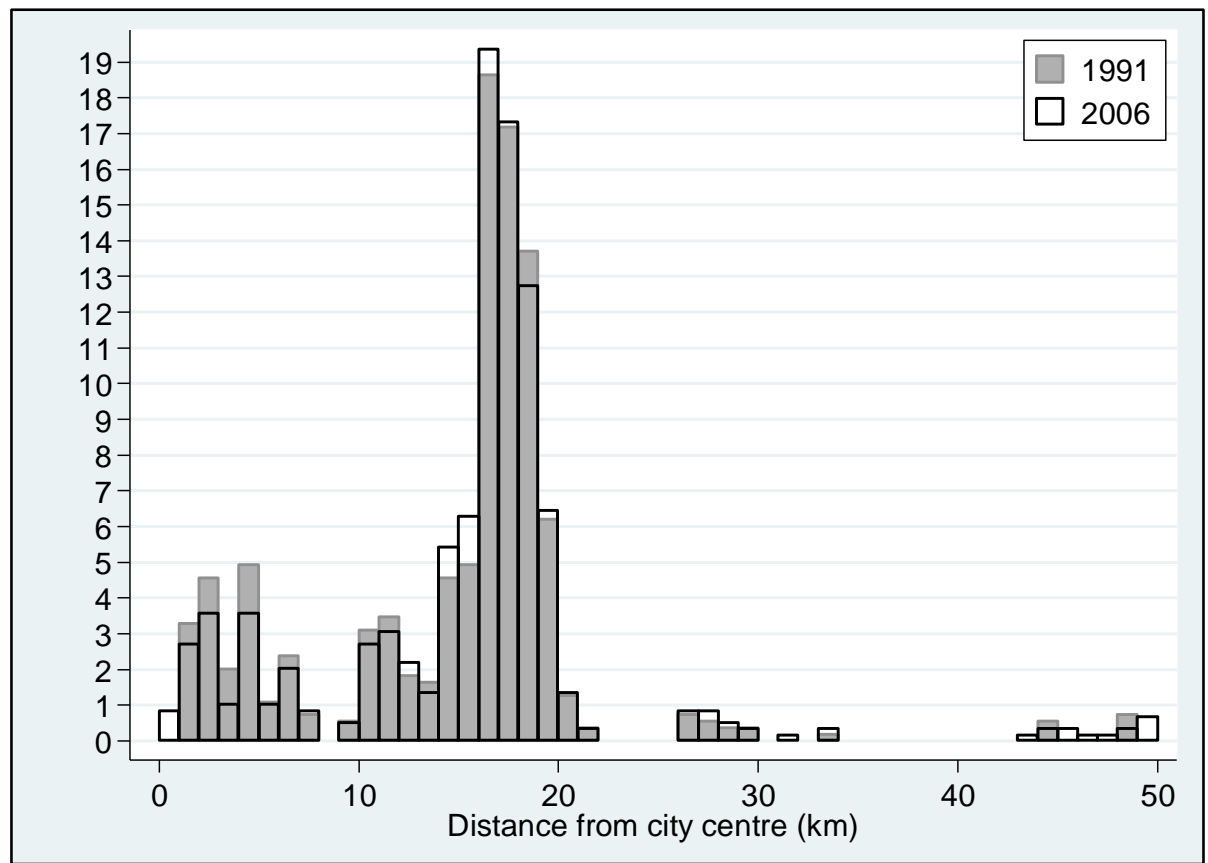

Figure 5.4. Spatial distribution of highly deprived meshblocks in Wellington, 1991-2006.

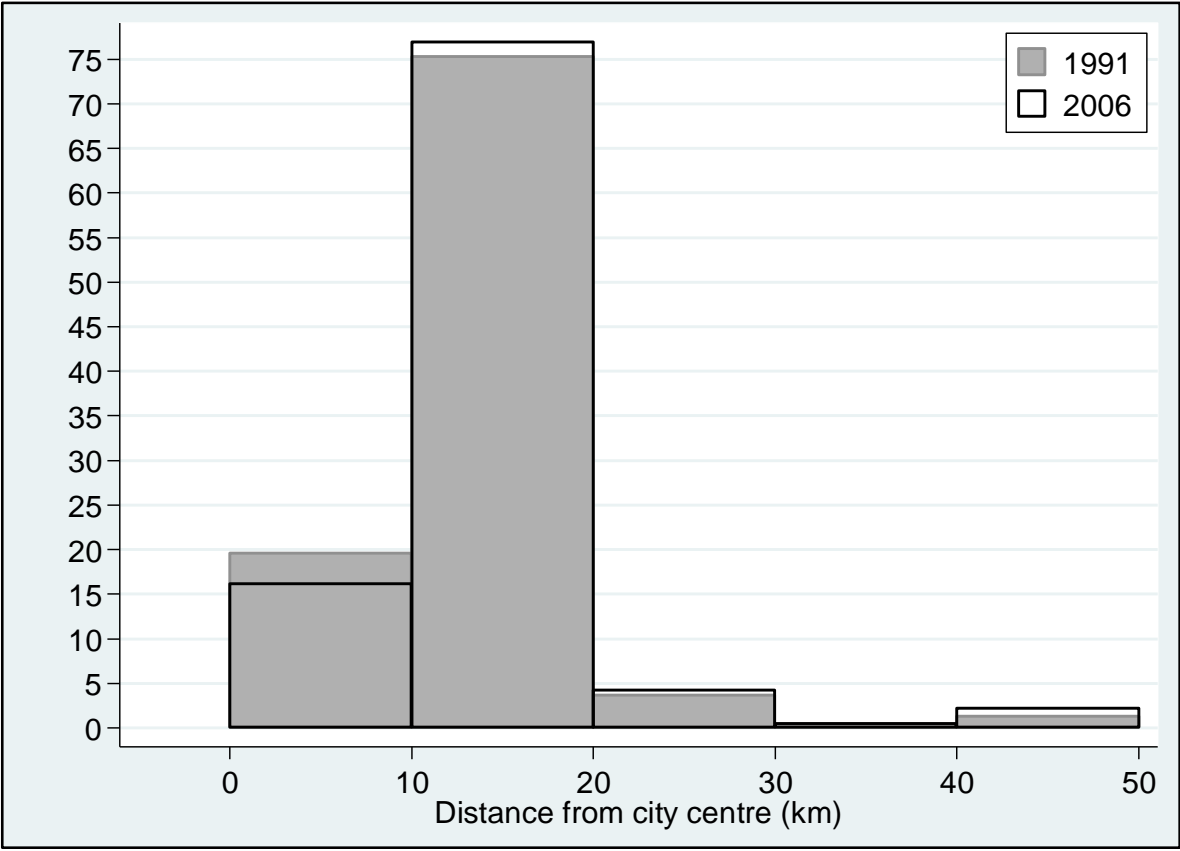

Next, I look at the second period in this analysis, the contracting macro-economic period. The period 2006 to 2013 corresponds with when the economy is in a state of "contracting", and I would therefore assume there to be a higher proportion of the 
population concentrating in the highly deprived meshblocks. I would also expect that the number of highly deprived meshblocks would increase nearer the city.

Figure 5.5 plots the percentage of all highly deprived meshblocks in Wellington across $1 \mathrm{~km}$ bands for 2006 and 2013, up to a maximum of 50km. In Figure 5.5, it looks like there is an increase in the proportion of highly deprived meshblocks over $1-6 \mathrm{~km}$, with large decreases from $15-20 \mathrm{~km}$. There are also small increases from 21 $50 \mathrm{~km}$.

Figure 5.5. Spatial distribution of highly deprived meshblocks in Wellington, 2006-2013.

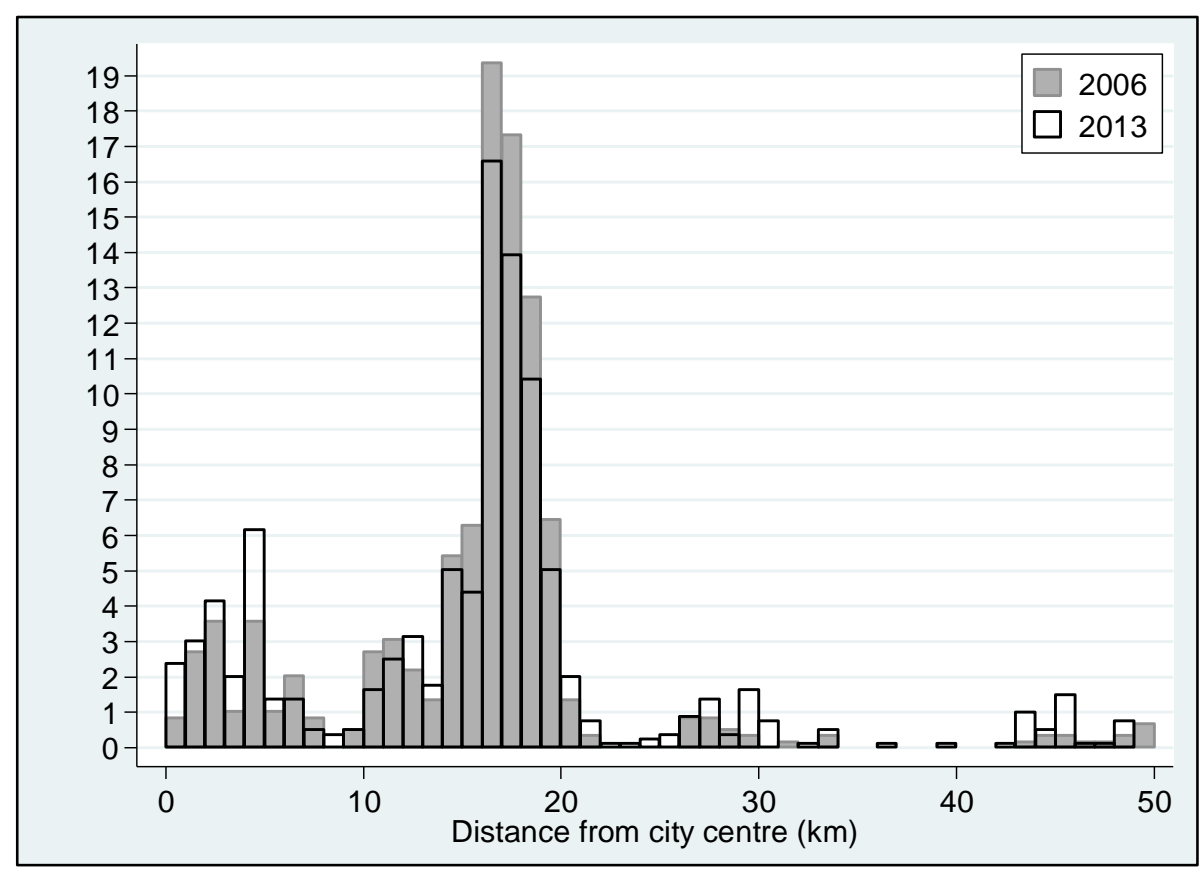

Figure 5.6 also illustrates these findings, where it plots the percentage of all highly deprived meshblock in Wellington in 10km bands for 2006 and 2013, up to a maximum of $50 \mathrm{~km}$. There is about a $6 \%$ point increase in the first $10 \mathrm{~km}$ and a large decrease in the second band. The second distance band, $10-20 \mathrm{~km}$, is still home to the majority of highly deprived meshblocks. However, there are small increases in the three distance bands beyond it, $20-50 \mathrm{~km}$. 
Figure 5.6. Spatial distribution of highly deprived meshblocks in Wellington, 2006-2013.



To examine the geographic locations of this change in the spatial distribution of the highly deprived meshblocks, I have constructed some maps with the locations. The shading for each meshblock indicates the level of deprived population contained within (the darker, the more the population is deprived). Looking at Figure 5.7, there does not appear to be a great change. There is perhaps a decrease in the prevalence of highly deprived meshblocks in the first $10 \mathrm{~km}$ ring, near the city centre. However, that area was already quite sparse in comparison to the second ring. There is a clear darkening around Porirua, the northern cluster of darkly shaded highly deprived meshblocks. This suggests that there has been an increase in the proportion of the deprived population concentrating in that area.

Turning to Figure 5.8, there is a slight difference between 2006 on the left and 2013 on the right. There is a lightening in most locations, which suggests that there is a decrease in the proportion of population concentrating in highly deprived meshblocks. In particular, the lightening is very noticeable in the second distance band. Both Porirua, the northern grouping, and Lower Hutt, the North-eastern grouping, show a lightening, and in some cases a disappearance of highly deprived meshblocks. 
Figure 5.7. Spatial distribution of highly deprived meshblocks in Wellington, 1991 and 2006



Figure 5.8. Spatial distribution of highly deprived meshblocks in Wellington, 2006 and 2013

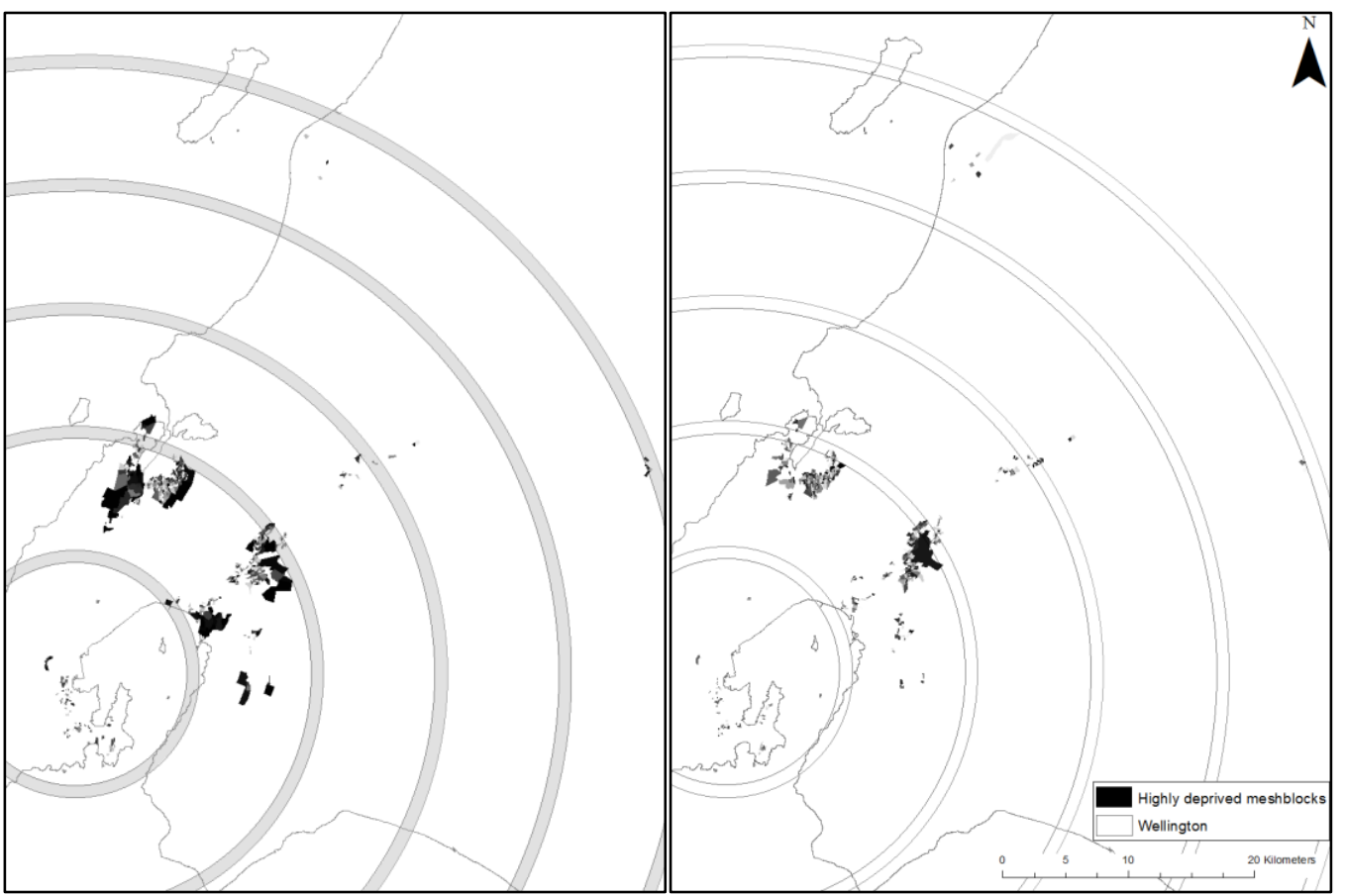

From the Wellington experience, I have shown that there was a distinct difference across the two periods corresponding with strong and weak macroeconomic conditions. During the expanding period, there was a decrease in the highly deprived 
meshblocks within the first $10 \mathrm{~km}$ of Wellington's city centre, and an increase in the proportion of population concentrated in those highly deprived meshblocks. This suggests that during strong macroeconomic conditions, there is a subset of the population who become more concentrated in highly deprived areas. They might attain this through crowding or through living in poor quality dwellings.

\subsubsection{Auckland}

Based on the analysis in my previous chapter, I found that Auckland saw a decrease in the percentage of highly deprived meshblocks (meshblocks at or beyond one standard deviation above the national mean deprivation score) within the first $10 \mathrm{~km}$ between 1991 and 2013. This was in line with my expectations and in line with the international evidence. I also found a decrease in the proportion of the population in those meshblocks when compared with the general population. I was curious to know whether this increase in percentage of highly deprived meshblocks was a linear transition, or whether there were fluctuations over this period, as it appears Wellington experienced.

This analysis that follow looks at the periods from 1991 to 2006, and then 2006 to 2013. These periods chosen are closest to matching changes in the macroeconomic conditions of the country. The period 1991 to 2006 is when the economy is in a state of "expanding", and I would therefore assume there to be a lower proportion of the population concentrating in the highly deprived meshblocks. I would also expect that the number of highly deprived meshblocks would decrease nearer the city.

I calculated highly deprived meshblocks as meshblocks at or beyond one standard deviation of the national mean deprivation score. Figure 5.9 plots the percentage of all highly deprived meshblocks in Auckland across 1km bands for 1991 and 2006, up to a maximum of $50 \mathrm{~km}$. I chose $50 \mathrm{~km}$ as the maximum distance in this chapter, for easy comparability between Wellington and Auckland. In Figure 5.9, it looks like there is a large decrease in the proportion of highly deprived meshblocks over 3$11 \mathrm{~km}$, with very large increases from $14-25 \mathrm{~km}$.

Figure 5.10 also illustrates these findings, where it plots the percentage of all highly deprived meshblocks in Auckland in 10km bands for 1991 and 2006, up to a maximum of $50 \mathrm{~km}$. There is about a $16 \%$ point decrease in the first $10 \mathrm{~km}$ and a $5 \%$ 
point increase in the second band. The second distance band, $10-20 \mathrm{~km}$, over this time period becomes home to the majority of highly deprived meshblocks. There was also an $8 \%$ point increase in the third $10 \mathrm{~km}$ distance band.

Figure 5.9. Spatial distribution of highly deprived meshblocks in Auckland, 1991-2006.

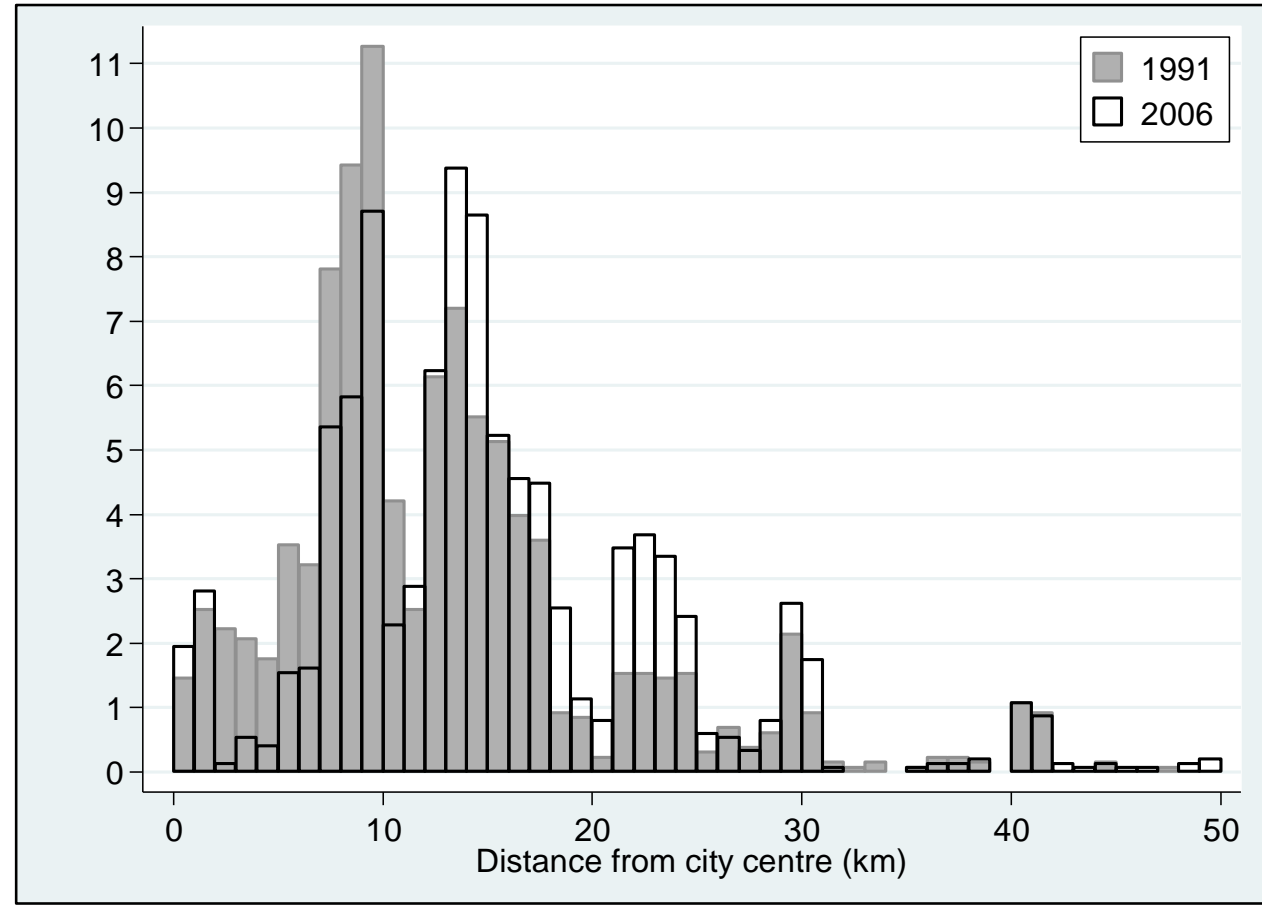

Figure 5.10. Spatial distribution of highly deprived meshblocks in Auckland, 1991-2006.

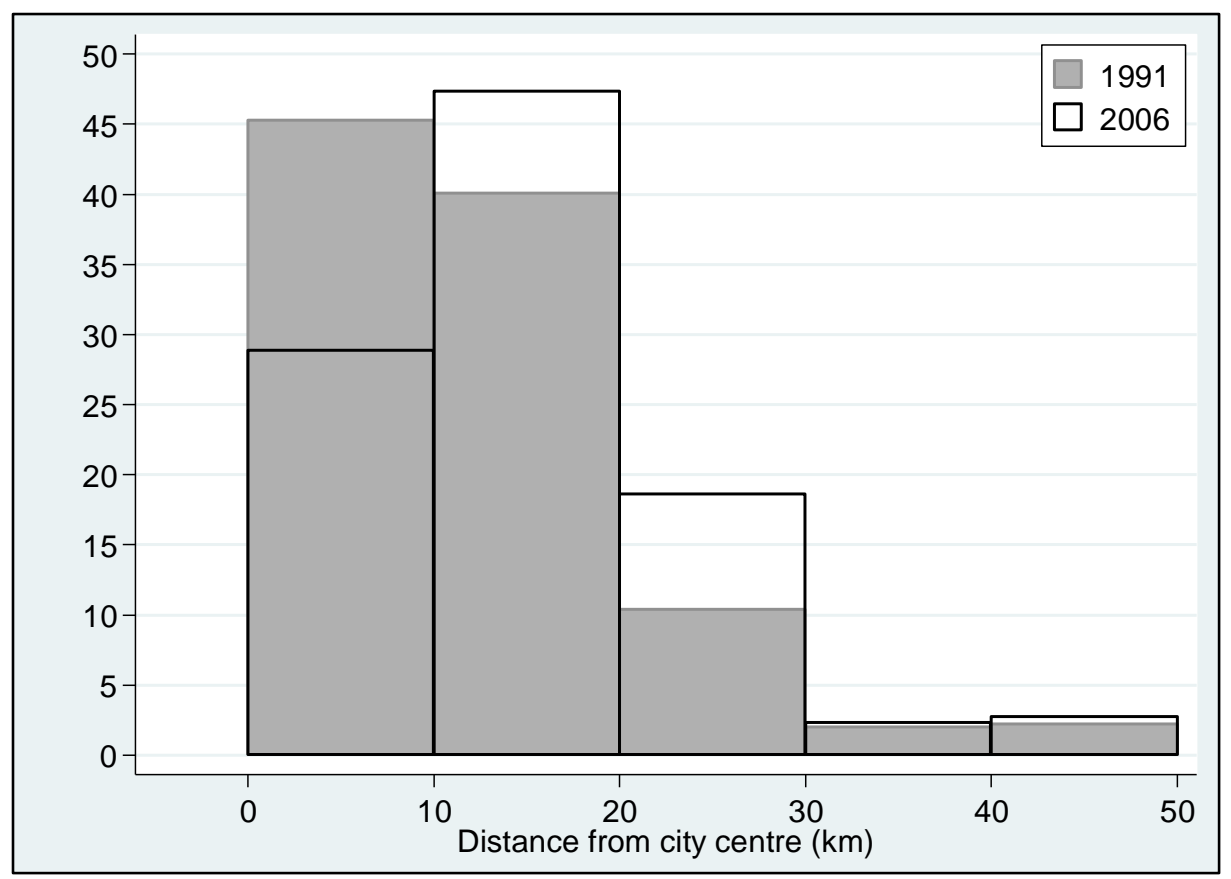


Next, I look at the second period in this analysis, the contraction macro-economic period. The period 2006 to 2013 corresponds with when the economy is in a state of "contracting", and I would therefore assume there to be a higher proportion of the population concentrating in the highly deprived meshblocks. I would also expect that the number of highly deprived meshblocks would increase or at least slow nearer the city.

Figure 5.11 plots the percentage of all highly deprived meshblocks in Auckland across $1 \mathrm{~km}$ bands for 2006 and 2013, up to a maximum of 50km. In Figure 5.11, it looks like there is an increase in the proportion of highly deprived meshblocks over $2-7 \mathrm{~km}$, with large decreases from $8-10 \mathrm{~km}$. Looking at Figure 5.12 shows me that there is a very small decrease as a whole in the first $10 \mathrm{~km}$. Despite increases in the $3-$ $5 \mathrm{~km}$ bands but decreases in the $8-10 \mathrm{~km}$ range seen in Figure 5.11. There are small decreases in the second band and there are also some small increases from $22-50 \mathrm{~km}$. This is shown in Figure 5.12 with a $3 \%$ decrease in the proportion of highly deprived meshblocks in the $20-30 \mathrm{~km}$ distance band.

Figure 5.11. Spatial distribution of highly deprived meshblocks in Auckland, 2006-2013.

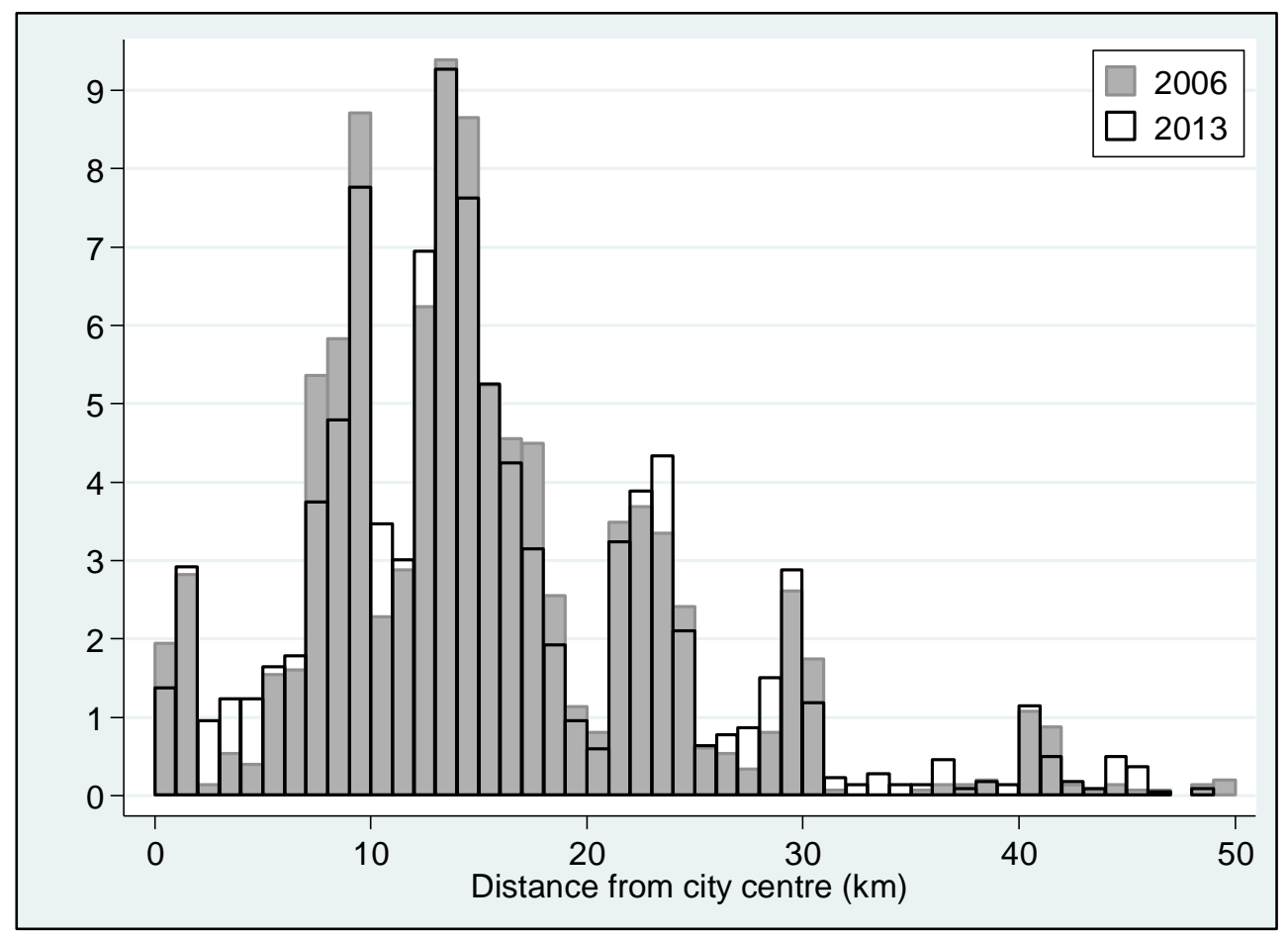


Figure 5.12. Spatial distribution of highly deprived meshblocks in Auckland, 2006-2013.

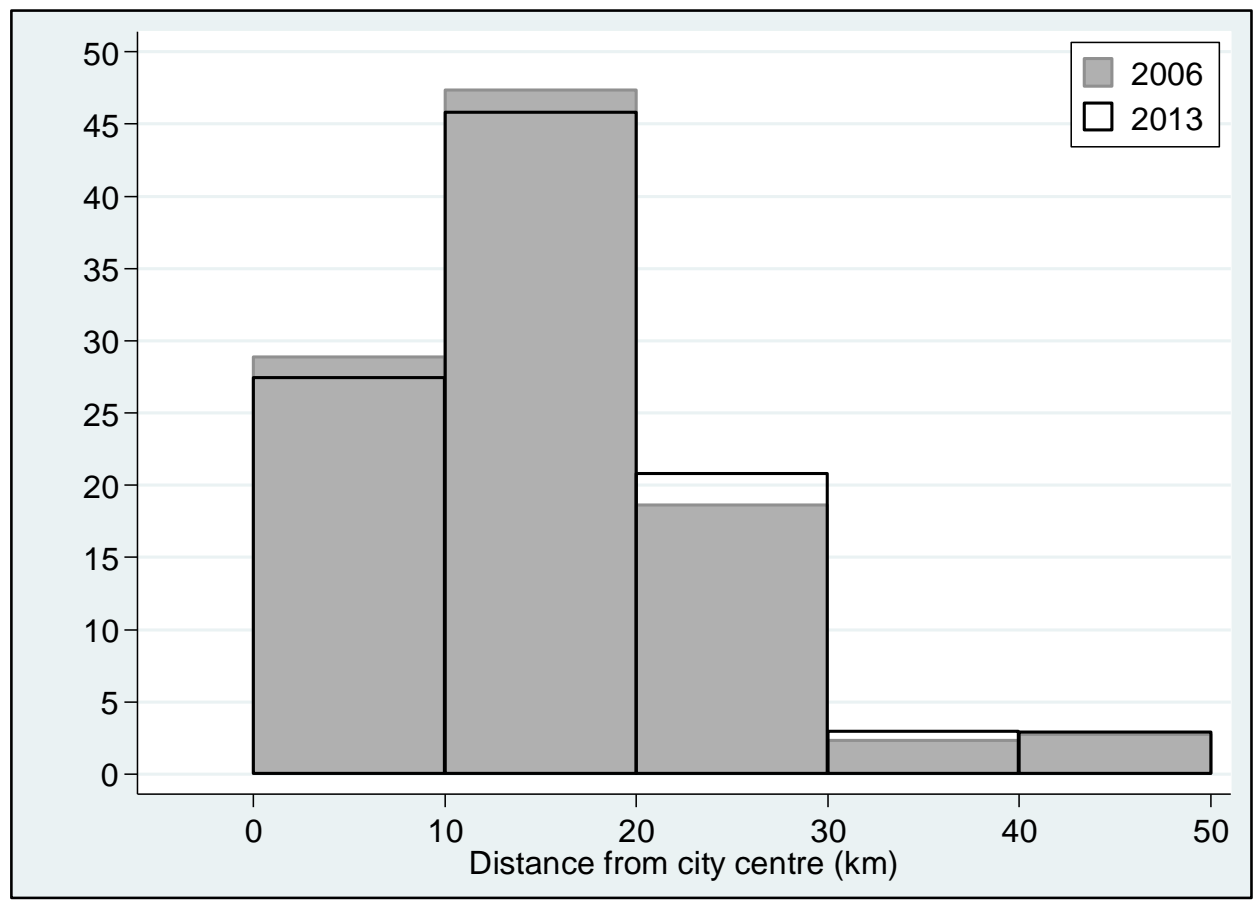

To examine the geographic locations of these changes in the spatial distribution of the highly deprived meshblocks, I have constructed some maps with the locations. The shading for each meshblock indicates the level of population contained within (the darker, the more highly deprived population). Looking at Figure 5.13, there are a few very noticeable changes in the geography. There is a marked decrease in the prevalence of highly deprived meshblocks in the first $10 \mathrm{~km}$ ring, near the city centre. However, perhaps the biggest increase is the increase in both the darkening and the appearance of highly deprived meshblocks to the South in the second and third distance bands.

Turning to Figure 5.13, there is a slight difference between 2006 on the left and 2013 on the right. There is a darkening and increase in the second and third bands. South Auckland sees a darkening, and an increase in the prevalence of highly deprived meshblocks. 
Figure 5.13. Spatial distribution of highly deprived meshblocks in Auckland, 1991 and 2006

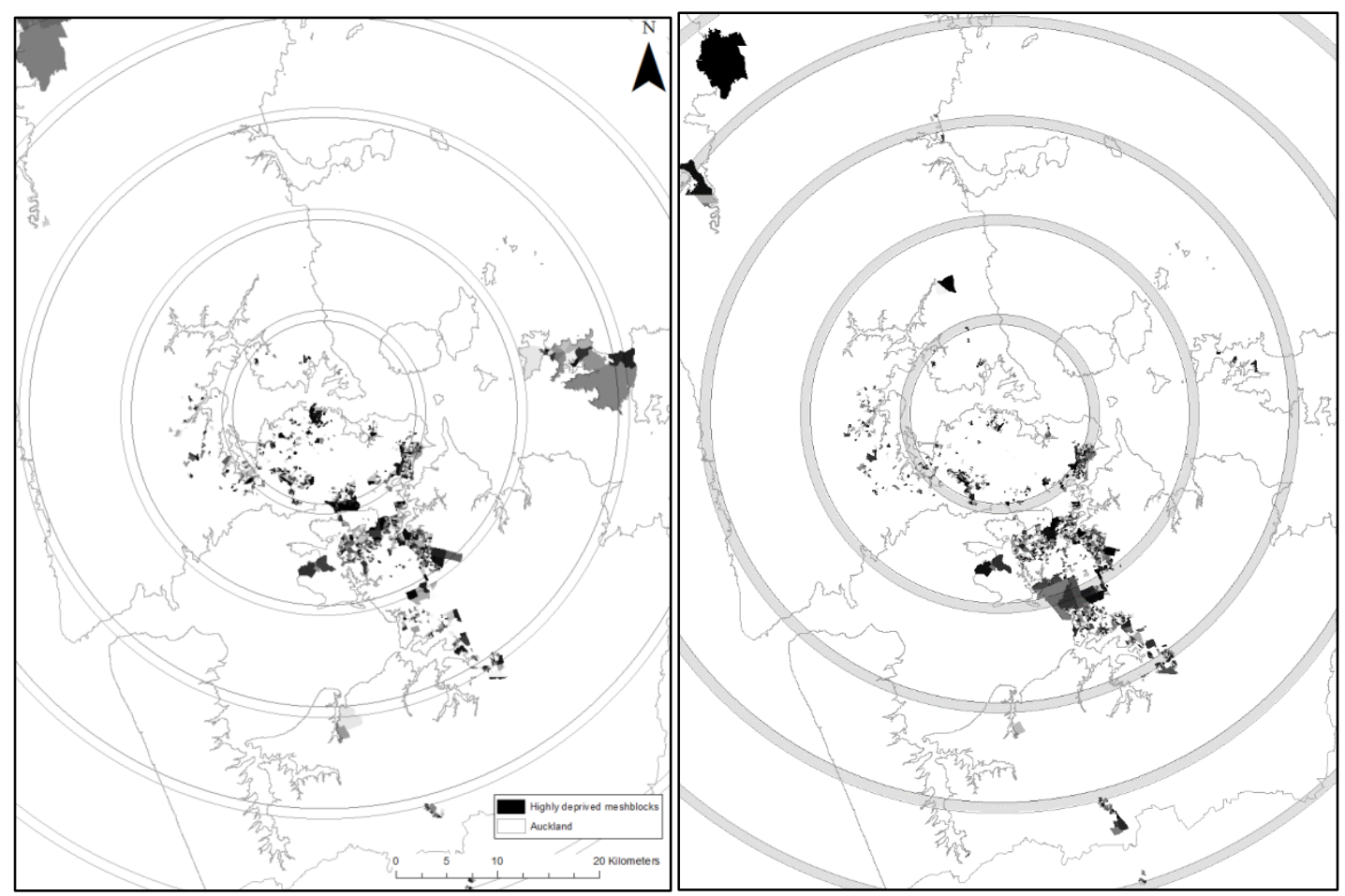

Figure 5.14. Spatial distribution of highly deprived meshblocks in Auckland, 2006 and 2013

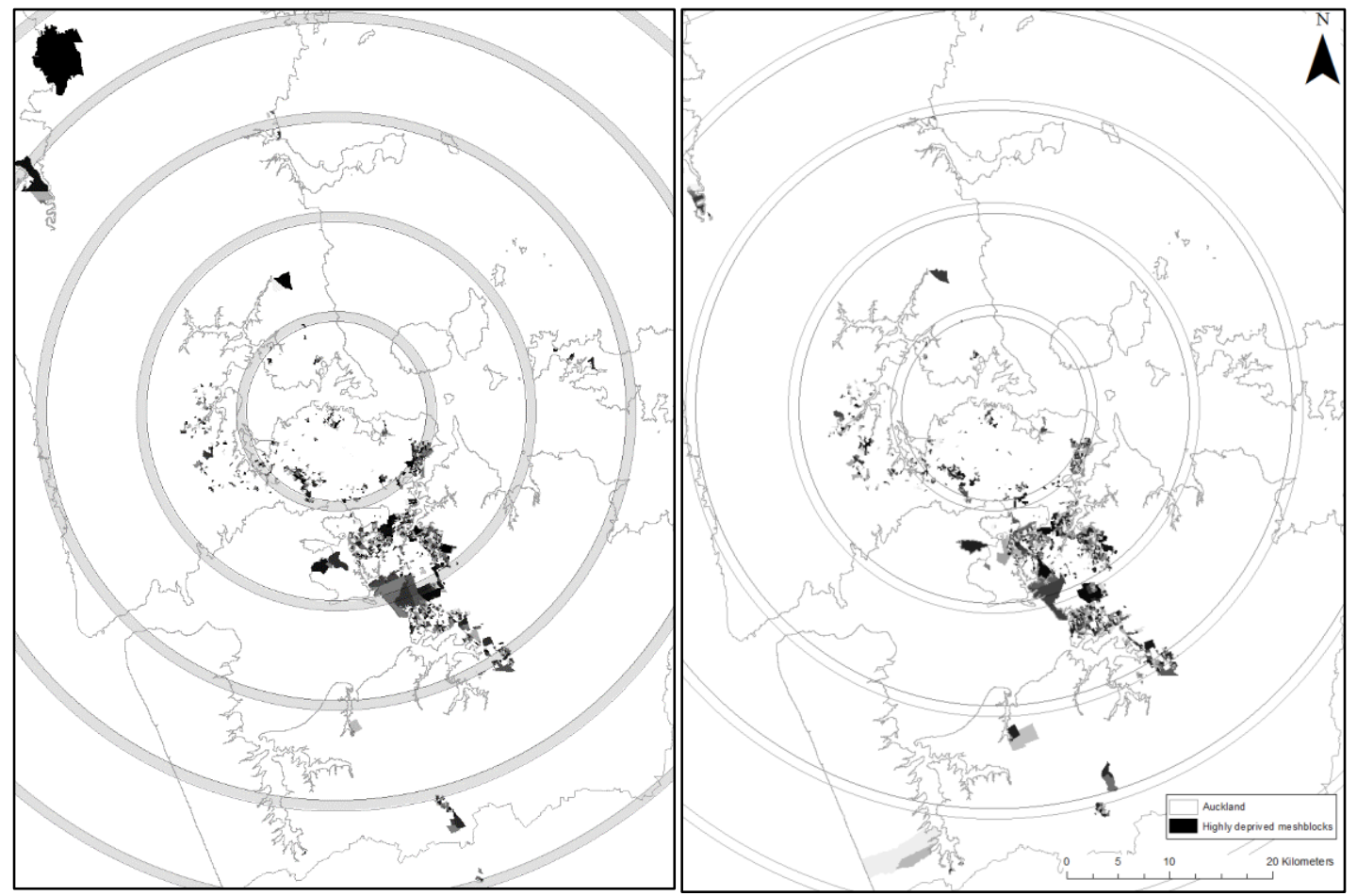


Auckland has seen a reduction in the proportion of highly deprived meshblocks in the central city. The location of deprivation has shifted south.

\subsection{Summary}

In this chapter, I introduced the concept of temporal differences in the changing spatial distribution of deprivation. The temporal differences that I examined corresponded to changing strengths in the macroeconomic conditions. The period I measured first, 1991-2006, was a time of economic 'expanding' and saw large decreases in the proportion of highly deprived meshblocks in the central cities of both Wellington and Auckland. The second period I measured, 2006-2013, was a time of economic 'contracting' and saw an increase in the proportion of highly deprived meshblocks in the central city for Wellington (see Figure 5.6), and a very small decrease for Auckland. Across both periods for both cities, there was still a suburbanisation of highly deprived meshblocks. 
Chapter Six: The changing concentration of the individual components that make up deprivation in Wellington and Auckland

\subsection{Introduction}

Deprived areas generally contain a large proportion of deprived individuals. However, not all individuals contained within deprived areas are deprived. Likewise, not all deprived individuals are contained within deprived areas.

Academics and health officials from the Ministry of Health and Otago University created the deprivation score by combining a number of different weighted variables collected from the census. The data they used was at a unit-record level that is not publicly available. However, we can analyse publicly available census data the smallest geographic levels and gain an insight into how the deprived differ, and whether there are differences in the spatial distribution of deprivation.

In the previous two chapters, I found there was a shift of deprivation away from the city centre towards the middle and outer suburbs in Wellington and Auckland between 1991 and 2013. In chapter four, I found the number of highly deprived meshblocks (defined as the number of meshblocks at or beyond one standard deviation above the national mean of the New Zealand deprivation score) decreased in the first 10km of Auckland and rose in the 10-50km of Auckland between 1991 and 2013. Wellington saw a small increase in the number of highly deprived meshblocks in the first 10km from the city centre between 1991 and 2013. However, in chapter five, I found that there was a large decrease in the number of highly deprived meshblocks in the first $10 \mathrm{~km}$ from the city centre of Wellington between 1991 and 2006, and then a large increase in the same spatial area of Wellington between 2006 and 2013.

In this chapter, I will separate the deprivation score into its individual components. From these individual components, I will observe the distributions and the differences in these distributions. These observations will give a better understanding of how the different groups of deprived populations locate, and if these locations or distributions have changed over time. 
I start by providing an explanation of the breakdown of deprivation, and how the measure is used. Next, I look at the two smallest geographic levels at which deprivation score and other census variables are available. Then, I begin to look at each individual component of deprivation, starting with income.

\subsection{Components of deprivation}

The New Zealand deprivation score is a measure of relative deprivation that provides a deprivation score for each meshblock in New Zealand. The higher the score the more deprived a meshblock is. Based on these scores meshblocks are categorised into deprivation deciles known as the deprivation index.

Deprivation score is a weighted variable that summarises how deprived a meshblock is based on the prevalence of individuals living in the meshblock. Deprivation score says how deprived a meshblock is based on levels of income, employment, education, housing, and a couple of other amenities. It does not say how deprived a meshblock is, controlling for these factors. Deprivation is a measure that relates to a meshblock and not to an individual. An individual who moves from a decile 10 (the most deprived decile) meshblock to a decile 1 (the least deprived decile) meshblock is not necessarily improving their situation or livelihood. They are just as likely to be unemployed or low skilled regardless of the physical location they live in (putting aside contextual effects of residential area).

Several factors enable me to determine how to define someone as deprived or disadvantaged. First, I might consider someone deprived if they have a low relative income. Low income affords people less choices and limits their ability to pursue lives that they value. Employment, as well as providing income, enables participation in society. Education levels are shown to be another factor correlated with other outcomes in relation to wellbeing. Other indicators such as health status are likely to be important. Composite measures of deprivation are better than any one indicator alone, but it is important to keep in mind that what we are measuring is not wellbeing, but an imperfect and limited proxy.

Deprivation score does not include indicators of health status because the authors developed it to test the correlation between indicators of deprivation and health 
outcomes. In most cases, they found health was highly correlated with other measures of well-being and deprivation.

As described in chapter three, the score is calculated based on compiling the input variables and weighting them based on how they might contribute to an individual being disadvantaged. The order in which the authors have weighted the variables likely has a large impact on the deprivation score for deprived areas. Table 6.1 shows the variables included in the calculation and the decreasing weights are in order of descent.

Table 6.1. Variables included in the New Zealand deprivation score, 2006 and 2013

\begin{tabular}{|lcc|}
\hline & \multicolumn{2}{c|}{ Weight } \\
\cline { 2 - 3 } Proportion of persons (with a lack of something) & $\mathbf{2 0 0 6}$ & $\mathbf{2 0 1 3}$ \\
\hline People aged <65 with no access to the Internet at home & - & $\mathbf{0 . 3 7 2}$ \\
People aged 18-64 receiving a means tested benefit & 0.371 & $\mathbf{0 . 3 6 4}$ \\
People living in households with equivalised* income below an & 0.356 & $\mathbf{0 . 3 5 6}$ \\
People aged 18-64 unemployed & & $\mathbf{0 . 3 3 8}$ \\
People aged 18-64 without any qualifications & 0.332 & $\mathbf{0 . 3 3 2}$ \\
People not living in own home & 0.326 & $\mathbf{0 . 3 2 2}$ \\
People aged <65 living in a single parent family & 0.334 & $\mathbf{0 . 3 1 7}$ \\
People living in households below an equivalised* bedroom & 0.333 & $\mathbf{0 . 3 0 3}$ \\
Peccupancy threshold & 0.318 & $\mathbf{0 . 2 8 6}$ \\
People with no access to any phone at home & & $\mathbf{-}$ \\
\hline Percentage of variance explained & 0.311 & 0.314 \\
\hline Equivalisation: methods used to control for household composition. & $55.4 \%$ & $\mathbf{6 0 . 7} \%$ \\
\hline
\end{tabular}

What are my expectations for how each variable is distributed? Based on my analysis in chapters four and five, I already know that there has been a reduction of the population in highly deprived meshblocks for the first $10 \mathrm{~km}$ for both Wellington and Auckland. This was mirrored with increases of the population in highly deprived meshblocks for the outer distance bands. Therefore, the null hypothesis for the individual components would be that each variable follows the same pattern as the overall deprivation score. After all, deprivation score is a variable created from its 
inputs. However, there might be subtle differences that I can tease out. I will address each variable used in this analysis, and the expectations for the spatial distribution of each variable.

Firstly, the number of people with no access to the internet at home. I expect that the further from the centre of a city, the more likely a house does not have access to the internet. The reason I suspect this variable to follow that spatial distribution is the cost of installing and maintaining the electrical infrastructure needed for an internet connection. In less densely populated areas, the cost per person would increase. This means that telecommunications companies are less likely to incur those costs, or they are more likely to charge more if they do offer a service.

The second variable is the number of people who receive a means tested benefit. A means tested benefit is a government supplement to income, predominantly based on a lack of ability to support oneself without this help. My expectation of the distribution of those receiving a means tested benefit draws from Morrison and Walgrave (2002). They conceptualise and find that beneficiaries concentrate away from a city centre.

The third variable is the number of people below a certain income threshold. The census collects income data in categories. While you cannot get a precise picture of those at a certain percentage of a median wage, for example, you can get the number below a certain income grouping. I expect the number of low-income groupings to increase with distance from the city centre. The main reason I expect this is due to bid rent theory being a prominent land use theory (discussed in more depth in chapter two). Bid rent theory states that the cost of land decreases the further from a city centre. It follows then that higher income groupings are the ones who occupy land closer to the city centre, as they have the ability to afford the use of the land.

The fourth variable contained in deprivation score is the number of unemployed. I expect the number of unemployed people to increase with distance from city centre. Unemployed people have less money and therefore less discretion as to where to live. It is quite likely that the distribution of unemployed people mirrors that of those receiving a means tested benefit. Many unemployed people would receive a benefit of some kind. 
The fifth variable I look at is the number of people without any qualifications. I expect qualifications to decrease with distance from city centre. The educated are likely to be in well-paid jobs, and therefore locate closer to the city to save on time commuting and increase accessibility to leisure goods.

The sixth variable I look at is housing tenure, or more specifically, the number of those who do not own the dwelling they live in. I expect the housing tenure people not living in their own home, to decrease from city centre. As mentioned previously, the price of land decreases away from the city centre. This suggests to me that those wanting to own a home can buy a house for a reasonable price further from the city centre. Poorer or more deprived people can then rent or increase their people to room ratio and take advantage of the accessibility opportunities that housing closer to the city centre brings.

The seventh variable I look at is the proportion of households with children that have only one parent. I expect the number of households with children but only one parent to increase from the city centre. One-parent households are generally relying on a sole income. Households with more than one income will more than likely have a higher overall household income and are able to outbid those with lower incomes for locations closer to the centre of a city.

The eighth variable I look at is number of household members per bedroom, crowding level. I expect crowding to decrease away from a city centre. While I expect both household members and bedrooms to increase away from a city centre due to the cost of land decreasing, crowding is an effective mechanism for poorer households or individuals to live in areas that are more expensive.

The last variable I look at is access to a vehicle. I expect access to a vehicle to increase further from a city centre. Those who choose to locate closer to a city centre generally have greater access to alternative forms of transport such as public and active transport. Additionally, those further from a city centre are less likely to live near public transport routes or can adhere to a normal public transport timetable. This means they must use vehicle access as a means of travel. 


\subsection{Individual components of deprivation}

The purpose of this analysis is to investigate whether there are differences in the concentration of the individual components that go into the deprivation score variable. In the previous two chapters (chapter four and chapter five), I measured the population changes in meshblocks with a high NZDep score (at or beyond one standard deviation above the mean for New Zealand). The purpose of these chapters was to determine the spatial distribution of the highly deprived meshblocks, and to identify whether the population contained within these highly deprived meshblocks was increasing, decreasing, or largely staying the same. An effective way to view these measurements is through location quotients. For a more comprehensive explanation of how a location quotient is calculated, refer to chapter three, section five. Essentially, an LQ greater than 1 means that a disproportionately high number of the variable is in that distance band.

$$
L Q=\frac{(X / Y)_{\text {distance band }}}{\left(X^{\prime} / Y^{\prime}\right)_{\text {region }}}
$$

I will apply the LQ to the individual components of deprivation in both Wellington and Auckland for 1991, 2006 and 2013. However, it must be noted that in some instances, 2001 is the oldest data available and is used in place of 1991.

\subsubsection{Wellington}

The first part of my analysis will focus on Wellington. In the two previous chapters, I have investigated the distribution and temporal comparisons of highly deprived areas, and the population contained within them. For Wellington, I will now break down the individual components and compare their concentrations to the general population within highly deprived areas.

Figure 6.3 shows a line plot of the location quotients for the population contained within highly deprived meshblocks at successive distance bands from the city centre. The LQ in Figure 6.3 was calculated as the population in highly deprived meshblocks $(\mathrm{X})$ in a distance band (10km concentric bands) as a proportion of the total population in that distance band (Y), over the population in highly deprived meshblocks for the whole region ( $\left.\mathrm{X}^{\prime}\right)$ as a proportion of the total population for the region $\left(\mathrm{Y}^{\prime}\right)$. 
As mentioned previously in this chapter, and in both chapters four and five, Figure 6.3 shows a very slight reduction in the population contained in highly deprived meshblocks over the longer period (1991-2013) in the first distance band. This reduction is mirrored by an increase in the four outer bands. The next section of this analysis will investigate whether each individual variable follows a similar pattern to Figure 6.3.

Figure 6.3. Location quotients for population in highly deprived meshblocks in Wellington, 19912006 and 2013.

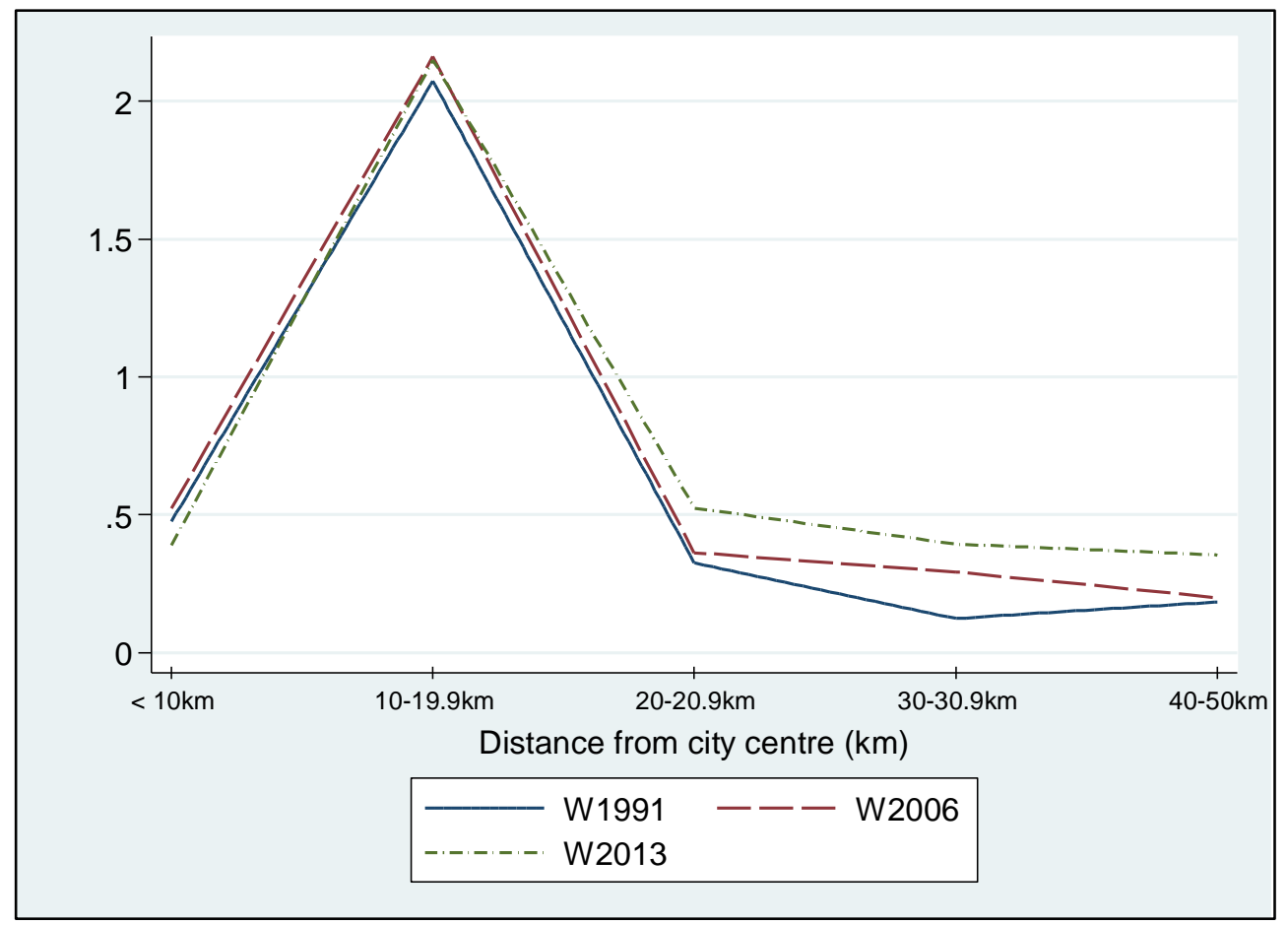

Figure 6.4 shows a line plot of the location quotients for the number of individuals with low-income contained within highly deprived meshblocks. The LQ in Figure 6.4 was calculated in the usual way but with $\mathrm{X}$ as the number low-income individuals in highly deprived meshblocks.

Figure 6.4 follows a similar pattern to Figure 6.3. However, there is a difference between 1991 and 2013 LQs in the second distance band. In 2001, the second distance band had more low-income individuals than in 2006 and 2013, unlike in Figure 6.3 where there was slightly more in 2013. The rest of the distance bands are similar to Figure 6.3. 
Figure 6.4. Location quotient for individuals with low-income in highly deprived meshblocks in Wellington, 20012006 and 2013

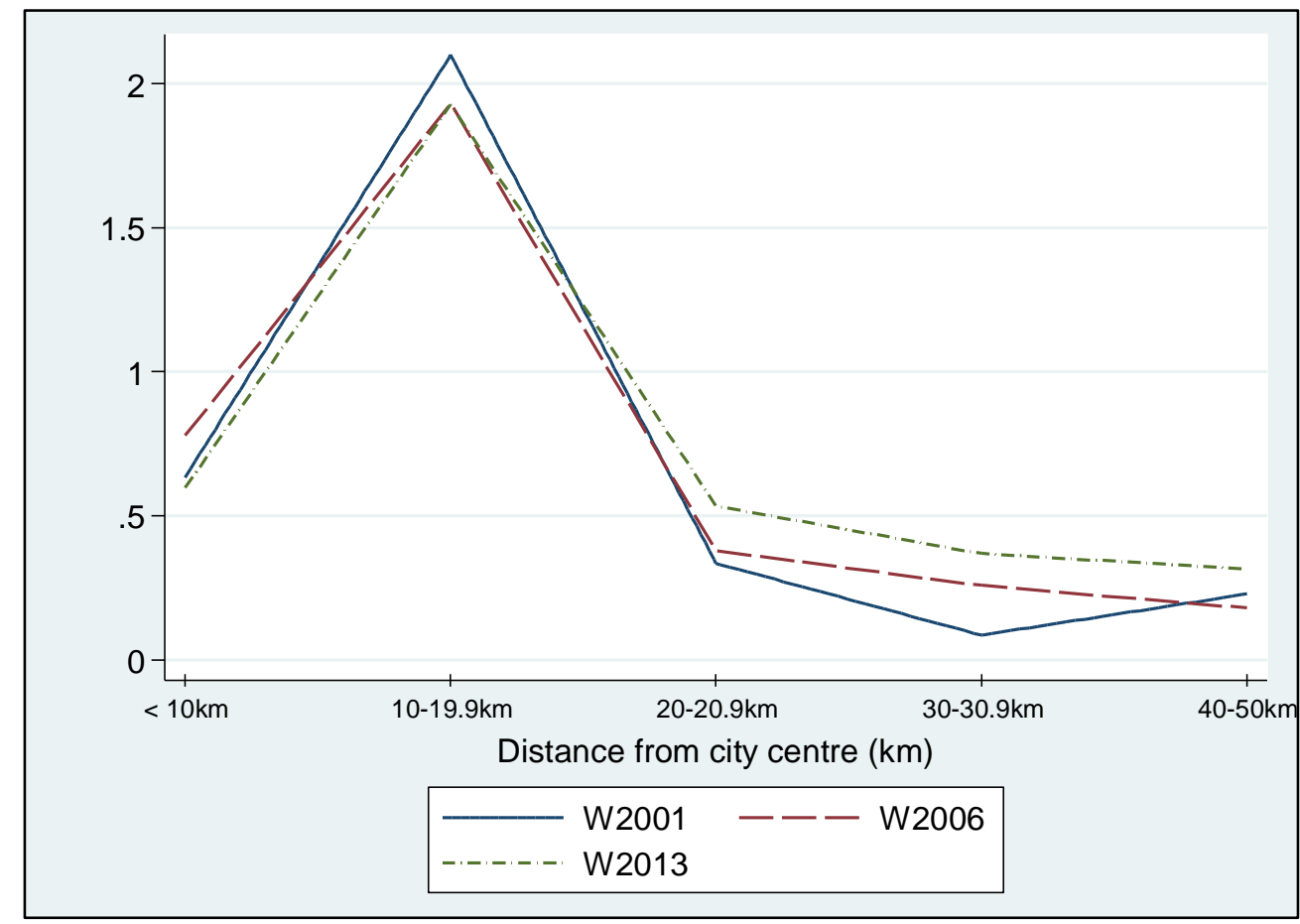

Figure 6.5 shows a line plot of the location quotients for the number of individuals receiving a means tested benefit contained within highly deprived meshblocks. The LQ in Figure 6.5 was calculated in the usual way but with $\mathrm{X}$ as population receiving a means-tested benefit in highly deprived meshblocks

Figure 6.5 follows a similar pattern to Figure 6.4. This makes sense, as low-income individuals are more likely to rely on government support in the form of means tested benefits. There are a very similar level of individuals receiving means tested benefits in highly deprived meshblocks when comparing 2001 and 2013. However, by 2013 , more individuals receiving means tested benefits are living in highly deprived meshblocks in the three outer distance bands. The large increase between 2001 and 2013 in the 20-50km range supports my original thesis, as well as addressing my third research question that the deprived are becoming more concentrated. 
Figure 6.5. Means tested benefit location quotients in highly deprived meshblocks in Wellington, 20012006 and 2013.

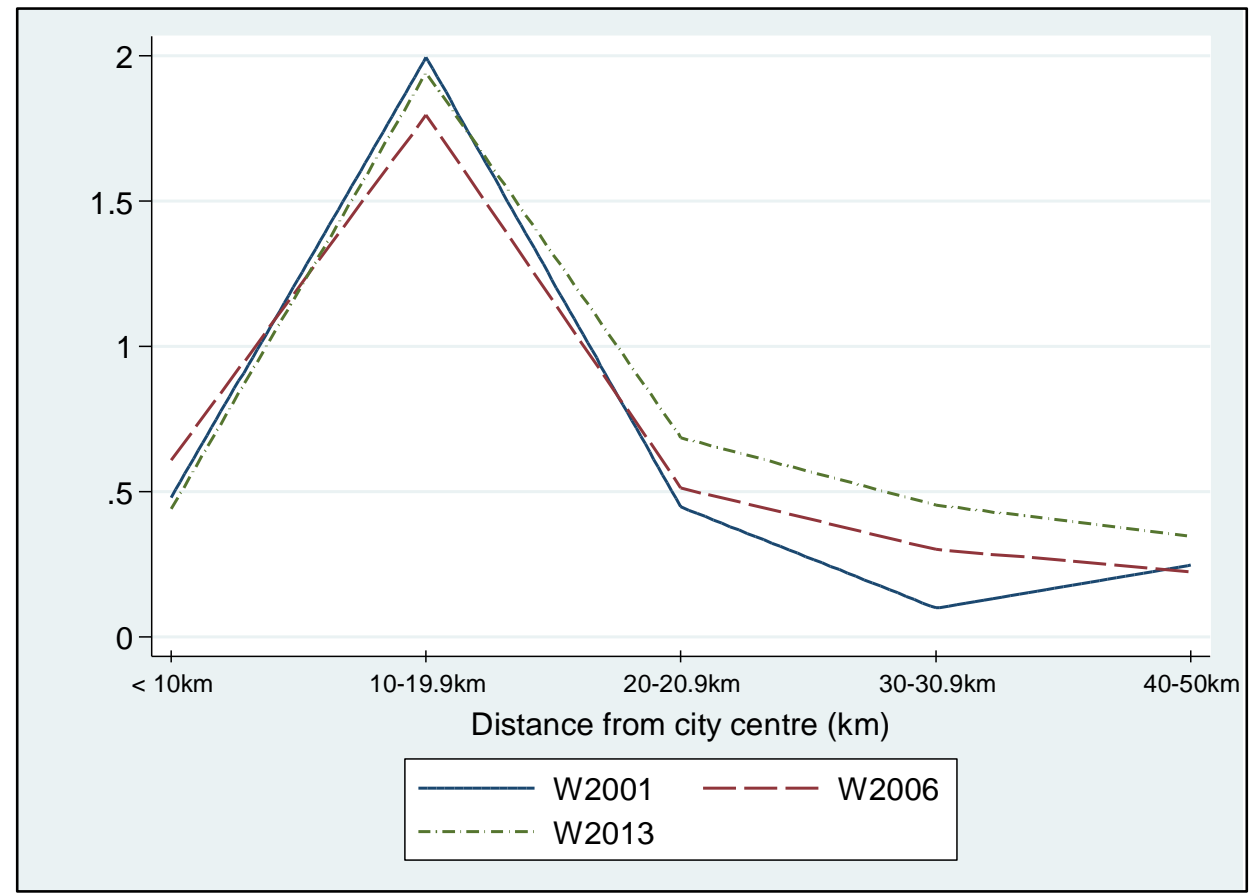

Figure 6.6 shows a line plot of the location quotients for the number of individuals unemployed contained within highly deprived meshblocks. The LQ in Figure 6.6 was calculated in the usual way but with $\mathrm{X}$ as unemployed individuals in highly deprived meshblocks.

Figure 6.6 shows an increase in unemployed individuals living in highly deprived meshblocks across all five bands from 1991 to 2013. This observation suggests that over this 22-year period, the unemployed have become more concentrated in highly deprived areas at all distances. 
Figure 6.6. Location quotients for the number of unemployed in highly deprived meshblocks in Wellington, 19912006 and 2013.

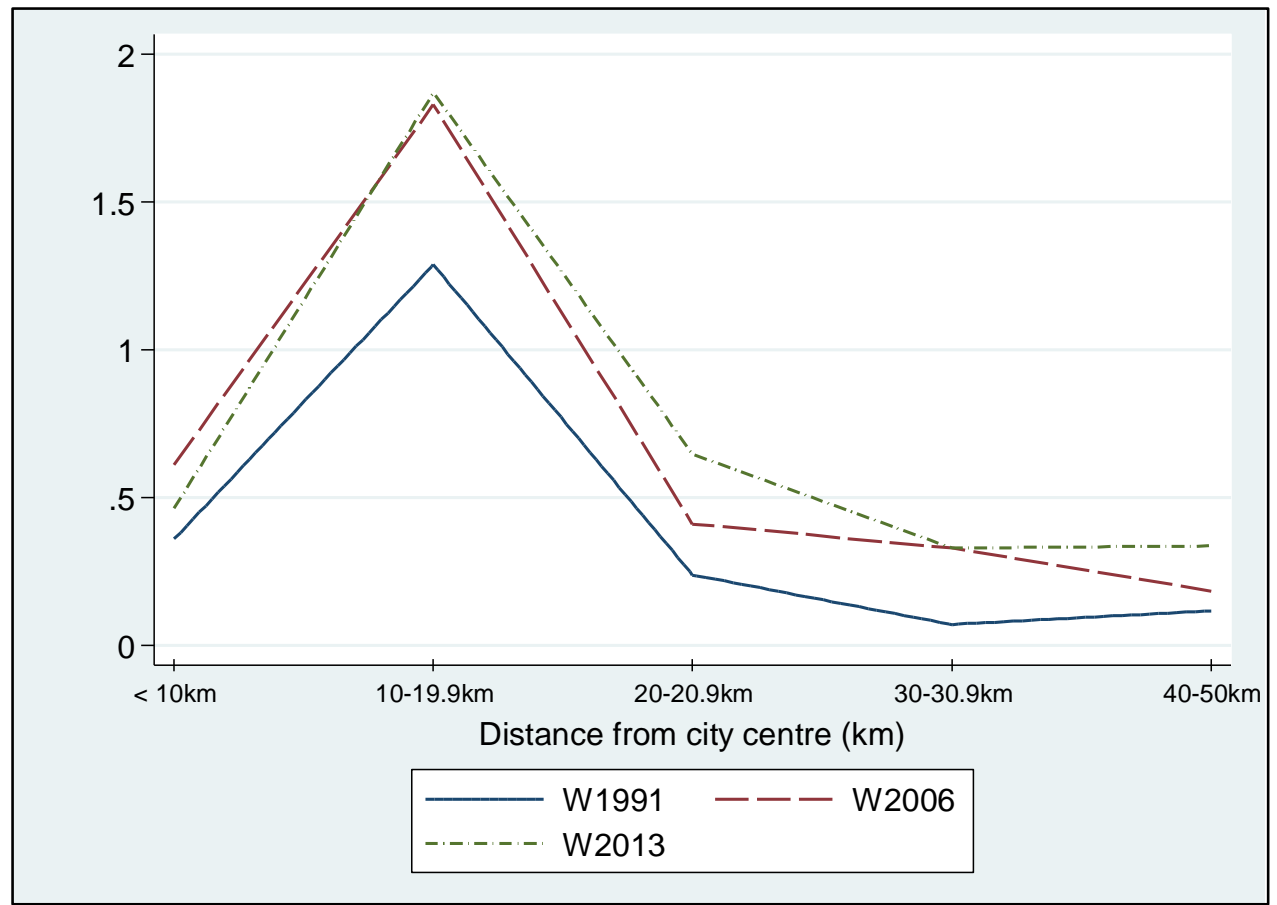

Figure 6.7 shows a line plot of the location quotients for the number of one-parent families contained within highly deprived meshblocks. The LQ in Figure 6.7 was calculated in the usual way but with $\mathrm{X}$ as one-parent families in highly deprived meshblocks.

Looking at the change between 1991 and 2013, Figure 6.7 shows a similar pattern to Figure 6.3. One-parent families have changed their concentration in highly deprived areas at a similar rate to the population in these areas. That is, a small decrease in the concentration in the first distance band, and small increases in the second and third bands. Additionally, a larger increase in the concentration of one parent families in highly deprived meshblock. 
Figure 6.7. Location quotient for number of one-parent families in highly deprived meshblocks in Wellington (1991, 2006 and 2013).

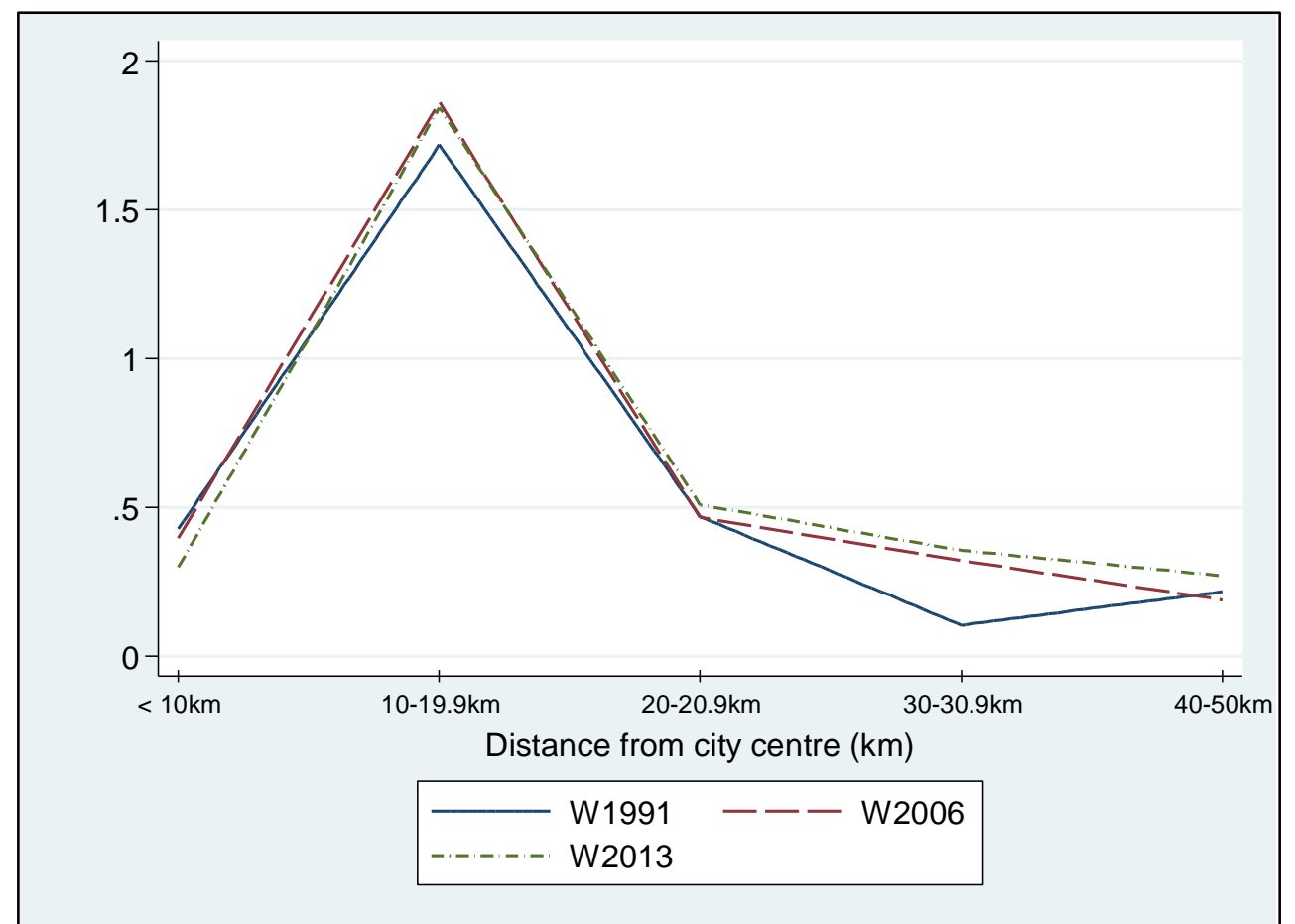

Figure 6.8 shows a line plot of the location quotients for the number of households who do not own their dwelling contained within highly deprived meshblocks. The LQ in Figure 6.8 was calculated in the usual way but with $\mathrm{X}$ as the number of households who do not own their dwelling in highly deprived meshblocks.

Figure 6.8 shows that households who do not own their own dwelling have become less concentrated in highly deprived areas in the first distance band. This is mirrored with a rise in the concentration of households who do not own their house in the four outer distance bands. Figure 6.8 shows a similar pattern to the general population change in highly deprived meshblocks shown in Figure 6.3. This is consistent with my overall thesis that the poor are becoming more suburbanised. 
Figure 6.8. Location quotient for number of households who do not own their dwelling for highly deprived meshblocks in Wellington, 19912006 and 2013.

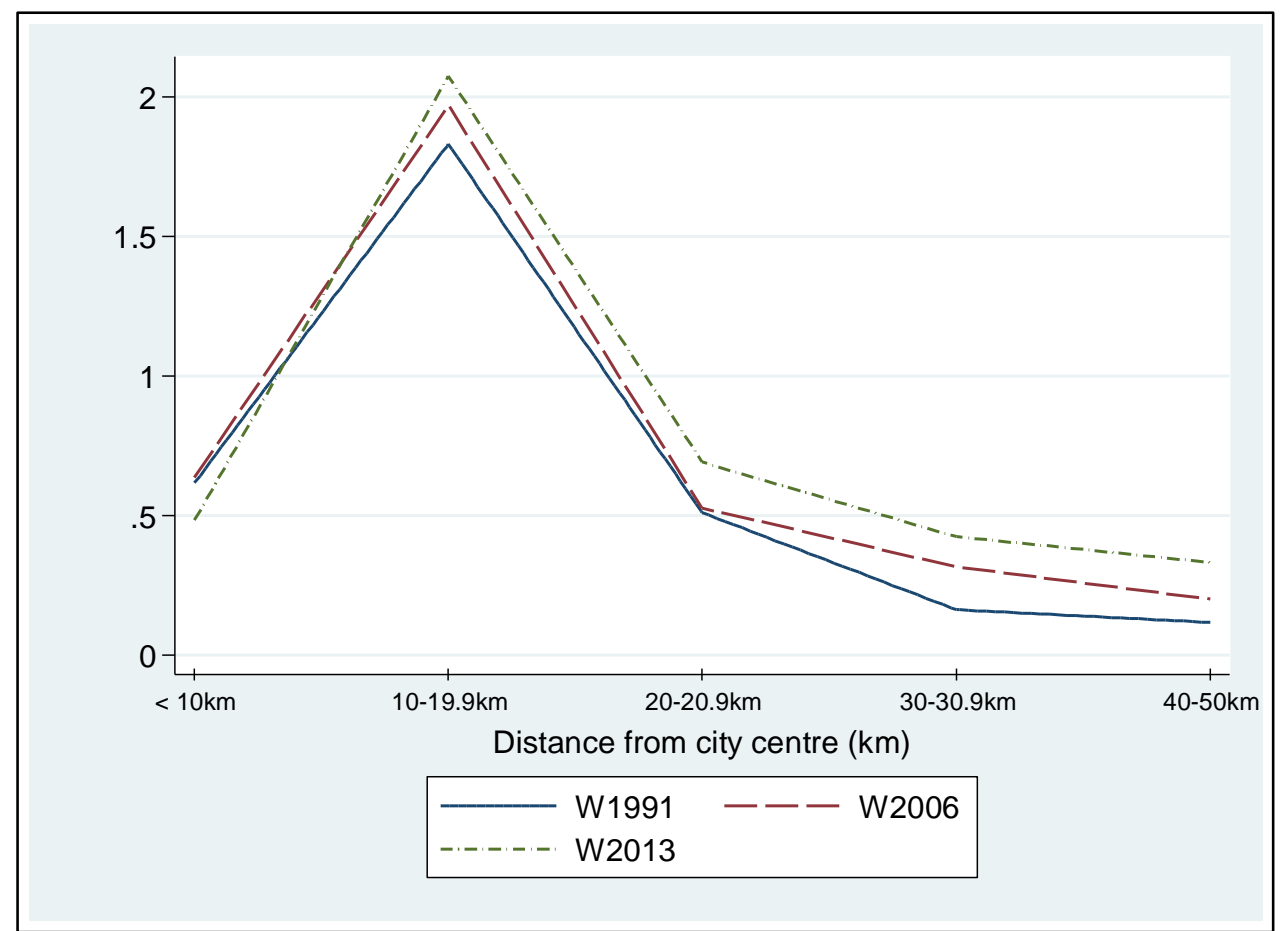

Figure 6.9 shows a line plot of the location quotients for individuals who do not possess a qualification contained within highly deprived meshblocks. The LQ in Figure 6.9 was calculated in the usual way but with $\mathrm{X}$ as individuals who do not possess a qualification in highly deprived meshblocks.

Figure 6.9 shows a decrease from 2001 to 2013 in the concentration of individuals without qualifications in highly deprived meshblocks in the first two distance bands. The third, fourth, and fifth distance bands showed increases in the concentration of individuals without qualifications in highly deprived meshblocks. 
Figure 6.9. Location quotient for number of individuals who do not possess a qualification for highly deprived meshblocks in Wellington, 20012006 and 2013.

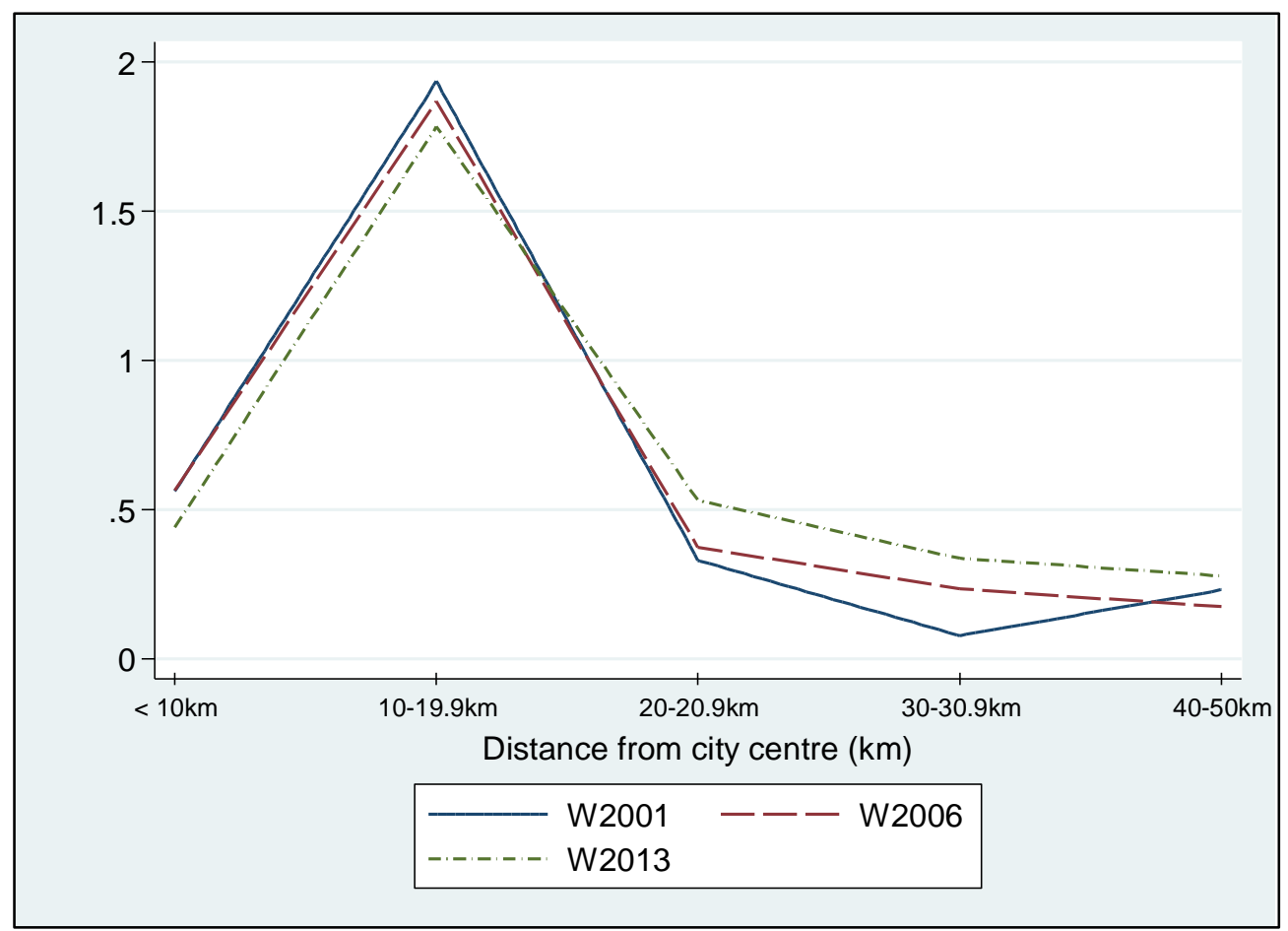

Figure 6.10 shows a line plot of the location quotients for the ratio of household members to bedrooms contained within highly deprived meshblocks. The LQ in Figure 6.10 was calculated in the usual way but with $\mathrm{X}$ as the ratio of household members to bedrooms in highly deprived meshblocks.

Figure 6.10 shows a different situation than the previous figures I have discussed. All three census years chosen have their highest crowding ratio in the first distance band. In the first distance band, the crowding ratio is the same for both 1991 and 2013. However, there is a decrease in the crowding LQ in between these years, i.e. for 2006. Furthermore, in all but the second band, 2006 had a lower crowding ratio than 1991 and 2013. In 2013, both the second and third bands had a higher crowding LQ. This makes sense in relation to my analysis in the previous chapter. In that chapter, I found that during strong macroeconomic periods, crowding still takes place nearer the centre of the city, but falls off in the outer suburbs. 
Figure 6.10. Location quotient for crowding ratio for highly deprived meshblocks in Wellington, 19912006 and 2013.

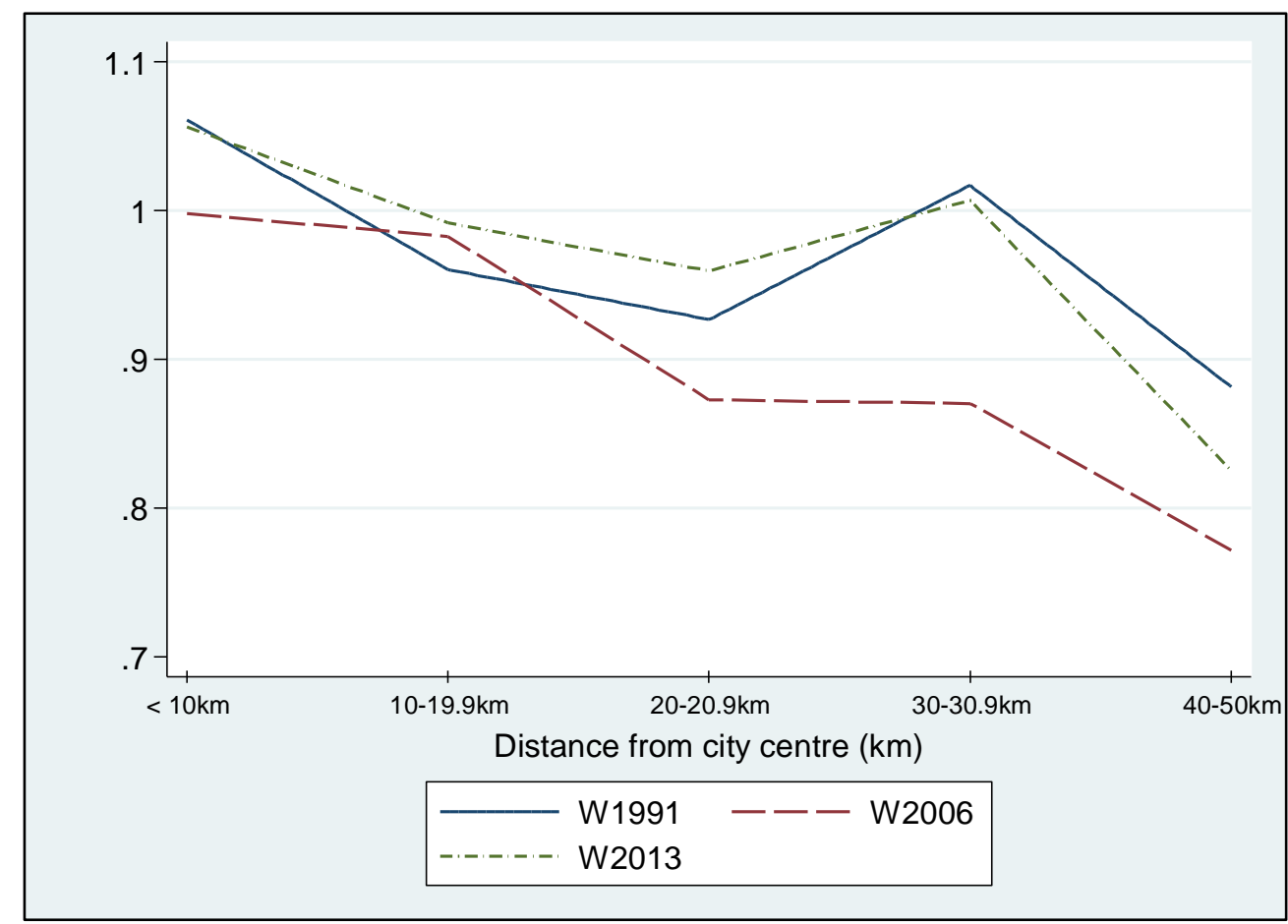

Figure 6.11 shows a line plot of the location quotients for individuals who have no access to a vehicle contained within highly deprived meshblocks. The LQ in Figure 6.11 was calculated as individuals who have no access to a vehicle in highly deprived meshblocks $(\mathrm{X})$ in a distance band (10km concentric bands) as a proportion of the total population of individuals who have no access to a vehicle in that distance band (Y), over individuals who have no access to a vehicle in highly deprived meshblocks for the whole region $\left(\mathrm{X}^{\prime}\right)$ as a proportion of the total population who have no access to a vehicle in the region ( $\left.\mathrm{Y}^{\prime}\right)$.

Figure 6.11 shows that a decrease in the concentration of individuals without access to a vehicle in the first two distance bands, going from 1991 to 2013. However, in the fourth and fifth band, there were increases in this concentration. 
Figure 6.11. Location quotient for individuals with no access to a vehicle for highly deprived meshblocks in Wellington, 19912006 and 2013.



To summarise, Wellington saw a very slight decrease of the population within highly deprived meshblocks for the first distance band between 1991 and 2013.

Simultaneously, there were increases in the population within the highly deprived meshblocks in the outer four distance bands. Most of the components contained in the deprivation score followed a similar pattern of concentration in highly deprived meshblocks. The exceptions to the similarity were location quotients for the number of unemployed in highly deprived meshblocks, and location quotients for the crowding ratio. The location quotients for the number of unemployed followed a similar increase and decrease in the distribution moving from the centre outwards. However, for all five-distance categories 2013 had a higher LQ ratio, i.e. more concentration, of the number of unemployed in highly deprived meshblocks than in 1991. This observation suggests that over this 22-year period, the unemployed have become more concentrated in highly deprived areas through whatever reason, be it crowding or the need for cheaper housing.

Crowding decreased in concentration in highly deprived meshblocks from 1991 to 2006, and then increased again from 2006 to 2013. In my analysis in chapter 5, I observed that Wellington experienced a 'temporal effect' in the distribution and 
concentration of population in highly deprived areas. This temporal effect refers to a non-linear increase or decrease over time. Macro-economic conditions oscillate, and in my observations, I found that 2006 had a dispersion of highly deprived areas. This partly explains the similarity between 1991 and 2013, as 2006 was different and by 2013 the crowding ratio had readjusted.

\subsubsection{Auckland}

In the second part of this analysis, I will look at the components of deprivation score in Auckland. Auckland follows a linear path across the periods measured.

Figure 6.12 shows a line plot of the location quotients for the population contained within highly deprived meshblocks. The LQ in Figure 6.12 was calculated in the usual way but with $\mathrm{X}$ as the population in highly deprived meshblocks.

Figure 6.12 shows a linear decrease in population contained with highly deprived meshblocks across the three years in the first distance band. This decrease is mirrored by a linear increase in the third distance band. Curiously, both the second and fourth distance bands have almost no change across the time series. Essentially, the population in highly deprived areas has become less concentrated in the first distance band, and much more concentrated in the middle distances. 
Figure 6.12. Location quotients for population in highly deprived meshblocks in Auckland, 19912006 and 2013.

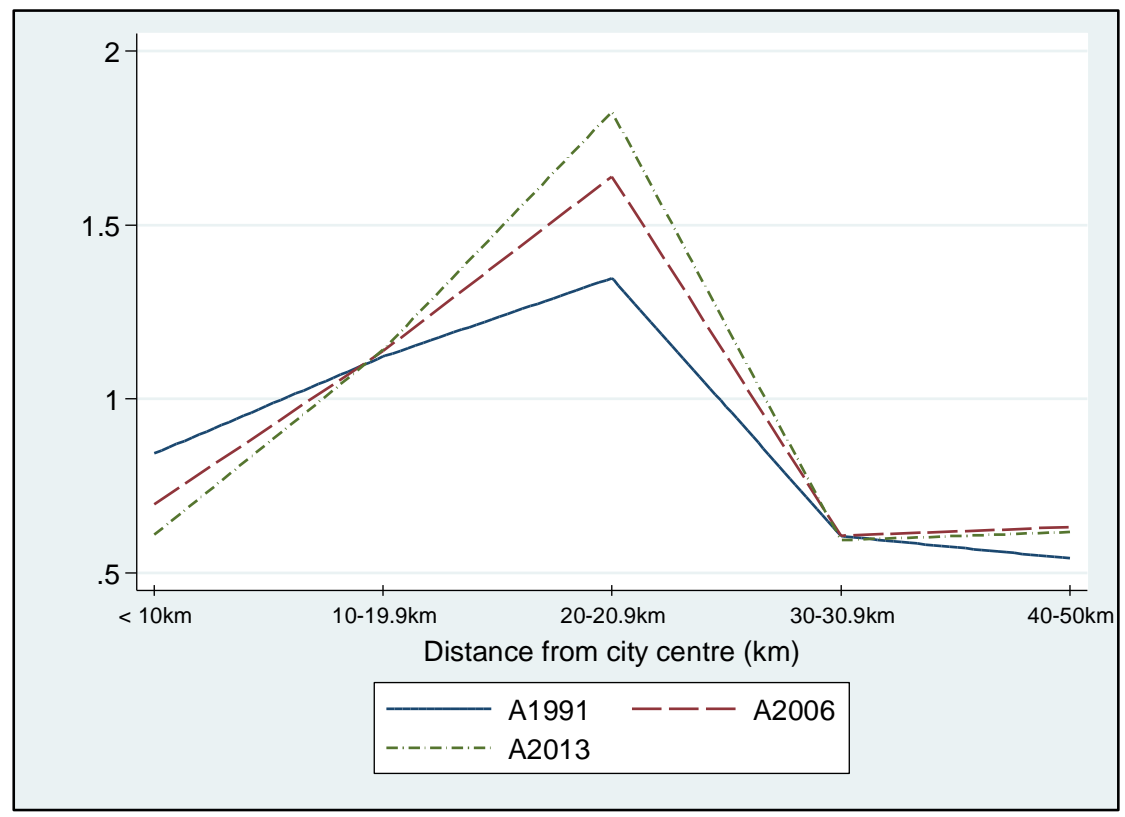

Figure 6.13 shows a line plot of the location quotients for the number of individuals with low-income contained within highly deprived meshblocks. The LQ in Figure 6.13 was calculated in the usual way but with $\mathrm{X}$ as low-income individuals in highly deprived meshblocks.

Figure 6.13 shows a slightly different pattern of the concentration of low-income in highly deprived meshblocks than the overall population seen in Figure 6.12. There is a very slight increase in the LQ for the first distance band, followed by a large decrease in the second distance band. Across the third and fourth distance bands, there were large increases in the concentration of low income in highly deprived meshblocks. 
Figure 6.13. Location quotients for number of low income individuals in highly deprived meshblocks in Auckland, 20012006 and 2013.

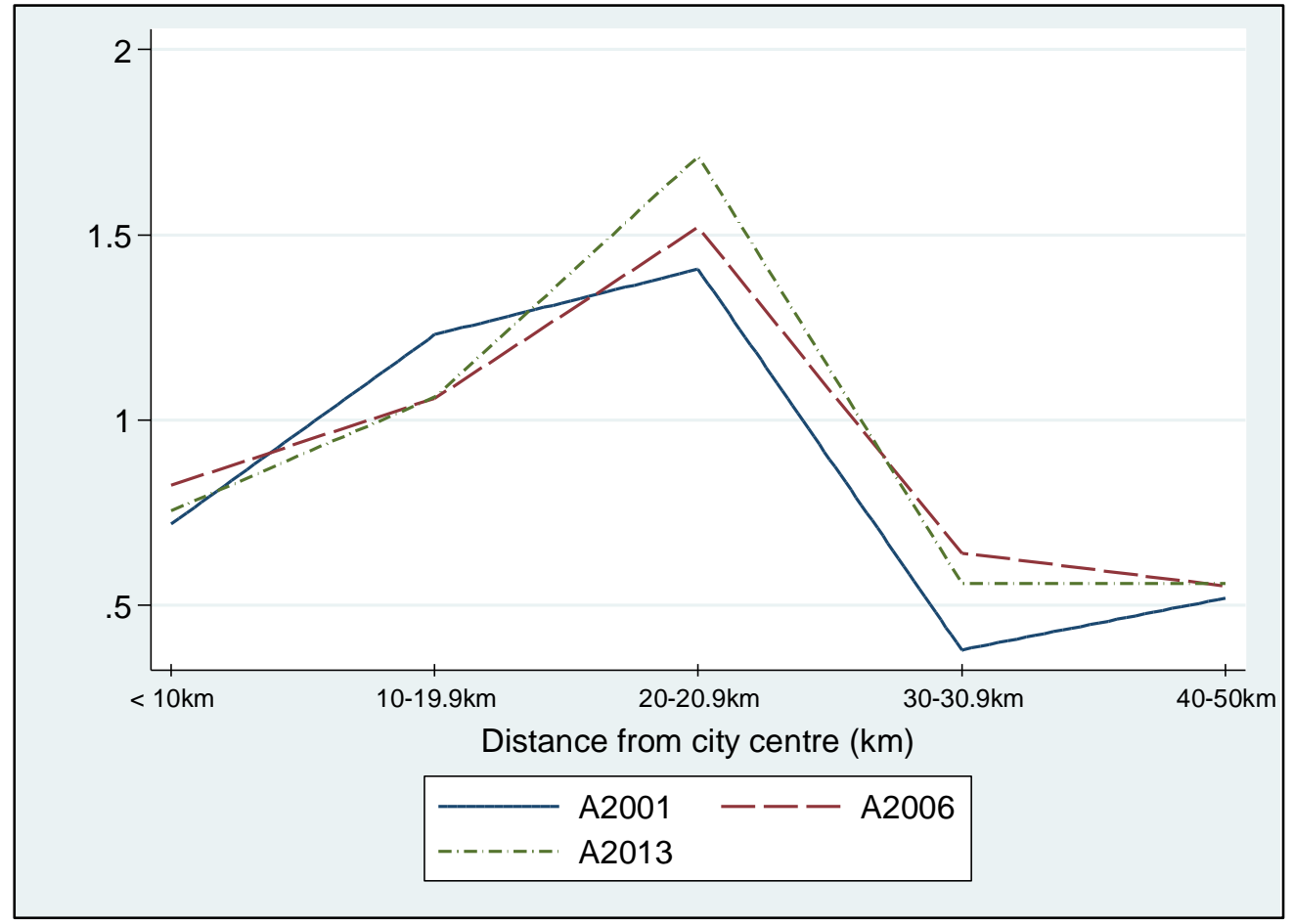

Figure 6.14 shows a line plot of the location quotients for the number of individuals receiving a means tested benefit contained within highly deprived meshblocks. The LQ in Figure 6.14 was calculated in the usual way but with $\mathrm{X}$ as population receiving a means-tested benefit in highly deprived meshblocks.

Figure 6.14 follows a similar pattern to Figure 6.13. This makes sense, as lowincome individuals are more likely to rely on government support in the form of means tested benefits. There is a very similar proportion of individuals receiving means tested benefits in highly deprived meshblocks when comparing 2001 and 2013. However, by 2013, more individuals receiving means tested benefits are living in highly deprived meshblocks in the three outer distance bands. There was also a decrease in the concentration of means tested benefits in the second distance band. 
Figure 6.14. Location quotients for number of means tested benefit in highly deprived meshblocks in Auckland, 20012006 and 2013.

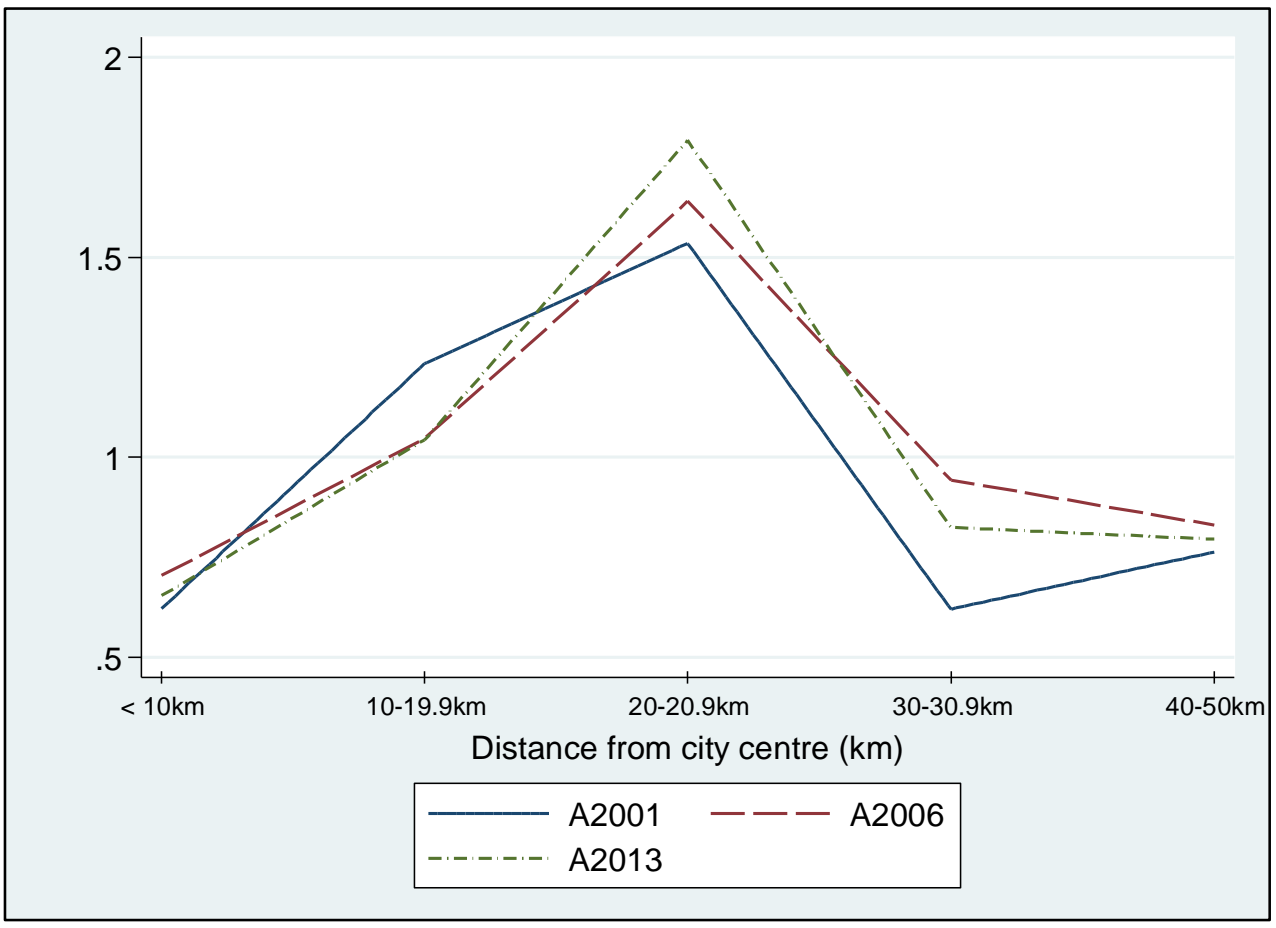

Figure 6.15 shows a line plot of the location quotients for the number of individuals unemployed contained within highly deprived meshblocks. The LQ in Figure 6.15 was calculated in the usual way but with $\mathrm{X}$ as unemployed individuals in highly deprived meshblocks.

Figure 6.15 shows a decrease in the concentration of unemployment in highly deprived meshblocks for the first and second distance bands. However, over the time series there was a large increase in the concentration of unemployment in highly deprived meshblocks in the third distance band. 
Figure 6.15. Location quotient for number of unemployed in highly deprived meshblocks in Auckland, 19912006 and 2013.

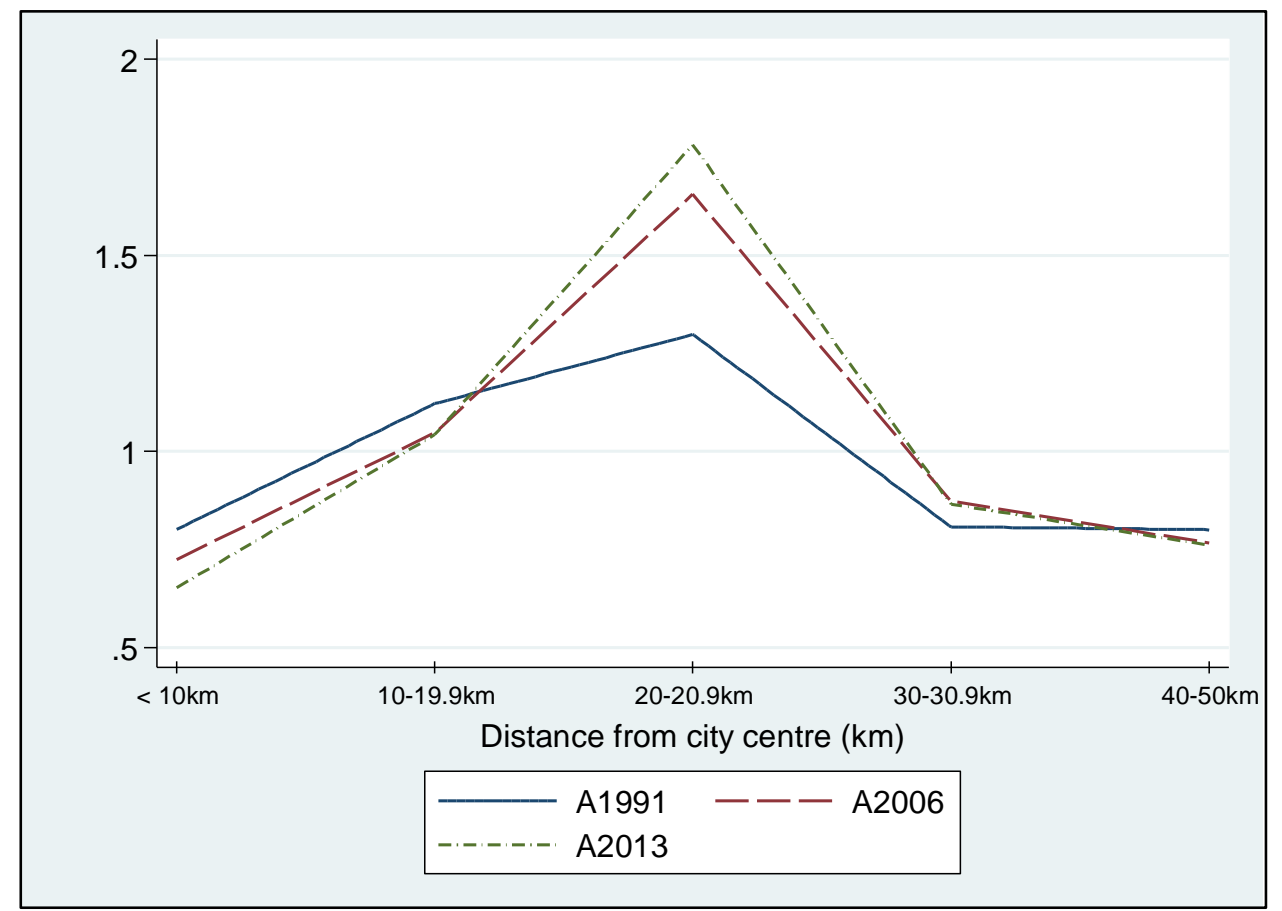

Figure 6.16 shows a line plot of the location quotients for the number of one-parent families contained within highly deprived meshblocks. The LQ in Figure 6.16 was calculated in the usual way but with $\mathrm{X}$ as one-parent families in highly deprived meshblocks.

Figure 6.16 shows a large decrease over the time series in the concentration of one parent families in highly deprived meshblocks for the first distance band, and a small decrease in the fourth and fifth distance bands. There was a large increase in the concentration of one parent families in highly deprived meshblocks for the third distance band. There was no change in concentration across the time series for the second distance band. 
Figure 6.16. Location quotient for number of one-parent family in highly deprived meshblocks in Auckland, 19912006 and 2013.

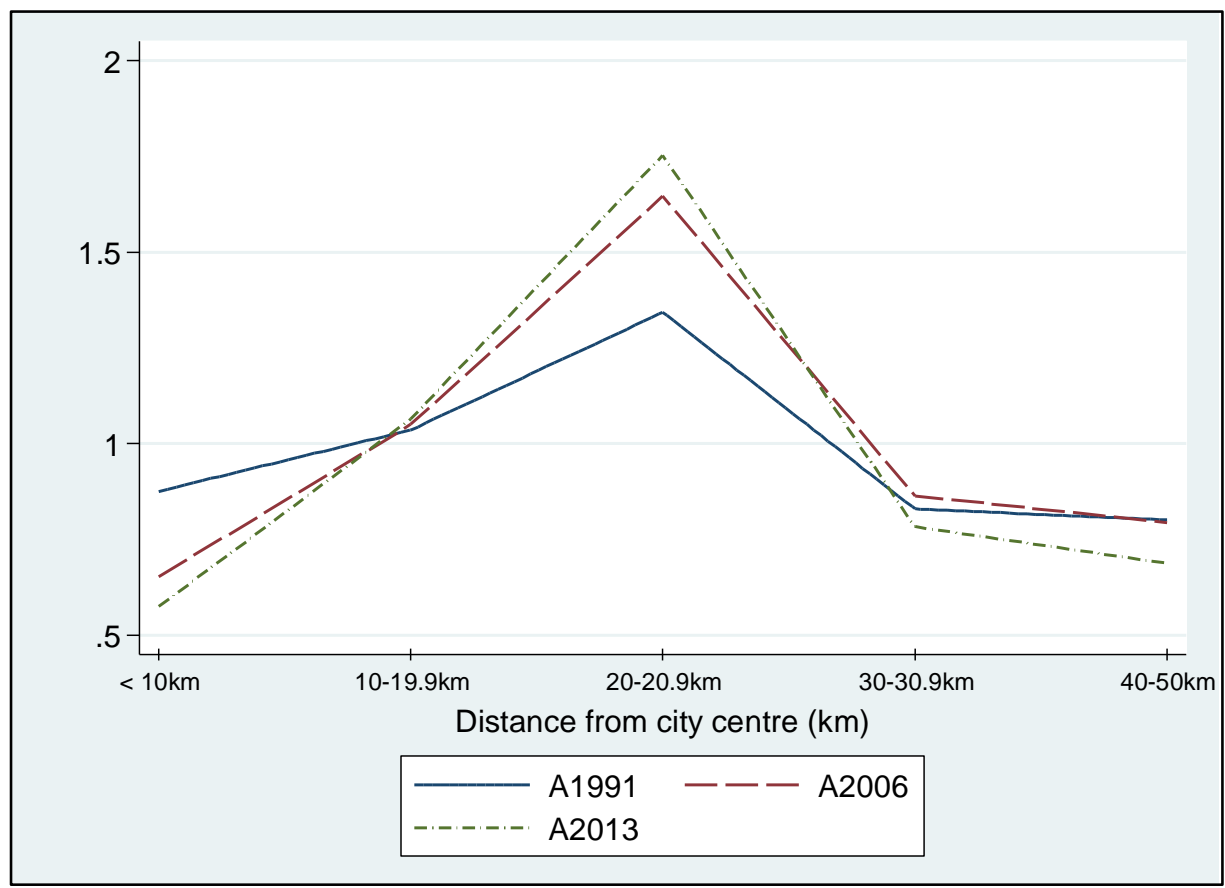

Figure 6.17 shows a line plot of the location quotients for the number of households who do not own their dwelling contained within highly deprived meshblocks. The LQ in Figure 6.17 was calculated in the usual way but with $\mathrm{X}$ as households who do not own their dwelling in highly deprived meshblocks.

Figure 6.17 shows a similar pattern to the concentration of the unemployed in highly deprived meshblocks shown in Figure 6.15. There is a decrease in the concentration of household who do not own their home in highly deprived meshblocks for the first two distance bands. Across the same period, there is a large increase in the concentration of households who do not own their home in highly deprived meshblocks for the third distance band, and slighter increases for the fourth and fifth distance bands. 
Figure 6.17. Location quotient for number of households who do not own their dwelling for highly deprived meshblocks in Auckland, 19912006 and 2013.

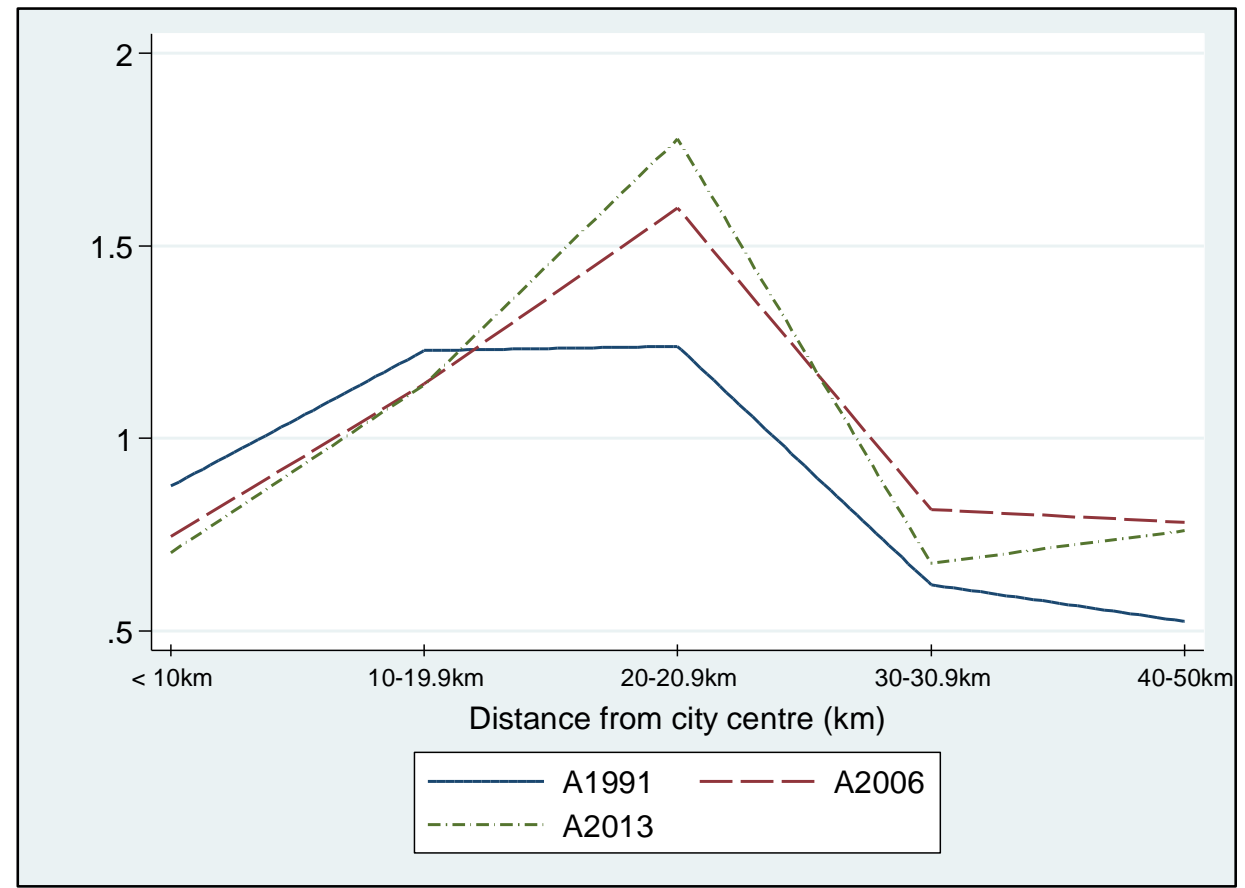

Figure 6.18 shows a line plot of the location quotients for individuals who do not possess a qualification contained within highly deprived meshblocks. The LQ in Figure 6.18 was calculated in the usual way but with $\mathrm{X}$ as individuals who do not possess a qualification in highly deprived meshblocks.

Figure 6.18 shows a decrease in the concentration of non-qualified individuals in highly deprived meshblocks for the first two distance bands, and an increase for the third, fourth and fifth distance bands. 
Figure 6.18. Location quotients for number of individuals who do not possess a qualification for highly deprived meshblocks in Auckland, 20012006 and 2013.

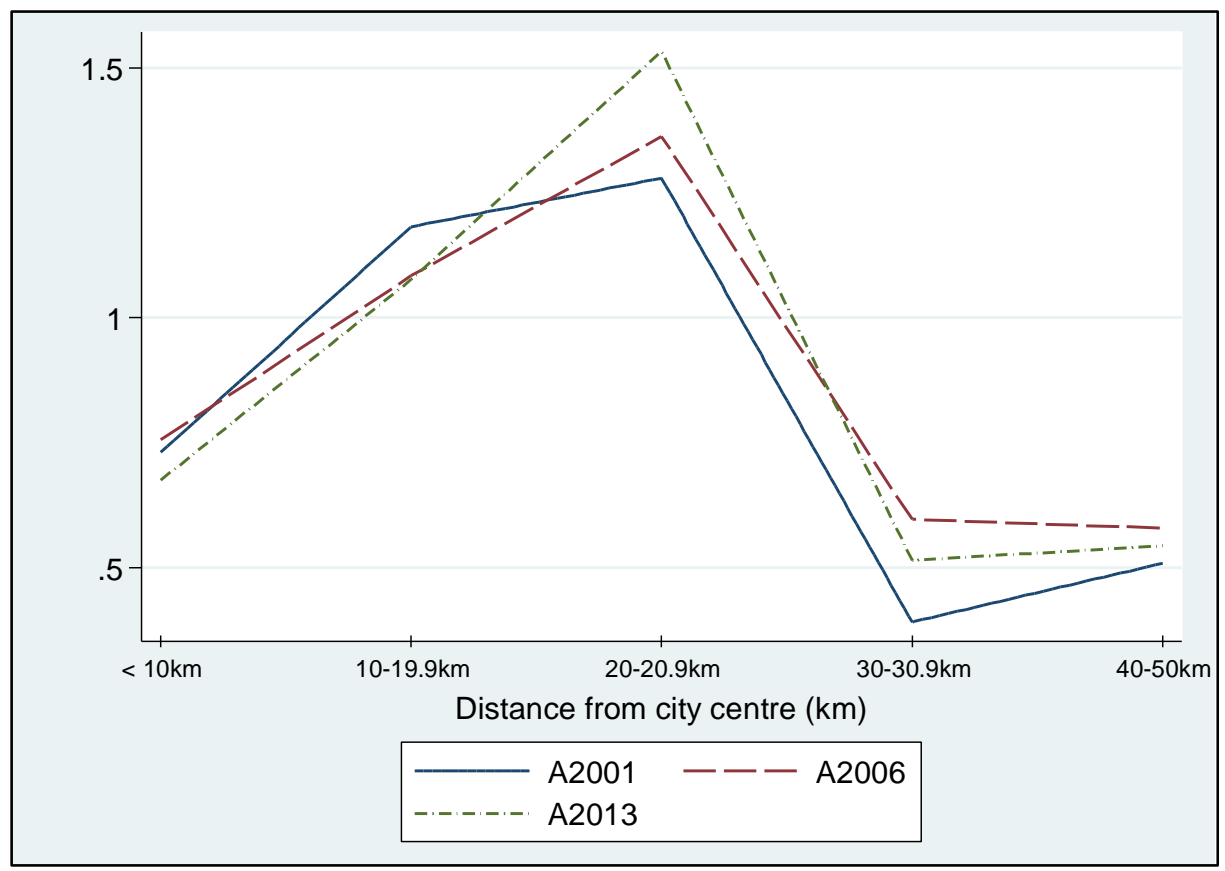

Figure 6.19 shows a line plot of the location quotients for the ratio of household members to bedrooms contained within highly deprived meshblocks. The LQ in Figure 6.19 was calculated in the usual way but with $\mathrm{X}$ as the ratio of household members to bedrooms in highly deprived meshblocks.

Figure 6.19 shows a decrease over the time series in the crowding ratio LQ in highly deprived meshblocks for the second distance band. Additionally, Figure 6.19 shows an increase in the crowding ratio LQ in highly deprived meshblocks for the first, third, fourth and fifth distance bands over the period measured. Interestingly, the crowding ratio LQ in highly deprived areas for 2006 was an increase from 1991 for the first band and third distance band, and a decrease for the second, fourth and fifth distance bands. Figure 6.19 shows a large amount of variation and change between periods. 


\section{Figure 6.19. Location quotient for crowding ratio for highly deprived}

meshblocks in Auckland, 19912006 and 2013.

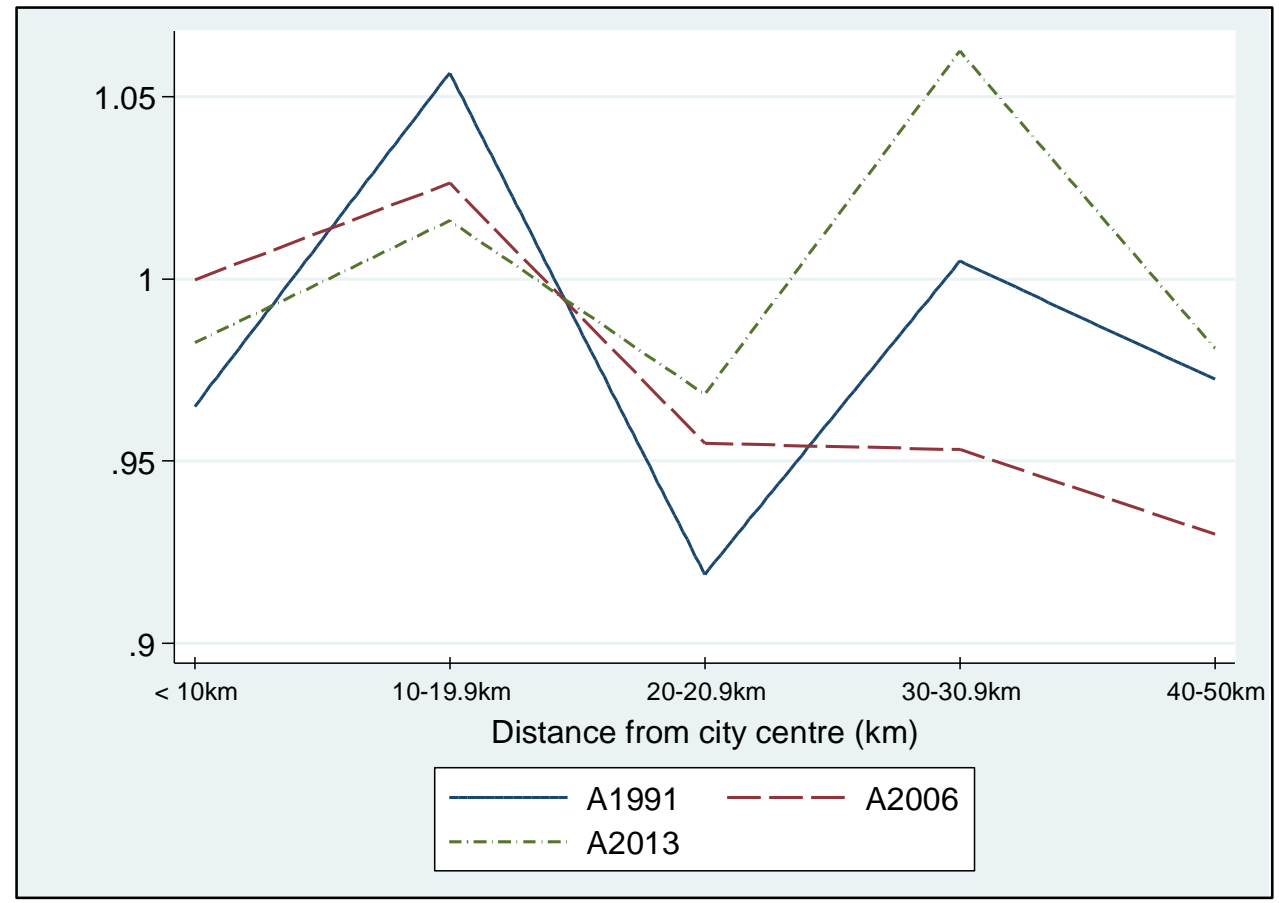

Figure 6.20 shows a line plot of the location quotients for individuals who have no access to a vehicle contained within highly deprived meshblocks. The LQ in Figure 6.20 was calculated in the usual way but with $\mathrm{X}$ as individuals who have no access to a vehicle in highly deprived meshblocks.

Figure 6.20 shows an increase over the time series in the concentration of population with no access to a vehicle in highly deprived areas for the first, third, fourth and fifth distance bands. There was a decrease across the time series in the concentration of population with no access to a vehicle in highly deprived meshblocks for the second distance band. 
Figure 6.20 Location quotient for individuals with no access to a vehicle for highly deprived meshblocks in Auckland, 19912006 and 2013.

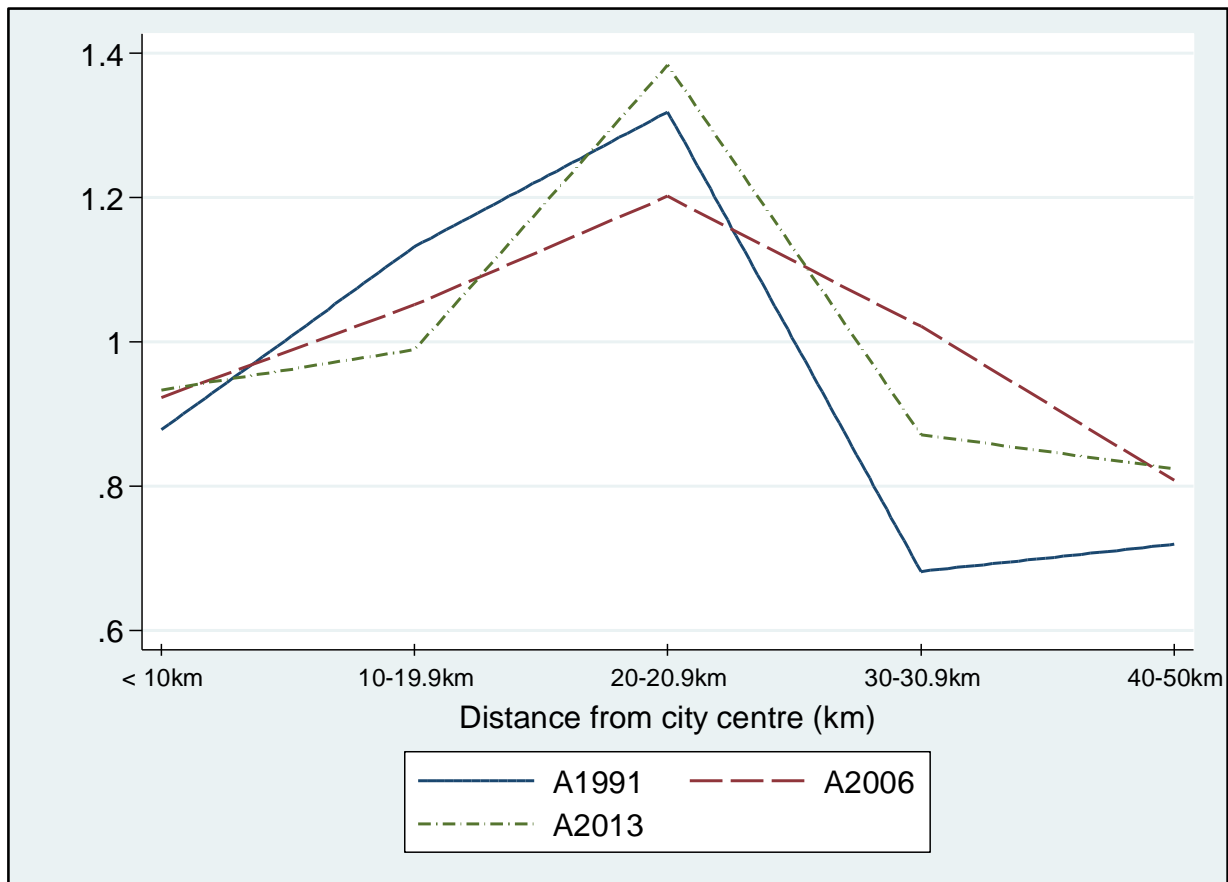

In summary, Auckland saw a decrease of the proportion of population in highly deprived meshblocks within the first 10km from the city centre from 1991 to 2013 . The concentration of deprived population remained the same in the second and fourth distance bands across this time series and increased for the third and fifth distance bands. Most of the components that make up deprivation score followed a similar trend, except in the second distance bands.

Every individual deprivation component - apart from one parent families experienced a decrease of concentration in highly deprived areas in Auckland for the second distance band. In my chapter four analysis, I found that the population in highly deprived meshblocks was initially highest in the first distance band and was the highest in the second distance band by 2013. The second band also experienced the biggest absolute increase in population in highly deprived meshblocks. This suggests that while population in highly deprived meshblocks has proportionally stayed the same initially across this period, there has been more dispersion into meshblocks not considered highly deprived for the different individual components of deprivation. 
Alternatively, the crowding ratio LQ might provide an explanation for the dissimilarity of the concentration of components of deprivation with the concentration of population in highly deprived meshblocks for the second distance band. The second distance band was the only distance band to experience a decrease in the crowding ratio LQ between 1991 and 2013. This suggests that crowding is associated to different individual components of deprivation.

\subsection{Summary}

In this chapter, I have analysed the concentration in highly deprived meshblocks of the different components that make up deprivation. The purpose of performing this analysis was to see whether different aspects of deprivation are becoming more concentrated in highly deprived areas or more dispersed away from deprived areas. From location quotients, I was able to determine that those on means-tested benefits and unemployed individuals are becoming more concentrated in deprived areas. I was also able to determine that crowding was associated with the temporal differences that saw Wellington and Auckland have different spatial distributions of deprivation between 1991-2006 and 2006-2013. In Wellington but not Auckland, crowding decreased as distance increased. By 2013, in Auckland, crowding was more likely the further from the city centre. 


\section{Chapter Seven - Conclusion}

\subsection{Introduction}

Researchers studying patterns in urban geography have started seeing an emerging suburbanisation of the poor. Through researching the geographic locations and spatial concentrations of social disadvantage, researchers and policy makers can identify where to focus social policy. This research comes from a commitment to a fair distribution of society's benefits, wealth, and community resources as a means of achieving social change.

My main aim in this thesis was to determine if and to what extent the spatial distribution and concentration of the 'urban poor' has changed in recent years for Wellington and Auckland, New Zealand's two largest cities. I was motivated to investigate this due to three ideas discussed in the literature. First, income polarisation has led to increasing income inequality in the last few decades. The spatial distribution of the 'urban poor' is a manifestation of income and the inherent inequalities associated with it. Based on this information, I wanted to make more visible the socioeconomic divisions that characterise our society.

Second, processes such as gentrification have led to areas in accessible locations developing at faster rates than non-accessible locations. Because the most accessible locations are closest to the city centres, many cities around the world have seen dramatic increases in the cost of living closer to the city centres. Reports of displacement and replacement of the previous residents in these areas has led to a new research focus for urban scholars around the world.

Third, over the past several years there has been substantial popular media coverage of a so-called 'housing crisis' in Auckland, and in more recent times, a 'rental crisis' in Wellington. Other cities around the world mirror these crises. However, Auckland has consistently ranked highly in comparison to other developed cities for housing unaffordability.

In this concluding chapter, I will summarise the research put forward in this thesis. I will start by outlining my research questions for this thesis, and the expectations that came with these questions. I will then discuss how each of my hypotheses was tested 
and answered. I will then discuss how these findings might be relevant to policy, both in a local and national sense. I will then mention some of the limitations to the

methodology I used in this thesis and provide some recommendations for any future research on this topic. Lastly, I will summarise the contribution my research has made.

\subsection{Hypotheses}

This research had three main research questions that I wished to answer. I posited each research question in a rather broad sense. Next, I outlined my expectations in answer to each research question based on what I already knew from the literature and conceptualising the problem. I followed up each research question with my hypothesis. My hypotheses came in a simplified form so that I could answer them definitively. I will address each research question, hypothesis and result in turn.

The first and primary research question I sought to answer in chapter four centred on the distribution of the urban poor. Specifically, I wanted to investigate whether there had been a shift in the distribution of the urban poor away from the urban centre, towards the suburbs and periphery of cities. This research question forms the backbone of my thesis. The period I looked at was from 1991 (the earliest possible data available) to 2013 (the latest possible data available). The two main variables I was looking at were NZ deprivation score (explained in chapter three) and distance. The geographic unit I used was meshblocks - the smallest area available, consisting of on average 78 people. I considered meshblocks to be "highly deprived" if they were at or beyond one standard deviation above the mean of the NZ deprivation score. The distance variable was meshblocks categorised into $10 \mathrm{~km}$ concentric bands away from the city centres.

My expectation was that I would see a decrease in the level of the urban poor near the centre of the cities. Various other research measured or observed this phenomenon in different cities around the world. In particular, Randolph and Tice's (2017) research looked at Australia's five largest cities, and all five cities saw decreases in the prevalence of "highly disadvantaged CDs" in a distance band closest to the city centre. 
Therefore, my hypothesis was that both Wellington and Auckland would see decreases in the number of high-deprivation meshblocks within $10 \mathrm{~km}$ of their respective city centres. This decrease in the first $10 \mathrm{~km}$ would be replicated with an increase in high-deprivation meshblocks in a further distance band or bands. My hypothesis would be incorrect if I found no increases or decreases in the distribution of highly deprived meshblocks across any of the distance bands for each city over the period.

My analysis showed a very slight increase in the highly deprived meshblocks within $10 \mathrm{~km}$ for Wellington over the 22-year period from 1991 to 2013. However, my analysis showed a small decrease in the concentration of population within those meshblocks. Auckland experienced a large decrease in the highly deprived meshblocks within the first $10 \mathrm{~km}$, and a decrease in the concentration of population within these meshblocks. Both cities experienced increases in the number of highly deprived meshblocks beyond $20 \mathrm{~km}$, as well as increasing concentration beyond that distance. While the Wellington evidence did not match the Auckland and Sydney evidence exactly, my evidence confirms that New Zealand too was experiencing its own 'suburbanisation of the poor'.

The second research question I sought to answer in chapter five centred on the differences in the shift of the distribution of the urban poor between periods. Specifically, I wanted to investigate whether different periods coinciding with both weak and strong macroeconomic conditions had different experiences in the distribution of the urban poor. In this analysis, I introduced 2006 data to observe 1991 to 2006 (the strong macroeconomic period, or the "expanding" period) and 2006 to 2013 (the weak macroeconomic period, or the "contracting" period). The proxy I used to determine the macroeconomic period was the male unemployment rate for that particular city.

My expectation was that there would be less of a shift in the distribution of highly deprived meshblocks away from the city centre during strong macroeconomic conditions. Any shift would become more prominent in a "contracting" period. I also expected the concentration to be less during the "expanding" period. During the "contracting" period, I expected the concentration of population in highly deprived 
meshblocks to increase. At the very least, I expected the differences in deprivation to vary.

Based on this, my hypothesis was that both Wellington and Auckland would see decreases in the proportion of highly deprived meshblocks within $10 \mathrm{~km}$ for the first period measured. They would also both see increases in the proportion in the outer distance bands. The concentration of population in the highly deprived meshblocks for the first distance band would decrease, and potentially decrease in other distance bands too. For the second period measured, the reverse would be true. My hypothesis would be incorrect if there was no difference between the two periods.

My analysis showed there was a big decrease in the proportion of highly deprived meshblocks closest to the centre of the city in Auckland for the first period. Then, in the second period, there was only a slight decrease. There was also a decrease in the concentration of population within highly deprived meshblocks in the first $10 \mathrm{~km}$ distance band for both periods. In Auckland's case, I could not reject the null hypothesis, meaning my analysis was not able to determine whether the strength of macroeconomic conditions played a part in the distribution and concentration of highly deprived meshblocks and their population.

For Wellington, my analysis showed there was a decrease in the proportion of highly deprived meshblocks closest to the centre of the city for the first period. In the second period, there was an increase. However, the proportion of the population within highly deprived meshblocks increased for the first period and decreased for the second period, going against my expectation. In Wellington's case, my hypothesis was not correct. In fact, my analysis showed the opposite of my hypothesis. My analysis showed that there was some sensitivity or association with the temporal nature of the macroeconomic conditions. However, my analysis showed the opposite situation to what I expected for the concentration of population in highly deprived meshblocks.

Hochstenbach and Musterd (2017) looked at the changing urban geographies before and after the global financial crisis in the two largest cities in the Netherlands, Amsterdam and Rotterdam. The authors found that Amsterdam housing context was relatively crisis resistant, while Rotterdam is more sensitive to the cyclical nature of 
the economy. This bears resemblance to Auckland and Wellington. While the time differences did not seem to affect Auckland, Wellington had substantively different experiences between the two periods.

The third research question I sought to answer in chapter six centred on the individual components of disadvantage that make up the urban poor population. In my first two research questions, I used an aggregate variable called New Zealand deprivation score (NZDep score). This score compiled eight to 11 variables from the New Zealand census that are common when measuring disadvantage. The creators of NZDep score weighted each variable according to perceived effects on health outcomes. Specifically, I wanted to investigate if and how these variables differ in their concentration across a city. Therefore, I used approximate aggregated data for the smallest geographic region available (meshblocks) that was the best equivalent to each individual component that made up the NZDep score.

My expectation was that all variables used would have roughly the same concentration in highly deprived meshblocks as the concentration of population. The deprivation score is a composite variable, made from the input variables, so it follows that the variance would be relatively constant.

Based on this thought, my hypothesis was that the concentration of each individual component that makes up the deprivation score in highly deprived meshblocks is similar to the concentration of population in highly deprived meshblocks. My analysis showed that in Wellington, the unemployment and crowding ratio variables were the only two variables not to mimic the concentration of population in highly deprived meshblocks. In Auckland, only the crowding ratio did not follow the population concentration trends in highly deprived meshblocks. This suggests that crowding is a necessary housing consumption change that not only the disadvantaged or urban poor must make, but the wider population must make as well.

Based upon my research questions, hypotheses and analysis, what did I find? My research tells me there has been a shift in the spatial distribution of deprivation. In 1991, the majority of highly deprived meshblocks were in the first $10 \mathrm{~km}$ for Auckland. By 2006 and 2013, the 10-30km range from the central city contained the majority of highly deprived meshblocks. Likewise, while the central Wellington city 
did not have a majority of the highly deprived meshblocks, between 1991 and 2006 there was a significant decrease (see Figure 5.4). Wellington's situation is partly explained by an increase in the concentration of unemployed individuals as well as crowding increasing.

\subsection{Policy implications}

The conclusions I have drawn from this research have several policy implications. These implications focus primarily on three core areas - housing, transport, and health.

Auckland and Wellington are two of the most expensive places to live in New Zealand. The cost of housing, either owning or renting, is disproportionately higher than most of the country (except for Queenstown). If greater density or concentration of deprivation is seen as a problem (and in many cases it probably is, due to associations with poor health correlates), then this research can inform decision makers around housing developments.

My research has shown that in the cases of both Wellington and Auckland, deprivation (and logically, the components that make up deprivation score) has consistently shifted away from the city centres and become more concentrated. Based on these findings, two suggestions for housing development have arisen. First, housing development should occur nearer to the city and intensify the current housing stocks. By increasing the supply of housing and providing greater density in housing and population in the areas near the city centre, not only is this good for the environment, it is good for the affordability of housing. Having cheaper available housing in these areas, either for owner-occupiers or for renters can reduce the presence for some of the shift in the urban poor away from the city centre.

Second, greater densities in neighbourhoods proximate to employment centres and transport nodes would help spur further improvements in public transport, while an increased housing supply in centrally located areas would help to lower house prices in these neighbourhoods (Mattingly and Morrissey, 2014). If Edlund, Machado, \& Sviathci (2017) are right, and that there is an increasing opportunity cost of time driving gentrification, then these trends recognised in my research will continue. In future research, it would be valuable to explore this implication in more depth. 
My analysis showed populations in highly deprived areas were concentrating more over time. If this is the case, then increasing the density, and therefore the affordability of housing in those areas provides people living in those areas cheaper options to reduce their household consumption costs - savings they can use on other spending to reduce disadvantage. Populations concentrate in deprived or highly deprived areas because generally the housing is cheaper there. By developing areas that deprived populations are concentrating in, this can offset some of the components that make up deprivation.

However, if housing development and greater density in neighbourhood is to occur near employment centres and transport nodes, or develop with the intention of building transport infrastructure, the challenge is to avoid allowing that area to gentrify. Current policies such as KiwiBuild require or at the very least strongly encourage developers to include "affordable housing" in their development plans. Special agreements between central and local governments such as Housing Accords (a way to fast track planning permissions to freely make available land for housing development) are a criticised, yet interesting way that previous governments have opened land to develop quickly. Essentially Housing Accords are granted to large scale development on the basis that mixed tenure and mixed affordability homes be required (it remains to be seen how effective a policy like this is). Kiwibuild has a mechanism in place that will disincentivise someone to buy an affordable house and then immediately sell off the house for a gain. However, three years down the line there is no such constraint in place.

Measures such as rent control in dwellings such as apartments in Europe and cities such as New York have been able to stem the tide of replacement or displacement as modern cities have gentrified around the residents. New Zealand currently has weak rights for renters in tenancy laws.

My research also has policy implications for health. Following on from the housing developments discussion, providing newer and more modern houses for poor, disadvantaged or deprived populations is a health benefit. In addition, I found there was more crowding in disadvantaged areas by the poor during times of economic decline. The combination of crowding and poor housing can exacerbate ill health. While the NZDep score was invented to measure against health indicators at a DHB 
level, seeing the city at $10 \mathrm{~km}$ intervals can give the interpreter or decision maker more nuance when allocating health resources.

\subsection{Limitations and future research}

There are limitations to this research that I will acknowledge in the hopes that any future research undertaken on a similar topic can attempt to consider. This research is not a comprehensive look at the changing spatial location and organisation of socioeconomically disadvantaged populations in urban centres, nor does it pretend to be. The criteria used to examine my research questions were limited, both in terms of public availability, and the period measured.

In my conceptual framework and following analysis, I assume that Auckland and Wellington are largely monocentric. However, patterns of location in both cities could be a mixture of monocentric attraction, polycentric additions to that, and other factors such as the availability of new housing in areas where certain groups feel comfortable - for ethnic reasons, for example. In this thesis I do not discuss in detail these other factors influencing patterns of location. For example, Porirua and South Auckland have strong Māori and Pasifika communities, so some households would be attracted to locate there for reasons of ethnic connection. It is possible that these factors may become more important during an economic downturn. These factors may modify or even outweigh the incentives created by lower rents as distance increases from the city centre, and these should be heavily considered in any future research.

Another aspect of this research that I took caution around was reification. Reification is the potential problem of confusing the indicator, or measure, with the underlying phenomenon. Reification often arises when attempting to measure socioeconomic position. The problem occurs due to the inability of any one socioeconomic indicator to capture all aspects of the complex social situation of the population that it attempts to measure. In using deprivation score, a number assigned to an area based on the individuals contained within that area, I made sure to never characterise the individuals within as deprived or highly deprived.

My research has focused on small geographical areas that Statistics New Zealand (StatsNZ) create by assigning artificial boundaries. Twice every decade, StatsNZ 
collects a nationwide survey of population and dwellings in a census. This comes in two forms, one for every individual, and one for each dwelling. While this census is mandatory for the entire population to complete, the detail is limited to what StatsNZ can realistically expect individuals to provide.

To limit people's concerns around anonymity, StatsNZ often asks for sensitive information as a ranged category and not a specific number. For personal information such as income, the census offers ranges so that the individual can give a best estimate and feel secure.

Both difficulties limit the interpretation I, or any other researcher, can draw from the data. StatsNZ can also grant some researchers special agreements to work in the StatsNZ data lab and have access to the non-confidentialised, non-grouped data. Having this access would allow a researcher to measure individuals, households or families.

Any future research should attempt to measure movements or take a "people-based approach" alongside the "place-based approach" that I undertook in this research (I describe the differences between these two approaches in chapter two). By measuring movement, known as internal-migration or residential mobility, future research could gain a better understanding as to how concentration of disadvantage is manifested.

Future research should also attempt to measure the change in distribution and concentration of disadvantaged households, rather than individuals. Often, individuals are not independent as economic actors. Rather, multiple actors in a household make joint economic decisions. Therefore, it follows that future research should focus on households as the unit of analysis and not individuals.

\subsection{Contribution}

While there has already been a body of literature focusing on the suburbanisation of poverty or disadvantage, this thesis adds to this literature in two keys ways. Firstly, this thesis focuses not only the changing distribution of deprivation, but on the changing concentration of this deprivation. Furthermore, this research focuses on the concentration of individual components that make up deprivation. This research 
takes a wider approach to measuring the poor or disadvantaged than in previous literature, and it takes a long view. This research builds upon what people such as Allard (2017) advocate for, arguing that there is a growing suburbanisation of the poor, and that social policy must take this into account.

Secondly, this research measures the spatial distribution and concentration of deprivation in New Zealand. Previously, no such studies looked at either of the two biggest cities in New Zealand on a city level. In this research, I was also able to compare my findings to similar cities in Australia. Australian and New Zealand cities have similar histories in terms of the time of their development. However, researchers tend not to compare these cities to one another. These comparisons can be useful for decision makers when allocating resources in the hopes of improving the wellbeing of their residents. 


\section{References}

Abramson, A. J., Tobin, M. S., \& VanderGoot, M. R. (1995). The changing geography of metropolitan opportunity: The segregation of the poor in U.S. metropolitan areas, 1970 to 1990 . Housing Policy Debate, 6(1), 45-72.

Acevedo-Garcia, D., McArdle, N., Hardy, E., Dillman, K.-N., Reece, J., Crisan, U. I., Osypuk, T. L. (2016). Neighborhood opportunity and location affordability for low-income renter families. Housing Policy Debate, 26(4-5), 607-645.

Acolin, A., \& Wachter, S. (2017). Opportunity and housing access. Cityscape, 19(1), 135.

Allard, S. (2017). Places in Need: The Changing Geography of Poverty. New York: Russell Sage Foundation.

Allen, N. (2015). Understanding the importance of urban amenities: A case study from Auckland. Buildings, 5(1), 85-99.

Arribas-Bel, D., \& Sanz-Gracia, F. (2014). The validity of the monocentric city model in a polycentric age: US metropolitan areas in 1990, 2000 and 2010. Urban Geography, 35(7), 980-997.

Atkinson, R. (2004) The evidence on the impact of gentrification: new lessons for the urban renaissance? International Journal of Housing Policy, 4(1), 107-131.

Atkinson, J., Salmond, C., \& Crampton, P. (2014). NZDep2013 Index of Deprivation. Retrieved from Dunedin, NZ:

Baer, W. C., \& Williamson, C. B. (1988). The Filtering of Households and Housing Units. Journal of Planning Literature, 3(2), 127-152.

Barron, K., Kung, E., \& Proserpio, D. (2017). The Sharing Economy and Housing Affordability: Evidence from Airbnb. 
Bayona, J., \& Gil Alonso, F. (2012). Suburbanisation and international immigration: The case of The Barcelona Metropolitan Region (1998-2009). Tijdschrift Voor Economische en Sociale Geografie, 312-329.

Bertaud, A. (2014). Cities as labor markets. New York University: New York, NY, USA.

Bochnovic, M. A. (2014). An Analysis of Bid-Rent Curve Variations Across American Cities: Arizona State University.

Boddy, M., \& Gray, F. (1979). Filtering Theory, Housing Policy and the Legitimation of Inequality. Policy \& Politics, 7, 39-54.

Brueckner, J. K., Thisse, J.-F., \& Zenou, Y. (1999). Why is central Paris rich and downtown Detroit poor?: An amenity-based theory. European Economic Review, 43(1), 91-107.

Butler, T. and Hamnett, C. (2009) Walking Backwards to the Future - Waking Up to Class and Gentrification in London. Urban Policy and Research, 27(3): 217-228.

Clark, W. A. V., \& Morrison, P. S. (2012). Socio-spatial Mobility and Residential Sorting: Evidence from a Large-scale Survey. Urban Studies, 49(15), 3253-3270.

Collins, F. L. (2010) International students as urban agents: International education and urban transformation in Auckland, New Zealand. Geoforum, 41(6), 940-950.

Cooke, T. J. (2010). Residential Mobility of the Poor and the Growth of Poverty in Inner-Ring Suburbs. Urban Geography, 31(2), 179-193.

Cooke, T. J., \& Denton, C. (2015). The suburbanisation of poverty: An alternative perspective. Urban Geography, 36(2), 14.

Cox, W., Pavletich, H., \& Hartwich, O. (2017). 13th annual demographia international housing affordability survey: 2017.

Dixon, J., \& Dupuis, A. (2003). Urban Intensification in Auckland, New Zealand: A Challenge for New Urbanism. Housing Studies, 18(3), 353-368. 
Dodge, N. (2017). A quarter acre pavlova paradise lost? The role of preferences and planning in achieving urban sustainability in Wellington, New Zealand. Victoria University of Wellington.

Dorling, D., \& Rees, P. (2003). A Nation Still Dividing: The British Census and Social Polarisation 1971-2001. Environment and Planning A, 35(7), 1287-1313.

Dubin, R. (1991). Commuting patterns and firm decentralization. Land Economics, 67(1), 15-30.

Duranton, G., \& Puga, D. (2015). Urban land use. In Handbook of regional and urban economics (Vol. 5, pp. 467-560). Elsevier.

Dwyer, R. E. (2010). Poverty, Prosperity, and Place: The Shape of Class Segregation in the Age of Extremes. Social Problems, 57(1), 114-137.

Edlund, L., Machado, C., \& Sviatschi, M. (2017). Gentrification and Rising Returns to Skill. (No. Working Paper 21729). National Bureau of Economic Research. Retrieved from https://www.gc.cuny.edu/CUNY_GC/media/CUNY-GraduateCenter/PDF/Programs/Economics/Other\%20docs/GAll2017x11x13_1.pdf

Ellen, I. G., \& O'Regan, K. (2011). Gentrification: Perspectives of Economists and Planners. In N. Brooks, K. Donaghy, \& G. J. Knaap (Eds.), The Oxford Handbook of Urban Economics and Planning. UK: Oxford University Press.

Fallis, G. (1984). Housing Economics: Elsevier.

Fischer, C. S., Stockmayer, G., Stiles, J., \& Hout, M. (2004). Distinguishing the geographic levels and social dimensions of U.S. metropolitan segregation, 19602000. Demography, 41(1), 37-59.

Forman, C. (1989). Spitalfields: A Battle for Land. London, UK: Hilary Shipman.

Freeman, L., \& Braconi, F. (2004). Gentrification and Displacement New York City in the 1990s. Journal of the American Planning Association, 70(1), 39-52. 
Friesen, W. (2009) The demographic transformation of inner city Auckland, New Zealand population review, 35, 55-74.

Galster, G., \& Rothenberg, J. (1991). Filtering in Urban Housing: A Graphical Analysis of a Quality-Segmented Market. Journal of Planning Education and Research, 11(1), 37-50.

Glaeser, E. L., Gyourko, J., \& Saks, R. E. (2005). Why have housing prices gone up? American Economic Review, 95(2), 329-333.

Glass, R. L. (1964). Introduction to London: Aspects of change. London, UK: Centre for Urban Studies.

Haarhoff, E., Beattie, L., Dixon, J., Dupuis, A., Lysnar, P., \& Murphy, L. (2012). Future intensive: Insights for Auckland's housing.

Hackworth, J., \& Smith, N. (2001). The changing state of gentrification. Tijdschrift voor economische en sociale geografie, 92(4), 464-477.

Hamnett, C. (1991). The Blind Men and the Elephant: The Explanation of Gentrification. Transactions of the Institute of British Geographers, 16(2), 173-189.

Hamnett, C. (2003). Gentrification and the Middle-class Remaking of Inner London, 1961-2001. Urban Studies, 40(12), 2401-2426.

Hedin, K., Clark, E., Lundholm, E., \& Malmberg, G. (2012). Neoliberalization of Housing in Sweden: Gentrification, Filtering, and Social Polarization. Annals of the Association of American Geographers, 102(2), 443-463.

Hochstenbach, C., \& Musterd, S. (2017). Gentrification and the suburbanization of poverty: changing urban geographies through boom and bust periods. Urban Geography, 1-28.

Horn, K., \& Merante, M. (2017). Is home sharing driving up rents? Evidence from Airbnb in Boston. Journal of Housing Economics, 38, 14-24. 
Howell, A. J., \& Timberlake, J. M. (2014). Racial and Ethnic Trends in the Suburbanization of Poverty in U.S. Metropolitan Areas, 1980-2010. Journal of Urban Affairs, 36(1), 79-98.

Hwang, J., \& Lin, J. (2016). What Have I Learned About the Causes of Recent Gentrification? Cityscape, 18(3), 9.

Jager, M. (1986) Class definition and the esthetics of gentrifciation: Victoriana in Melbourne, in eds Smith, N. and Williams, P. Gentrification of the city, Allen and Unwin, Mass. 78-91.

Kavanagh, L., Lee, D., \& Pryce, G. (2016). Is Poverty Decentralizing? Quantifying Uncertainty in the Decentralization of Urban Poverty. Annals of the American Association of Geographers, 106(6), 1286-1298.

Kenna, T., Goodman, R., \& Stevenson, D. (2017). Privatising the suburbs: examining the trends and implications of 20 years of private residential development in Sydney, Australia. Geographical Research.

Kneebone, E., \& Holmes, N. (2015). The growing distance between people and jobs in metropolitan America. In E. Roberto (Ed.), Commuting to opportunity: The working poor and commuting in the United States. Washington, DC: Brookings Institution, Metropolitan Policy Program.

Kulish, M., Richards, A., \& Gillitzer, C. (2012). Urban structure and housing prices: Some evidence from Australian cities. Economic Record, 88(282), 303-322.

Latham, A. (2000) Urban renewal, heritage planning and the remaking of an innercity suburb: a case study of heritage planning in Auckland, New Zealand, Planning Practice and Research, 15(4), 285-298.

Lees, K. (2014). Big city life? Challenges and trade-offs for Auckland city. NZIER Working Paper 2014/2, New Zealand Institute of Economic Research.

Lees, L. (2012) The geography of gentrification Thinking through comparative urbanism. Progress in Human Geography, 36(2): 155-171. 
Lees, L., Slater, T., \& Wyly, E. (2013). Gentrification. New York, US: Routledge.

Ley, D. (1994) Gentrification and the politics of the new middle class. Environment and Planning D: Society and Space, 12, 53-74.

Lowry, I. S. (1960). Filtering and Housing Standards: A Conceptual Analysis. Land Economics, 36(4), 362-370.

Maclennan, D. (1982). Housing economics: An applied approach: Longman Publishing Group.

Maré, D. C., Pinkerton, R. M., Poot, J., \& Coleman, A. (2012). Residential Sorting Across Auckland Neighbourhoods. New Zealand Population Review, 38, 23-54.

Merle Zwiers, Gideon Bolt, Maarten Van Ham \& Ronald Van Kempen (2016) The global financial crisis and neighborhood decline, Urban Geography, 37(5), 664-684.

Mieszkowski, P., \& Mills, E. S. (1993). The Causes of Metropolitan

Suburbanization. The Journal of Economic Perspectives, 7(3), 135-147.

Morrison, P. S. (2005). Changing patterns of home ownership in New Zealand, 1991 to 2001. Retrieved from

http://repository.digitalnz.org/system/uploads/record/attachment/338/housing_tenure _aspirations_and_attainment_-_appendix_3.pdf

Morrison, P. S., \& McMurray, S. (1999). The Inner-city Apartment versus the Suburb: Housing Sub-markets in a New Zealand City. Urban Studies, 36(2), 377397.

Morrison, P. S., \& Nissen, K. (2010). Moving In and Out of Areas of Deprivation: Evidence from the New Zealand Census. Population Association of New Zealand, $36,55-80$.

Murphy, L. (2003) Reasserting the 'social' in social rented housing: politics, housing policy and housing reforms in New Zealand. International Journal of Urban and Regional Research 27(1), 90-101. 
Murphy, L. (2004) To the market and back: Housing policy and state housing in New Zealand. GeoJournal, 59(2), 119-126.

Murphy, L. (2008). Third-wave gentrification in New Zealand: the case of Auckland. Urban Studies, 45(12), 2521-2540.

Nolan, B., \& Whelan, C. T. (1996). Resources, deprivation, and poverty. OUP Catalogue.

Nunns, P. (2014). Location Affordability in New Zealand Cities: An Intra-urban and Comparative Perspective. Auckland, New Zealand: MRCagney Pty Ltd. Retrieved from http://transportblog.co.nz/wp-content/uploads/2014/07/Nunns-2014Locationaffordability-in-New-Zealand-cities-NZAE.pdf

Nunns, P., Hitchins, H., \& Owen, P. (2015). To buy or not to buy? A spatial analysis of house prices and rents in Auckland, $2001-2013$ (No. Technical Report 2015/002).

OECD. (2015). In It Together: Why Less Inequality Benefits All: OECD Publishing.

Pendall, R., Weir, M., \& Narducci, C. (2013). Governance and the geography of poverty: Why does suburbanization matter. MacArthur Foundation Network on Building Resilient Regions. Berkeley, US.

Persky, J., \& Wiewel, W. (2011). Urban Decentralization, Suburbanization, and Sprawl: An Equity Perspective - Oxford Handbooks. In N. Brooks, K. Donaghy, \& G. J. Knaap (Eds.), The Oxford Handbook of Urban Economics and Planning. UK: Oxford University Press.

Randolph, B., \& Tice, A. (2014). Suburbanizing Disadvantage in Australian Cities: Sociospatial Change in an Era of Neoliberalism. Journal of Urban Affairs, 36(s1), 384-399.

Raphael, S., \& Stoll, M. A. (2010). Job sprawl and the suburbanization of poverty. Washington, DC: Metropolitan Policy Program at Brookings.

Rérat, P., Söderström, O., and Piguet, E. (2010) New forms of gentrification: issues and debates. Population, Space and Place, 16(5), 335-343. 
Salmond, C., Crampton, P., \& Sutton, F. (1998). NZDep91: A New Zealand index of deprivation. Australian and New Zealand journal of public health, 22(7), 835-837.

Salmond, C., King, P., Crampton, P., \& Waldegrave, C. (2005). NZiDep. A New Zealand index of socioeconomic deprivation for individuals. Wellington: University of Otago/The Family Centre Social Policy Research Unit.

Slater, T. (2011). Gentrification of the city. In G. Bridge \& S. Watson (Eds.), The New Blackwell Companion to the City. New York, US: John Wiley \& Sons.

Smith, N. (1987). Gentrification and the Rent Gap. Annals of the Association of American Geographers, 77(3), 462-465.

Smith, N. (1996) The new urban frontier: gentrification and the revanchist city. New York: Routledge.

Smith, N. (2002) New Globalism, New Urbanism: Gentrification as Global Urban Strategy. Antipode, 34(3), 427-450.

Stillman, S., \& Mare, D. (2008). Housing Markets and Migration: Evidence from New Zealand. Department of Labour, NZ.

Stoll, M., \& Raphael, S. (2010). Job Sprawl and the Suburbanization of Poverty. Washington, DC: Brookings Institution.

The World Bank. (2009). World Development Report: Reshaping Economic Geography. United States.

Thorns, D. C. (1977). Urbanisation suburbanisation and social class in New Zealand. In D. Pitt (Ed.), Social Class in New Zealand (pp. 56-77). Auckland, NZ: Longman Paul.

Townsend, P. (1987). Deprivation. Journal of social policy, 16(2), 125-146.

Trussell, B. (2010). The bid rent gradient theory in Eugene, Oregon: An empirical investigation. Department of Economics, University of Oregon. 
Walker, K. E. (2017). The Shifting Destinations of Metropolitan Migrants in the U.S., 2005-2011. Growth and Change.

Watt, P. (2009) Housing Stock Transfers, Regeneration and State-Led Gentrification in London. Urban Policy and Research, 27(3), 229-242.

Watt, P. (2013) "'It's not for us' Regeneration, the 2012 Olympics and the gentrification of East London." City, 17(1), 99-118.

Wei, F., \& Knox, P. L. (2015). Spatial Transformation of Metropolitan Cities. Environment and Planning A, 47(1), 50-68.

Wyly, E. K., and Hammel, D. J. (1999) Islands of Decay in Seas of Renewal:

Housing Policy and the Resurgence of Gentrification. Housing Policy Debate, 10(4), 711.

Yeoman, R., \& Akehurst, G. (2015). The Housing We'd Choose: A Study of Housing Preferences, Choices and Trade-offs in Auckland. Market Economics Limited.

Zuk, M., Bierbaum, A. H., Chapple, K., Gorska, K., Loukaitou-Sideris, A., Ong, P., \& Thomas, T. (2015, 2015). Gentrification, Displacement and the Role of Public Investment: A Literature Review.

Zwiers, M., Bolt, G., Van Ham, M., \& Van Kempen, R. (2016). The global financial crisis and neighborhood decline. Urban Geography, 37(5), 664-684. 